\title{
The Potential of Unsaturated Polyesters in Biomedicine and Tissue Engineering: Synthesis, Structure-Properties Relationships and Additive Manufacturing
}

DOI:

10.1016/j.progpolymsci.2016.12.008

\section{Document Version}

Accepted author manuscript

Link to publication record in Manchester Research Explorer

Citation for published version (APA):

Gonçalves, F. A. M. M., Fonseca, A. C., Domingos, M., Gloria, A., Serra, A., \& Coelho, J. F. J. (2016). The Potential of Unsaturated Polyesters in Biomedicine and Tissue Engineering: Synthesis, Structure-Properties Relationships and Additive Manufacturing. Progress in Polymer Science.

https://doi.org/10.1016/j.progpolymsci.2016.12.008

\section{Published in:}

Progress in Polymer Science

\section{Citing this paper}

Please note that where the full-text provided on Manchester Research Explorer is the Author Accepted Manuscript or Proof version this may differ from the final Published version. If citing, it is advised that you check and use the publisher's definitive version.

\section{General rights}

Copyright and moral rights for the publications made accessible in the Research Explorer are retained by the authors and/or other copyright owners and it is a condition of accessing publications that users recognise and abide by the legal requirements associated with these rights.

\section{Takedown policy}

If you believe that this document breaches copyright please refer to the University of Manchester's Takedown Procedures [http://man.ac.uk/04Y6Bo] or contact uml.scholarlycommunications@manchester.ac.uk providing relevant details, so we can investigate your claim.

\section{OPEN ACCESS}




\section{Accepted Manuscript}

Title: The Potential of Unsaturated Polyesters in Biomedicine and Tissue Engineering: Synthesis, Structure-Properties

Relationships and Additive Manufacturing

Author: F.A.M.M. Gonçalves A.C. Fonseca M. Domingos A.

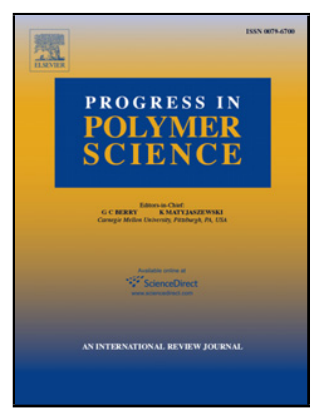

Gloria A.C. Serra J.F.J. Coelho

PII:

S0079-6700(16)30118-6

DOI: http://dx.doi.org/doi:10.1016/j.progpolymsci.2016.12.008

Reference: JPPS 1010

To appear in:

Progress in Polymer Science

Received date:

4-12-2015

Revised date: $19-10-2016$

Accepted date:

3-11-2016

Please cite this article as: Gonçalves FAMM, Fonseca AC, Domingos M, Gloria A, Serra AC, Coelho J.F.J.The Potential of Unsaturated Polyesters in Biomedicine and Tissue Engineering: Synthesis, Structure-Properties Relationships and Additive Manufacturing.Progress in Polymer Science http://dx.doi.org/10.1016/j.progpolymsci.2016.12.008

This is a PDF file of an unedited manuscript that has been accepted for publication. As a service to our customers we are providing this early version of the manuscript. The manuscript will undergo copyediting, typesetting, and review of the resulting proof before it is published in its final form. Please note that during the production process errors may be discovered which could affect the content, and all legal disclaimers that apply to the journal pertain. 


\title{
The Potential of Unsaturated Polyesters in Biomedicine and Tissue Engineering: Synthesis, Structure-Properties Relationships and Additive Manufacturing
}

F.A.M.M. Gonçalves ${ }^{a}$, A. C. Fonseca ${ }^{a}$, M. Domingos ${ }^{b}$, A. Gloria ${ }^{c}$, A.C. Serra ${ }^{\text {a }}$, J.F.J. Coelho ${ }^{\text {a }}$

\begin{abstract}
${ }^{a}$ CEMUC, Chemical Engineering Department, University of Coimbra, Rua Sílvio Lima-Pólo II, 3030-790 Coimbra, Portugal

${ }^{\mathrm{b}}$ School of Mechanical, Aerospace and Civil Engineering, University of Manchester, United Kingdom

c Institute of Polymers, Composites and Biomaterials, National Research Council of Italy, Naples 80125, Italy
\end{abstract}

Corresponding author: jcoelho3@gmail.com ;Tel.: +351 239798744; Fax: + 351239798703.

\begin{abstract}
The success of Tissue Engineering (TE) based approaches is strongly dependent on the development of novel biomaterials for the design of 3D matrices with tailored biomechanical properties to promote the regeneration of human tissues and organs.

This review covers the critical aspects related with the preparation of new unsaturated polyester (UP) resin formulations with suitable biological, chemical, thermal and morphological properties for the additive manufacturing (AM) of TE constructs. In this context, the basic principles of available AM technologies, with a special focus on novel stereolithography processes such as microstereolithography (micro-SLA), stereothermal-lithography (STLA), two-photon polymerization (TPP) and nanostereolithography (nano-SLA), are also presented and discussed. Ultimately, the present review will provide a better insight into the limitations and potential of combining UP and AM towards the rationale design/fabrication of complex artificial tissue substitutes.
\end{abstract}


AbbreviationsAA: adipic acid

AcA: acrylic acid

AIBN: $\quad \alpha, \alpha^{\prime}$-azoisobutyronitrile

AM: $\quad$ additive manufacturing

BM: 4,4-bismaleimidodiphenylmethane

BMP: $\quad$ butyl-3-mercapto propionate

BPO: benzoyl peroxide

BOD: biochemical oxygen demand

CA: $\quad$ Candida Antarctica

CAD: $\quad$ computer-aided design

CALB: $\quad$ Lipase B from Candida Antarctica

CAM: $\quad$ computer aided manufacturing

CDM: 1,4-cyclohexanedimethanol

CDRSP: Centre for Rapid and Sustainable Product Development (Portugal)

CHD: cyclohexanediol

CHMD: 1,4-cyclohexanedimethanol

$\varepsilon$-CL: $\quad \varepsilon$-caprolactone

CTNB: carboxy terminated nitrile rubber

CQ: camphorquinone

DACC: 3,4-diacetoxycinnamoyl chloride

DAHs: dianhydrohexitols

DCC: dicyclohexylcarbodiimide

DEF: diethyl fumarate

DEG: diethylene glycol

DHCA: 3,4-dihydroxycinnamic acid

DHO: $\quad$ 6,7-dihydro-2 $(5 H)$-oxepinone

DMAMEA:dimethylamino methyl ethylacrylate

DMAP: dimethylaminopyridine

DMD: 2,2-dimethyl-1,3-propanediol

DMI: dimethyl itaconate

DMTA: dynamic mechanical thermal analysis

DN: double network

DSC: differential scanning calorimetry

EG: ethylene glycol

EO: ethylene oxide

EVA: ethylene vinyl acetate

FA: fumaric acid

FAME: fatty acid methyl ester

FU: diethyl fumarate 
FUPR: $\quad$ fluorinated modified unsaturated polyester resin

GL: diethyl trans-glutaconate

Gl: $\quad$ globalide

HDA: $\quad$ 10-hydroxycaproic acid

HEMA: 2-hydroxyethyl methacrylate

HMA: $\quad$ trans- $\beta$-hydromuconic acid

HM: $\quad$ diethyl trans- $\beta$-hydromuconate

HPR: hydroxyl-ended hyperbranched polyester resin

HTNR: hydroxyl terminated natural rubber

HTPB: hydroxyl terminated polybutadiene

IA: itaconic acid

IM: isomannide

IS: $\quad$ isosorbide

IT: diethyl itaconate

MA: maleic anhydride

mCPBA: m-chloroperbenzoic acid

MEKP: methyl ethyl ketone peroxide

MH: 6-mercapto-1-hexanol

MM: $\quad$ Mucor miehei

MMA: methyl methacrylate

MPD: 2-methyl-1,3-propanediol

MPDO: 2-methyl-1,5-pentanediol

nACA: $\quad \mathrm{N}$-acetylcysteamine

NPG: neopentylglycol

NVP: $\quad N$-vinylpyrrolidone

OMIS: oligo(isosorbide maleate)

PBF: poly(butylene fumarate)

PBSI: poly(butylene succinate-co-itaconate)

PC: $\quad$ Pseudomonas cepacia

PCL: $\quad \operatorname{poly}(\varepsilon$-caprolactone)

PCLF: poly( $\varepsilon$-caprolactone-co-fumarate)

PCL-PFPE-PCL: $\quad \operatorname{poly}(\varepsilon$-caprolactone)-perfluorpolyether- poly( $\varepsilon$-caprolactone)

PD: $\quad$ 1,2-propanediol

PEFS: poly(ethylene fumarate-co-sebacate)

PEG: poly(ethylene glycol)

PEGF: poly(ethylene glycol-co-fumarate)

PEGF-co-PHMCF: poly(ethylene glycol fumarate-co-hexamethylene carbonate- fumarate)

PET: poly(ethylene terephthalate)

P(FA-GLY-BA): $\quad$ poly(fumaric acid-glycol-brassylic acid)

P(FA-GLY-DDDA): poly(fumaric acid-glycol-dodecanedioic acid)

P(FA-GLY-PA): $\quad$ poly(fumaric acid-glycol-pentadecanedioic acid)

P(FA-GLY-SA): $\quad$ poly(fumaric acid-glycol-sebacic acid)

P(FA-GLY-TA): $\quad$ poly(fumaric acid-glycol-tetradecanedioic acid)

PG: propylene glycol 
PGA: $\quad$ poly(glycolic acid)

PGl: polyglobalide

PhA: phthalic anhydride

PHEMA: poly(2-hydroxyethyl methacrylate)

PHFS: poly(hydroquinone fumarate-co-sebacate)

PHMCA: poly(hexamethylene carbonate) diacrylate

PHV: poly(hydroxy valerate)

PHMCF: poly(hexamethylene carbonate-fumarate)

PRFS: $\quad$ poly(resorcinol fumarate- $c o$-sebacate)

PLA: $\quad$ poly(lactic acid)

PLLA: $\quad$ poly(L-lactic acid)

P(MA-GLY-SA): poly(maleic anhydride-glycol-sebacic acid)

PMMA: poly(methyl methacrylate)

PO: $\quad$ propylene oxide

PPF: poly(propylene fumarate)

PPFS: $\quad$ poly(propylene fumarate-co-sebacate)

PPS: $\quad$ poly $(1,2$-propylene succinate)

PSAGE: poly(3-allyloxy-1,2-propylene succinate)

PTSA: $\quad p$-toluenesulfonic acid monohydrate

PU: $\quad$ polyurethane

ROP: $\quad$ ring opening polymerization

SA: $\quad$ succinic acid

SebA: $\quad$ sebacic acid

SEM: scanning electron microscopy

SLA: stereolithography

SN: $\quad$ single network

Sorb: $\quad$ Sorbitol

SPD: $\quad(S)-(+)-1,2$-propanediol

STLA: stereo-thermal-lithography

TC: $\quad$ tamoxifen citrate

TE: $\quad$ tissue engineering

TEG: triethylene glycol

TGA: thermogravimetric analysis

THPA: cyclohex-4-ene-dicarboxylic anhydride

TMP: $\quad$ trimethylolpropane

TPA: terephthalic acid

TPP: $\quad$ two-photon polymerization

UM: $\quad$ unsaturated monomer

UPs: $\quad$ unsaturated polyesters

UPHR: unsaturated hyperbranched polyester resin

UPRs: $\quad$ unsaturated polyester resins

Keywords: unsaturated polyesters; structure/properties relationships; tissue engineering; additive manufacturing; stereolithography processes 


\section{Table of Contents}

1. Introduction

2. UPs and UPRs: From synthesis to biomedical applications

2.1 The chemistry of UPRs

2.2 Ways to tailor and improve the properties of UPs and UPRs

2.3 Alternative crosslinking methods for the UPs

2.4 UPs and UPRs from renewable monomers

2.5 UPs and UPRs directed to biomedical applications

2.6 UPs, UPRs and additive manufacturing towards scaffold-based tissue engineering

2.7 Experimental design and theoretical concepts in SLA

3. Conclusions and Outlook

\section{Introduction}

The history of polyesters dates back to the 1930's when Carothers reacted aliphatic diols with aliphatic diacids and established the relationships between the structure and properties of the obtained polymer. The results were not very promising since the polyesters obtained had low melting points, were very prone to hydrolysis, and no practical applications were found for the synthesized polymers. The search for polyesters with better properties continued and, in 1941, Whinfeld and Dickson, from Calico Printers Association, reported the synthesis of high melting and fiber forming polyesters from the reaction of terephthalic acid (TPA) and aliphatic glycols. The polyester that resulted from this work was poly(ethylene terephthalate) (PET), that is still today one of the most produced and used polymers worldwide [1-3].

Nowadays, polyesters constitute one of the most important and versatile classes of polymers, being suitable to be used in a variety of applications (e.g., automotive industry, plastics industry, biomedical field, among others) [1, 3, 4]. Polyesters are prepared through a polycondensation process, where a dihydroxy compound (or a mixture of dihydroxy compounds) reacts with anhydrides or dicarboxylic acids [3, 4]. 
To achieve high reaction conversions and polyesters with high molecular weight the generated by-product, water, needs to be continuously removed from the reaction medium. For such purpose, a stream of nitrogen and vacuum can be used or, alternatively, the removal of water can be done with the help of solvents that are able to form azeotropes with water (e.g., xylene or toluene). The use of catalysts is also common in the field of polyesterification. The most used are metal based catalysts (e.g., $\mathrm{Sn}(\mathrm{Oct})_{2}, \mathrm{ZnCl}_{2}$ ), and organic acids (e.g., p-toluene sulfonic acid, PTSA) [5, 6]. The use of enzymes as catalysts has also been reported [7]. Ring opening polymerization (ROP) is another method that can be used to prepare polyesters. Typically, with this synthetic method it is possible to obtain polyesters with high molecular weight and low polydispersity $(\bigoplus)[1,4]$. Polyesters can be divided into different classes (e.g., aromatic or aliphatic) depending on the type of monomers used. Two classes that result from this division are the saturated polyesters and the unsaturated polyesters (UPs). Examples of saturated polyesters are poly ( $\varepsilon$ caprolactone) (PCL), poly(L-lactic acid) (PLLA), poly(glycolic acid) (PGA), as well as their copolymers. These polyesters found a broad range of applications in the biomedical field due to their biodegradability and biocompatibility. Some of the applications include scaffolds for tissue engineering [8, 9], sutures [10] and drug delivery systems [11]. Nevertheless, there is still a need to develop materials with more specific properties, for example, in terms of solubility, crystallinity, reactivity, among others [12]. Overall, this type of materials are hydrophobic and with few reactive groups along the backbone, thus limiting their applicability and further functionalization.

Regarding the UPs, these are characterized by their low-molecular weight and high polydispersivity values $(\bigoplus)$. The unsaturations present in the polymer backbone allow the UPs to be used in cure reactions via radical polymerization reactions, in the presence of an unsaturated monomer (UM), usually styrene, leading to thermosetting polyesters, known as unsaturated polyester resins (UPRs) [4, 13]. Maleic anhydride (MA) and fumaric acid (FA) are the most significant commercial monomers for introducing unsaturations in the polyester chain. The UP properties can be easily tuned by using different types of diols and diacids or even by changing the reactant ratio [13-15]. The properties of the UPRs depend not only on their molecular composition but also on the extent of the cure reaction, which means that it is very important to understand the reactions occurring during the curing and its implications in the process [15]. UPRs were developed in the 1930 's, and still today are widely used in a variety of applications 
closely related with the industry (e.g., construction and automotive). Nevertheless, in the last years, efforts have been made to prepare UPRs more directed to biomedical applications [16-19]. In this case UPs are very attractive candidates mainly due to their unsaturations, providing further functionalization sites [20, 21] and enabling the fabrication of complex 3D structures via Additive Manufacturing (AM) processes [18]. This review intends to give a broad overview about the synthesis and preparation of UPRs, in particular the relationship between structure and properties as well as the latest developments regarding their application in the biomedical field. AM processes used for the production of TE scaffolds are reviewed with special focus on stereolithography (SLA).

\section{UPs and UPRs: From synthesis to biomedical applications}

\subsection{The chemistry of UPRs}

The transformation of UPs into a structural material requires the addition of another component, the UM, commonly named as diluent and generally used in weight percentages ranging from 30 to $40 \%$ [13]. The generic process to obtain UPRs is divided in two main steps: the synthesis of the UPs and the curing reaction (Fig.1).

$<$ Insert Figure 1>

The UM is added to the UP for two main purposes: (1) to reduce the viscosity of the system (aiding the resins processing) and (2) to create an efficient crosslink network with the double bonds available in the UP backbone. Styrene is the most commonly used UM, but others, like dimethacrylates, alkyl methacrylates vinyl esters, and divinylbenzene can also be used $[22,13]$. Due to the radical nature of the curing process, the addition of a radical initiator to the formulation is needed. The most employed initiators are the organic peroxides, namely ketone peroxides, alkyl hydroperoxides, diacyl or dialkyl peroxides $[4,22]$. Another important component of the formulation is the accelerator or promoter, a compound able to reduce the activation energy involved in the initiator decomposition, leading to the reduction of the temperature required for crosslinking. Vanadium or cobalt salts and tertiary amines 
(e.g., $N, N$-diethylaniline, $N, N$-dimethylaniline, or $N, N$-dimethyl-p-toluidine) are the most commonly used accelerators [4, 22]. Inhibitors, like hydroquinone or $t$-butyl hydroquinone, can also be used to avoid unwanted radical polymerization during the polycondensation (due to the high temperatures), mixture with $\mathrm{UM}$, handling and storage. The amount of inhibitor, however, should be carefully adjusted to avoid further slowdown of the crosslinking reaction $[4,13,22]$.

When the UPR formulation is exposed to heating and/or radiation, the crosslinking reaction starts by the formation of free radicals from initiators. The first radicals formed are trapped by any inhibitor in the mixture until its full consumption. At this stage, the radical crosslinking reactions starts, forming long chain molecules through the connection of vinyl monomers, by intermolecular and intramolecular reactions (Fig 2A). These long chain molecules are predisposed to form spherical structures called microgels (Fig.2B). These gels can be defined as crosslinking dense structures, where several pendant groups (from UM) are confined to the interior of these structures [23]. This fact can result in the lowering of the final conversion, due to a chain segmental immobility in the crosslinked network. In the case of the reaction between UP and UM, previous studies demonstrated that gelation begins at an early stage of nearly $3-5 \%$ of conversion, which means that the reaction might be diffusion-controlled over almost its entire course [24]. Thus, the formation of microgel particles is a key feature of the UMUP copolymerization. Yang and Lee [25] observed similar results in sheet molding compounds and in polyurethane-polyester interpenetrating polymer networks.

The curing process and the reaction kinetics are very complex due to the simultaneously occurrence of different reactions: UM-UP copolymerization, homopolymerization of UM and UP homopolymerization. The importance of each reaction can be adjusted depending on the formulation used and the curing conditions [26]. As shown in Fig.2A, these three processes can be divided into four possible reactions:

(1) Intermolecular crosslinking with (reaction I) or without (reaction II) linking between the UM;

(2) Intramolecular crosslinking with (reaction III) or without (reaction IV) linking through UM;

(3) Branching on the polyester molecule by UM (reaction V);

(4) UM homopolymerization (reaction VI).

$<$ Insert Figure 2> 
Reaction (1) results in a macroscopic network formation through the connection of adjacent polyester molecules; reaction (2) increases the crosslinking density but does not contribute to the macroscopic network formation; the other side reactions (3) and (4) may increase the polymer coil size, however their impact on the network formation is residual [25]. All these reactions affect the curing kinetics, but only the first two actually contribute to network formation.

Usually, the course of the UPRs cure is followed by differential scanning calorimetry (DSC) analysis [27-33].

\subsection{Ways to tailor and improve the properties of the UPs and UPRs}

Due to their excellent properties, easy synthesis, high versatility and low cost, UPRs applications continue to expand globally at robust rates. These type of materials had a leading role in the improvement of fiberglass reinforced products, for example in building materials for boats and cars $[1,3]$, as they are a very inexpensive and useful solution $[15,22]$. UPRs are widely employed as adhesives and coatings but also in the building and electrical industries, among others [34]. Apart from the advantages, UPRs present also some disadvantages, such as their high flammability, low impact strength and poor toughness, which a priori can be mitigated by changing the UPR formulations. These changes can be performed in the structure of the UP, in the amounts or types of $\mathrm{UM}$, or even in the initiator systems used.

Sanchez and co-workers [35] have studied the influence of styrene concentration in the final properties of the UPs using a commercial UPR, RESAPOL 10-203. The results provided by the dynamic mechanical thermal analysis (DMTA) showed a broadening of the $\tan \delta$ peak as the concentration of styrene increased (from $6 \%$ wt to $58 \%$ wt). This fact was attributed to the existence of microenvironments that differ in their composition and crosslinking density. Above $18 \mathrm{wt} \%$ of styrene, two distinct transitions were observed and ascribed to the presence of two different and immiscible phases within the crosslinked network: an UP-rich phase and a polystyrene-rich phase. An increase in the $T_{\mathrm{g}}$ values was also reported for increasing contents of styrene. The sample with $38 \%$ wt of styrene was found to be the most thermally stable. 
It is known that when the UPs are prepared with only one diol, namely ethylene glycol (EG) or diethylene glycol (DEG), a limited solubility in styrene is observed. Nevertheless, Matynia and co-workers [36] managed to synthesize styrene soluble UPs making use of only one diol, EG, and two acid anhydrides, viz. MA and phthalic anhydride (PhA). The synthesized UPs were end-capped with isopropyl alcohol or monoesters from the used anhydrides, which enhanced their solubility in styrene. The increase in the amount of double bonds yields UPRs with high reactivity, high crosslinking density and higher mechanical stability. The UPRs obtained from the UPs end-capped with the monoesters showed better thermal stability and higher heat deflection temperatures than those end-capped with isopropyl alcohol.

The enhancement of toughness and impact resistance is a very important issue in the UPRs' field. One possible approach to achieve this goal encompasses the preparation of block copolymers of UPs incorporating rubber segments that are subsequently used in the preparation of UPRs. Cherian and Tachil [37] prepared copolymers of UP with hydroxyl terminated polybutadiene (HTPB), carboxy terminated nitrile rubber (CTBN) and also hydroxyl terminated natural rubber (HTNR). The polycondensation was carried out in two stages, leading to UPs containing alternating rigid and soft segments. The UPs were then crosslinked with styrene, in the presence of methyl ethyl ketone peroxide (MEKP), as initiator, and cobalt napthenate, as accelerator. The mechanical properties of the UPRs were evaluated and the results showed that CTBN is the most promising in improving the mechanical properties of the UPRs because the toughness and the impact strength were significantly enhanced, without jeopardizing extensively the remaining properties. Another approach was studied by the same researchers [38], in which poly(ethylene glycol) (PEG) segments were incorporated in the UP structure. The mechanical properties of the ensuing UPRs (35\%wt styrene) were evaluated and the influence of the incorporation of PEG in the UP structure was accessed. The results showed that the use of UPs with PEG segments of molecular weights $c a .200 \mathrm{~g} / \mathrm{mol}$ resulted in UPRs with enhanced flexibility, fracture toughness and impact resistance. Following the same rationale, Cherian and co-workers [39] reported the use of polyurethane (PU) prepolymers as a mean to improve the mechanical properties of the UPRs. The prepolymers were prepared by reacting TDI with different polyols (HTNR, hydroxyl-terminated polybutadiene (HTPB), PEG and castor oil), and subsequently added in varying amounts (up to $10 \% \mathrm{wt}$ ) to the UP to be crosslinked in the presence of styrene, using MEKP and cobalt napthenate as initiator and accelerator, respectively. 
The results showed that the HTNR-PU prepolymer was the most effective in improving the mechanical properties of the UPRs. An increase of $20 \%$ in the tensile strength was observed, while the toughness was shown to increase $188 \%$. Very important, the dynamic mechanical thermal analysis (DMTA) of the modified UPRs showed only one $\tan \delta$ peak, indicating that the PU prepolymers are miscible with the UPR. In another approach, Rosa and Felisberti [40] incorporated poly(organosiloxane) segments in the UP network as a way to increase their flexibility.

The mechanical properties of UPRs have also shown to be improved by the addition of bismaleimides [41, 42], which are a class of compounds with two maleimide groups that are connected by a nitrogen atom via a linker, and are used as crosslinking agents in the polymer field. These molecules are known for their high thermal stability, strength, and fire resistance, among other interesting properties. Gawdzik and co-workers [42] proposed the modification of a commercial UP (D-1103) with 4,4bismaleimidodiphenylmethane (BM). The authors reported that the addition of the BM accelerated the curing reaction, resulting in UPRs with high $T_{\mathrm{g}}$ values $\left(\mathrm{ca} .180^{\circ} \mathrm{C}\right.$ vs 70 ${ }^{\circ} \mathrm{C}$ for the unmodified ones) and high hardness. It was also shown that BM can react with the UP at high temperatures, without any chemical initiator. When styrene is added to the system, different reactions can take place, namely UP-BM crosslinking, UPstyrene crosslinking, or even UP-(BM-styrene sequences) crosslinking, leading to UP moieties bridged by BM-styrene. Fig. 3 presents the structures of the BM and of the BM-styrene bridges.

$<$ Insert Figure 3>

In a very interesting approach, Cherian and Tachil [43] studied how the addition sequence of the reactants in the UPs preparation influenced the final properties of the UPRs. The authors used five different sequences of reactants' (PhA, propylene glycol (PG) and MA) addition and found out that reacting first $\mathrm{PhA}$ with the whole amount of $\mathrm{PG}$, with the subsequent addition of MA was the most promising sequence. This procedure led to shorter reaction times, and the resulting UPs yield UPRs with enhanced elongation at break and toughness.

Fluorinated polymers, in turn, have shown to be suitable to improve both the mechanical properties and surface properties of the UPRs, as demonstrated by Messori and co-workers [44]. The authors reported the modification of an UPR by blending it with $\operatorname{poly}(\varepsilon$-caprolactone)-perfluoropolyether- poly( $\varepsilon$-caprolactone) (PCL-PFPE-PCL) 
triblock copolymers. The fluorinated modified UPR (FUPR) showed a surface enrichment in fluorine segments and, as expected, a decrease in the water diffusion coefficient value. The morphology of the FUPR has shown to be strongly dependent on the molecular weight and the PFPE/ PCL ratio. It was also found that a plasticization effect occurred with an increase in the molecular weight of the triblock copolymer and in the PCL length. The absorbed energy at break was observed to be enhanced when the PFPE/PCL ratio was 2/10.

In another work, Nebioglu and co-workers [45] studied the effect of the amount of both multifunctional UM and internal and terminal unsaturation in the network structure and in the mechanical properties of the resulting UPRs. Acrylate-terminated UPs were obtained from the reaction of MA, adipic acid (AA), neopentyl glycol (NPG), and trimethylolpropane (TMP), and their end-chains were modified with acrylic acid (AcA). The UPRs were obtained from the photopolymerization of the UPs in the presence of trimethylolpropane triacrylate (TMPTA) as UM, and Irgacure 184 as photoinitiator. The DMTA showed that both high concentrations of TMTPA and high internal unsaturation led to phase separation in the cured UPRs. It was also observed a broadening of the tan $\delta$ curve, revealing the heterogeneity of the sample, as the amount of TMTPA increased. Surprisingly, the increase in the amount of internal and terminal unsaturations was not translated in an improvement of the crosslinking density. The authors attributed this result to the fact that a higher unsaturation concentration causes more microgelation, resulting in a higher amount of trapped free radicals inside the microgels, with consequent reduction in the crosslinking density. The microgels were also responsible for a decrease in the fracture toughness properties and on the reverse impact resistance. In a subsequent work, the authors [46] used the same type of UPs to obtain UV-cured films and studied how the extent of microgelation affected the viscoelastic, fracture and tensile properties of the films. The results demonstrated that when the microgelation occurred in a low extent, the microgels acted as micro-support units enhancing the mechanical properties. However, for high extent of microgelation, a phase separation occurred jeopardizing the mechanical properties of the films.

Another very important aspect in the field of UPRs is related with their thermal stability. Some strategies regarding the improvement of this property have been presented in literature. Tawfik [47] developed different UPs based on durene derivatives, viz. 3,6-bis(methoxymethyl)durene and 3,6-bis(benzyloxymethyl)durene (Fig. 4A), that were obtained from the 3,6-bis(chloromethyl)durene. The other 
monomers used in the preparation of the UPs were PhA, MA and succinic acid (SA) as well as different glycols, such as PG, triethylene glycol (TEG), and cyclohexane diol (CHD). The UPs were able to cure with styrene, at room temperature, in the presence of cobalt naphthenate and MEKP as accelerator and initiator, respectively. From the thermogravimetric analysis (TGA) and DSC studies, the authors found that the UPR prepared from UP V (see Fig. 4B) was the resin with the highest thermal stability. Additionally, both this UPR and that obtained from UP III (see Fig. 4B) showed flameretardant properties.

$<$ Insert Figure 4>

In a different approach, Tibilleti and co-workers [48] improved the thermal stability and fire behavior of UPRs through the introduction of nanometric alumina oxide and submicron alumina trihydrate.

Alkskas and co-workers [49] developed thermally stable UPs containing a cyclopentapyrazoline moiety in the main chain. The cyclopentapyrazoline moiety is known to enhance the thermal stability of the materials, their solubility and can also provide the materials with photoconductivity. The method for the preparation of the UPs was based on an interfacial polycondensation between diols bearing the cyclopentapyrazoline moiety, namely 3-p-hydroxyphenyl-6-p-hydroxybenzylidene cyclopentapyrazoline and 3-anillyl-7-vanillylidene cyclopentapyrazoline, and different diacyl chlorides, viz. adipoyl, sebacoyl, isophthaloyl, and terephthaloyl dichlorides (Fig. $5)$.

\section{$<$ Insert Figure 5>}

The UPs presented $T_{\mathrm{g}}$ values ranging from $103^{\circ} \mathrm{C}$ to $208^{\circ} \mathrm{C}$, being soluble in a variety of organic solvents. Thermal analysis showed that the aromatic based polyesters were more thermally stable than the aliphatic counterparts. It should be stressed, that this new UP also showed electrical conductivity when doped with iodine. Unfortunately, no data regarding the cure reaction of this UP to yield the UPRs was reported by the authors.

The synthesis of modified UPs to enable the control of product viscosity was performed by Chiu and co-workers [50]. The authors grafted thermally breakable functional groups based on diketogluconic acid onto the UPs backbone and the results showed that these moieties were crucial to control the viscosity during the moulding process. 
In another work related with the viscosity control, Zhang and co-workers [51] developed new unsaturated hyperbranched polyester resin (UHPR) based on the reaction between MA monoisooctyl alcohol ester and a hydroxyl-ended hyperbranched polyester resin (HPR). The hydroxyl ended HPR was prepared from PhA and TMP. The UHPR showed a viscosity below $10,000 \mathrm{cP}$, at room temperature, being suitable to be used in the field of coatings.

It is known that UPRs can have large volume shrinkage during the polymerization, which leads to sink mark formation, surface waviness, warpage, poor dimension accuracy, or internal crack. This particular aspect can pose several issues to the application of these materials in AM processes. Shenoy and co-workers [52] reported a study on the effect of the addition of ethylene vinyl acetate (EVA) (partially depolymerized and presenting different degrees of branching) on the mechanical, thermal, chemical and shrinkage properties of UPRs. The authors concluded that the addition of $0.5 \%$ wt EVA (with a high degree of branching) led to an improvement in the flexural and tensile properties, without deleterious effects in the HDT and impact properties. A decrease in the percentage of shrinkage of ca. $2 \%$ was observed for the system containing $0.5 \%$ wt EVA. Further increase in the EVA percentage led to a decrease in the volume shrinkage, but a notorious worsening of the remaining properties was observed. It is known that the increase of the crosslinking density results in a decrease of shrinkage behavior. This phenomenon will not be fully discussed here, although it assumes a great importance in industrial fields and has been intensively investigated [53-55].

Another important aspect in the UPRs field is related with the initiator systems that are used. As mentioned before, tertiary amines are widely used as accelerators, but often the formulations containing these compounds have a reduced shelf-life. A possible strategy to overcome this issue is to incorporate the amine in the UP structure [56-59]. For such purpose, Duliban [56] developed novel amine modifiers with hydroxyl terminal groups to be incorporated in the UPs. The amines were prepared from the reaction of ethylene oxide (EO) or propylene oxide (PO) with $N, N$ '-diphenylethane-1,2-diamine or from the reaction of EO with $N, N^{\prime}$-diphenylhexane-1,6-diamine (Fig. 6). The amine modifiers were used to partially replace propylene glycol (PG) (up to $2 \% \mathrm{~mol}$ ) in a UP composed by MA, PhA, PG and DEG. The UPs were cured in the presence of benzoyl peroxide (BPO), the most used initiator in amine-curing systems, or alternatively in the presence of the initiator methyl ketone hydroperoxide and the accelerator cobalt(II) octanoate. 
The results obtained from the cure reactions showed a reduction of the gelation time in both curing systems when $2 \%$ wt of the modifier was used. The best result, in terms of gelation time and storage stability, was obtained for the UP containing $1 \%$ wt of the modifier 3,6-diaza-3,6-diphenyloctane-1,8-diol. The addition of benzyltriethylammonium chloride to the cobalt curing system was also performed as a way to improve the storage stability of the resins. However, the stabilizer reduced the resins reactivity.

\section{$<$ Insert Figure 6>}

In the same line of research, Kucharski and co-workers [59] prepared diols bearing tertiary amine groups, from the reaction of $N, N$-dimethyl-p-phenylenediamine with EO or PO. The results showed that when the amine diols are incorporated in the UP structure, a reduction in the gelation time of the respective UPRs is observed. Nevertheless, the UPRs stability is also compromised exhibiting a significant reduction. Related works by Duliban $[57,58]$ show that amine diols (or polyols) bearing $s$-triazine rings (Fig. 7), when introduced in the structures of the UPs, are also effective in reducing the gelation times of the respective UPRs.

\section{<Insert Figure 7>}

The catalyst of polycondensation to prepare the UPs can also be modified as a route to improve the efficiency of the reaction. In this sense, Alemdar and co-workers [60] proposed a boric acid-pyridine mixture as a mild catalyst for the preparation of UPs, from hydroxyethyl esters in-situ generated from cyclic anhydrides (maleic, succinic and phthalic anhydrides) (Fig. 8). The UPs, with molecular weights ranging from 1650 to $1950 \mathrm{~g} / \mathrm{mol}$, were obtained after $4 \mathrm{~h}$ of reaction. This reaction time can be seen as a great advantage since it opens the possibility of avoiding side-reactions (e.g., branching or crosslinking from the reaction of hydroxyl groups with the double bonds). It was also found that the UPs easily bind to sodium bisulfite to give sulfonated derivatives that have an amphiphilic nature.

$<$ Insert Figure 8>

In another work, Lou and co-workers [61] demonstrated that it is possible to obtain UPs with a controlled structure and tailorable properties by ROP. The homopolymerization of 6,7-dihydro-2(5H)- oxepinone (DHO) and its copolymerization with $\varepsilon$-caprolactone 
$(\varepsilon-\mathrm{CL})[40]$ were initiated by aluminium isopropoxide $\left[\mathrm{Al}\left(\mathrm{O}^{\mathrm{i} P r}\right)_{3}\right]$, in toluene, at room temperature (Fig. 9).

$<$ Insert Figure 9>

The poly(DHO) was obtained with the predicted molecular weight, with a narrow molecular weight distribution, and with $T_{\mathrm{g}}$ and $T_{\mathrm{m}}$ of $-50^{\circ} \mathrm{C}$ and $35^{\circ} \mathrm{C}$, respectively. The copolymers DHO with $\varepsilon$-CL were also prepared in a controlled manner. From this experiment it was also possible to observe that an increase in the DHO amount in the random copolymer increases the $T_{\mathrm{g}}$ and decreases the $T_{\mathrm{m}}$, in comparison with PCL.

\subsection{Alternative crosslinking methods for the UPs}

Commonly, the UPRs are obtained from the cure reaction between the UP and the UM. Due to its low cost and availability, styrene is often used as UM. Additionally, styrene is known to provide UPRs with excellent mechanical properties. However, this UM has high volatility, and during the cure process it is released to the atmosphere. Thus, in the recent years, significant efforts have been devoted to find alternative UMs capable to overcome this problem. Possible strategies encompass the use of UMs with boiling temperatures higher than styrene $[62,63]$, the reduction of styrene content in the formulation and, more interesting, the introduction of different moieties in the UP structure to allow the further crosslinking in the absence of UM. It should be noted, that in this subsection the described strategies are exclusively related with fossil based UPRs. The strategies focused on the development of self-crosslinkable biobased UPs will be presented in the following section of the manuscript.

In a very interesting contribution, Straub and co-workers [64] developed alternative crosslinking methods for UPs avoiding the use of styrene. The strategy proposed was based on the use of maleic or fumaric diesters functionalized with triple bonds, followed by oxidative metal mediated homo-coupling of the introduced alkyne moieties (Fig. 10). The authors discovered that the combination of $\mathrm{Pd} / \mathrm{Cu}$ and air is a very effective system for the catalytic oxidative homo-coupling of alkynes, leading to the crosslinking of UPs chains.

$<$ Insert Figure 10> 
In turn, Cinar and co-workers [65] proposed the use of bis(nitrone)s as crosslinkers for UPs bearing maleate and fumarate groups. The nitrones are known to easily undergo 1,3-cycloadditions with double bonds. The crosslinking reaction successfully occurred at $120{ }^{\circ} \mathrm{C}$, for $30 \mathrm{~min}$, in the absence of catalysts (Fig. 11). Unfortunately, no data regarding the properties of the UPRs were presented by the authors.

$<$ Insert Figure 11>

Worzakowska [34] reported the synthesis of UPs through polycondensation of cyclohex-4-ene-dycarboxylic anhydride (THPA), MA and different diols (1,4butanediol, 1,6-hexanediol and EG), as well their selective epoxidation with peracetic acid in mild conditions (Fig. 12) [66], to yield unsaturated epoxyoligoesters. It should be noted that using this method only the double bonds in the cyclohexenyl ring were converted in epoxy groups, leaving the remaining $\mathrm{C}=\mathrm{C}$ bonds (from the maleate units) unmodified. The ensuing polymers have the ability of being crosslinked in the presence of UMs or by polyaddition reactions with suitable curing agents. Interestingly, the resins obtained from the cure of unsaturated epoxyoligoesters in the presence of $20 \% \mathrm{wt}$ styrene (usually, the percentage of styrene is about $37 \% \mathrm{wt}$ ), and using BPO as initiator, revealed a better thermal stability and increased viscoelastic properties in comparison to those obtained from the unmodified UP. The properties were further improved when THPA was added to the curing system. In this case the crosslinked network resulted from two types of reaction: (i) copolymerization of the $\mathrm{C}=\mathrm{C}$ double bonds in the polyester and the UM, and (ii) polyaddition of epoxy groups to anhydride groups, forming additional diester segments. The length of the diol has demonstrated an important influence in the final properties of the resins; shorter diols led to resins with better properties than those obtained with larger diols.

<Insert Figure 12>

\subsection{UPs and UPRs from renewable monomers}

A field that is nowadays attracting considerable attention from the scientific community is the preparation of polymers from renewable resources $[67,68]$. In the last years, 
many contributions regarding the use of renewable monomers (e.g., FA, 2,5furandicarboxylic acid (FDCA), itaconic acid (IA), sebacic acid (SebA), dianhydrohexitols (DAHs), 1,3-propanediol [16-18, 69-71], or vegetable oils [72-74]) in the preparation of UPs and, ultimately, UPRs have been reported. For a better understanding, the first part of this subsection will be devoted to the preparation of biobased UPs, where some approaches regarding the crosslinking reactions of these polymers in the absence of UM will be presented; the second part will be focused on the development of biobased UPRs, resulting from the crosslinking reaction of biobased UPs with UMs.

Takenouchi and co-workers [75] prepared a set of UPs based on different anhydrides (succinic, methylsuccinic, maleic and citraconic), FA, and EG and studied the effect of the geometric configuration ( $E$ - and $Z$-) of the double bonds in their biodegradation properties. Enzymatic degradation tests were carried out at controlled temperature (37 ${ }^{\circ} \mathrm{C}$ ) in the presence of Rizopous delemar lipase. Additional degradation tests were carried out with an activated sludge $\left(25^{\circ} \mathrm{C}\right)$ and the values of the biochemical oxygen demand (BOD) registered. The overall results showed that the UPs with the double bonds in the $E$-configuration are more prone to degradation, when compared to those that have the double bonds in the $Z$-configuration. It was also found that the methyl group as a pendent chain contributes to a decrease in the biodegradability of the samples.

Zheng and co-workers [76] synthesized multiblock copolymers based on poly (butylene fumarate) (PBF) and poly (1,2-propylene succinate) (PPS), by the chain extension reaction reaction of PBF diol and PPS diol with 1,6-hexamethylene diisocyanate (HDI) (Fig. 13). The main purpose of this work was to increase the biodegradability of PBF by introduction of PPS moieties.

$<$ Insert Figure 13>

The results showed that the biodegradability of PBF was enhanced by the copolymerization of PPS. For contents above $20 \% \mathrm{wt}$, the effect is more notorious. Also, the introduction of PPS led to materials with higher impact strength and less crystallinity when compared with PBF.

Najafi and Sarbolouki [77] prepared partially water-soluble UPs through the reaction of two linear unsaturated aromatic oligoesters, viz. poly(hydroquinone fumarate-cosebacate) (PHFS) and poly(resorcinol fumarate-co-sebacate) (PRFS), and PEG. Both 
diblock (PHFS-co-PEG and PRFS-co-PEG) and triblock copolymers (PEG-co-PHFSco-PEG and PEG-co-PRFS-co-PEG) were prepared and their thermal properties were assessed. It was found that both the diblock and triblock copolymers were thermally more stable than the unsaturated oligoesters. The DSC analysis showed that the block copolymers had one exothermic transition, corresponding to the melt of the PEG segment. The same authors [78] also reported the preparation diblock and triblock copolymers from poly(propylene fumarate-co-sebacate) (PPFS), poly(ethylene fumarate-co-sebacate) (PEFS), and PEG. Similarly to what was previously reported, the copolymerization of the unsaturated oligoesters with PEG results in an increase of the thermal stability. The in vitro hydrolytic degradation $\left(\mathrm{pH}=7.4,37^{\circ} \mathrm{C}\right)$ was evaluated and the ${ }^{1} \mathrm{H}$ NMR analysis revealed that the fumarate ester bond cleaves faster than the ester sebacate bonds.

Jasinska and Koning [79] also reported the preparation of water-soluble UPs making use of PEG, isosorbide (IS), and MA. The bulk polycondensation, catalyzed by titanium(IV) n-butoxide was the chosen synthesis method. The results have demonstrated that these UPs presented branched structures resulting from the reaction of the double bonds with the $-\mathrm{OH}$ groups of the PEG or IS moieties. The thermal properties of the UPs were evaluated and the results showed that the $T_{\mathrm{g}}$ was dependent on the amount of PEG in the structure; for higher contents of PEG, lower $T_{\mathrm{g}}$ were observed. The UPs were thermally stable up to temperatures of $255{ }^{\circ} \mathrm{C}\left(T_{5} \%\right)$. The authors suggested that these UPs could be suitable for coating applications.

Although the polycondensation reaction catalyzed by metals is the common method used in the industry and in most academic reports dealing with the preparation of UPs, in the last years the enzyme-catalyzed polycondensation has gained increasing importance.

Olson and Shears [12] prepared unsaturated aliphatic polyesters by polycondensation of trans- $\beta$-hydromuconic acid (HMA) with several diols ( $\mathrm{C}_{4}$ to $\mathrm{C}_{10}$, and DEG) using enzyme (Lipase B from Candida Antarctica (CALB)) and metal based catalysts (Fig. 14). The use of AA as the second diacid was also tested. HMA was the selected unsaturated diacid because it is not prone to the side reactions commonly associated with FA. The UPs prepared from this monomer usually present higher molecular weights. The UPs resulting from the reaction of HMA with the different diols were obtained in high yields, with molecular weights between 2500 to $10500 \mathrm{~g} / \mathrm{mol}$, and $Ð$ below 2. The highest molecular weight was obtained from the enzyme catalyzed 
reaction of HMA with the $\mathrm{C}_{8}$ diol. The UP also showed to be thermally stable up to temperatures of approximately the $320{ }^{\circ} \mathrm{C}$. When AA was used as comonomer, the enzyme catalyzed reaction has also shown to be effective in producing UPs with higher molecular weight when compared with those obtained from the metal-catalyzed reaction, for the same reaction time $(13000 \mathrm{~g} / \mathrm{mol} \mathrm{vs} 11600 \mathrm{~g} / \mathrm{mol})$. The $T_{\mathrm{m}}$ of all the prepared UPs was found to be dependent on the length of the diol, being higher when diols with longer aliphatic chains were used. Another UP, from DEG and HMA, was also prepared, being liquid at ambient temperature with a $T_{\mathrm{g}}$ of $-40^{\circ} \mathrm{C}$.

\section{<Insert Figure 14>}

In another contribution, Naves and co-workers [80] reported the polycondensation of IS or isomannide (IM) with diethyl adipate and different unsaturated diesters, viz. diethyl fumarate (FU), diethyl itaconate (IT), diethyl trans-glutaconate (GL) and diethyl trans$\beta$-hydromuconate (HM) (Fig.15), using CALB as catalyst.

\section{$<$ Insert Figure 15>}

The UPs based on IM showed higher molecular weights, but lower isolated yields, than their IS based counterparts. The UP with the highest molecular weight was obtained when FU was used as the unsaturated diacid; a decrease in the UPs' molecular weight was observed for increasing chain lengths of the unsaturated diacid. The same method of synthesis was used with less sterically hindered diols, namely 1,4-butanediol and 1,6hexanediol, and it was found that the molecular weights obtained were very close to that presented by the UPs prepared from IS and IM. The MALDI-Tof analysis showed inequivocally the presence of the double bonds, making the materials good candidates to be used in crosslinking reactions.

Jiang and co-workers [70] synthesized biobased UPs by the polymerization of diethyl succinate, dimethyl itaconate and 1,4-butanediol in solution, by a two-stage method (Fig. 16), in the presence of CALB.

\section{<Insert Figure 16>}

The use of diphenyl ether as the solvent allowed the preparation of UPs with higher molecular weight, when compared to that obtained with the other used solvents (diglyme and dodecane). The best result in terms of molecular weight ( $c$. 13000 $\mathrm{g} / \mathrm{mol}$ ) and yield (90\%) was obtained for the UP prepared with a molar feed amount of 
IT of $15 \%$. The NMR analysis showed that the amount of double bonds can be easily changed by using different amounts of dimethyl itaconate (up to $35 \% \mathrm{~mol}$ ). The results provided by the thermal analysis showed that the amount of dimethyl itaconate had no significant influence on the $T_{\mathrm{g}}$ (a variation of $3^{\circ} \mathrm{C}$ was observed) or on the thermal stability. In turn, the $T_{\mathrm{m}}$ revealed an almost linear decrease, with the increasing amount of dimethyl itaconate (from $c a .115^{\circ} \mathrm{C}$ to $70^{\circ} \mathrm{C}$ ).

The same research group [71] reported the enzymatic synthesis, using the same enzyme, of poly(butylene succinate-co-itaconate) (PBSI) making use of three different methods: two-stage melt polymerization, azeotropic polymerization using cyclohexane/toluene as solvent, and two-stage solution polymerization in diphenyl ether. The authors reported that when the dialkyl esters (dimethyl itaconate and diethyl succinate) were replaced by the respective dicarboxylic acids (IA and SA) only oligomeric species were obtained. When using dialkyl esters, the best results in terms of molecular weight and yields were obtained with the azeotropic distillation method. In this case, it was possible to use molar feed amounts of dimethyl itaconate up to $50 \%$. As previously noted [70], a decrease in the crystallinity of the UP was observed with increasing amounts of the itaconate moieties. The UPs were crosslinked via a hot press method, in the presence of dicumyl peroxide. The resulting crosslinked materials have shown to be brittle, presenting high tensile strain and low rupture strain.

Very recently, Jiang and co-workers [69] enlarged the library of biobased UPs, making use of the two-stage enzymatic polycondensation (catalyzed by CALB) previously reported [71, 70]. The authors prepared various polyesters using 1,4-butanediol, dimethyl itaconate and diacid ethyl esters with different chain lengths. The results showed CALB presents the highest specificity for diethyl adipate, among all the tested diacid ethyl esters. The thermal properties showed to be dependent on the length of the diacid ethyl ester used. The UV curing reaction was performed using Irgacure 184 and the thermomechanical properties ( $T_{\mathrm{g}}$, Young modulus', tensile stress, and rupture strain) of the cured film could be easily adjusted and tuned by controlling the amount of itaconate moieties in the UPs structure.

Another work, reported by Tsujimoto and co-workers [81], used enzymatic polymerization between divinyl esters and glycerol in the presence of unsaturated fatty acids to develop biodegradable crosslinking polyesters. In this study different lipases were tested as catalyst, namely, Candida Antarctica (CA), Mucor miehei (MM), and Pseudomonas cepacia (PC). The comparison between the activity of the three lipases, 
revealed that CA lipase was the best in promoting the polycondensation. The UPs were able to be crosslinked in the absence of UM, using two methods: (i) catalytic oxidation in air, using cobalt naphthenate, and (ii) thermal treatment $\left(150^{\circ} \mathrm{C}, 2 \mathrm{~h}\right)$. The film obtained from the UP made from divinyl sebacate and linoleic acid was subjected to the BOD test in an activated sludge. The results highlight the gradual degradation of the film, and after 42 days the percentage of biodegradation of the film was $45 \%$. The same enzymatic polymerization was used to synthesize polyesters based on divinyl sebacate, glycerol and unsaturated fatty acids or epoxidized fatty acids [82]. The polyesters bearing the unsaturated polyesters were further epoxidized in the presence of CA lipase. This work showed that the enzymatic polymerization can be carried out using both unsaturated and epoxidized moieties. The crosslinking reaction was carried out as previously presented [81] and the biodegradability of the films (assessed by the BOD test) showed a percentage of biodegradation near $50 \%$, after 50 days of test.

Very recently, Goerz and Ritter [83] crosslinked biobased UPs made from IA, IS and SA in the presence of N-alkylated dinitrones based on IS (Fig. 17). The results obtained showed that the new dinitrones were very effective in promoting the crosslinking of the biobased UPs via a 1,3-dipolar cycloaddition.

$<$ Insert Figure 17>

Another important class of renewable monomers that has been used in the development of UPs are the cinnamic acid derivatives. These compounds are able to undergo [2+2] cycloaddition reactions under UV irradiation $(\lambda>260 \mathrm{~nm})$, forming photoreversible crosslinks. Thus, the polymers comprising these derivatives in their structure are photoresponsive [84, 85]. Dong and co-workers [86] developed new biodegradable polyesters by the polycondensation reaction of 3,4-dihydroxycinnamic acid (DHCA), obtained from lignin, and 10-hydroxycaproic acid (HDA), obtained from the castor oil (Fig. 18). The authors evaluated how the properties of the UPs were affected by the amount of each monomer in the polymer chain. An increase in the amount of HDA led to more flexible materials, and was also shown to improve the elongation at break of the UPs. The UPs were further crosslinked by UV irradiation $(\lambda>320 \mathrm{~nm})$ and their mechanical properties were also studied. The crosslinked UPs showed improved tensile strength, but low elongation at break. The in vitro hydrolytic degradation tests revealed 
that the UPs were able to be degraded. Surprisingly, the degradation rate was higher for the crosslinked UPs.

$<$ Insert Figure 18>

The preparation of copolymers based cinnamic acid derivatives and LA [87-89] have also been reported, and different approaches have been used. In a very interesting report, Thi and co-workers [88] used the -OH terminal group of PLLA to attach 3,4diacetoxycinnamoyl chloride (DACC), to yield DACC-PLLA. The ensuing polymers showed excellent thermal stability when compared to neat PLLA (an increase of about $100{ }^{\circ} \mathrm{C}$ in the thermal stability was observed). Also, the DACC-PLLAs revealed the ability to undergo [2+2] cycloaddition reactions when irradiated with UV light with $\lambda>280 \mathrm{~nm}$ (Fig. 19).

$<$ Insert Figure 19>

With the intention of giving an application to these UPs, the authors used a DACCPLLA film to attach a fluorescent dye (Fig. 20) by means of [2+2] cycloaddition reaction. After the photoreaction, the film was extensively washed to remove the unreacted dye and then analyzed by confocal fluorescence scanning microscopy. The results confirmed the fluorescent features of these new polymers. Based on the obtained results, the authors suggested that these polymers could be very useful to conjugate fluorescent targeting molecules.

$<$ Insert Figure 20>

In a different, but very interesting approach, Kim and co-workers reported the synthesis and photocuring study of UPs in the presence of multifunctional thiols [90]. This experiment was conducted on the grounds that thiols can react with the double bonds through an anti-Markovnikov mechanism. The UPs were prepared from the polycondensation of FA with DEG and EG, and their end-groups were induced to react with trimethylolpropane diallyl ether in order to obtain an UP with allyl chain ends. For the photocuring reaction, the UPs were mixed with multifunctional thiols (with the ratio thiols/double bonds equal to 1), and the photoinitiator Irgacure 184. The reaction was monitored by FTIR and the results showed that the bands corresponding to the vinyl and thiol groups disappeared nearly at the same rate, suggesting a negligible homopolymerization of the UP through its double bonds. Using model compounds the 
authors proved that the reaction of the terminal allyl double bonds with thiyl radical was faster than with the internal double bond. It was also found that the addition of aluminum tris(N-nitroso-N-phenyl-hydroxylamine) to the formulation contributed to increase its storage stability. The use of the multifunctional thiol [pentaerythritol tetrakis(3-mercaptopropionate)] led to the production of films with increased crosslinking density. This fact that was attributed to the high chain transfer ability of the thiyl radical.

The properties of UPs can also be tailored through the manipulation of their double bonds. One of the strategies to accomplish such modifications is based on the so called click-chemistry. In this context, Ates and co-workers [21] proposed the functionalization of polyesters through the use of thiol-ene click reactions on UPs that were obtained from the ROP of unsaturated macrolactone globalide (Gl), derived from non-toxic fatty acids. The ROP of globalide was promoted by the use CALB and then polyglobalide (PGl) was functionalized with compounds, viz. 6-mercapto-1-hexanol (MH), butyl-3mercapto propionate (BMP) and $\mathrm{N}$-acetylcysteamine (nACA) (Fig. 21).

$<$ Insert Figure 21>

The different moieties used were able to introduce diverse chemical groups in the side chain of the UP. The use of MH led to the obtainment of an UP with $-\mathrm{OH}$ pendent groups. In the case of BMP and nACA, the authors foresaw the possibility of obtaining UPs with $-\mathrm{COOH}$ or $-\mathrm{NH}_{2}$ groups, respectively. Additionally, the authors believe that this approach could be very useful in preparing a vast range of polymeric materials with potential application in the biomedical field.

Chanda and Ramakrishnan [20], demonstrated that it is possible to modify the double bonds of the UPs bearing itaconate moieties using Michael addition reactions. . Different UPs were prepared via bulk transesterification of dibutyl itaconate with different diols, viz. 1,12- dodecanediol, 1,20-icosanediol, 1,4-cyclohexane dimethanol $(\mathrm{CDM})$ and PEG, in the presence of dibutyltin dilaurate. The ${ }^{1} \mathrm{H}$ NMR analysis of the obtained UPs showed that the double bonds remained intact after the reaction, enabling a further functionalization, with different thiols and amines (Fig. 22). The ${ }^{1} \mathrm{H}$ NMR analysis of the products suggested a quantitative functionalization. 
Another type of modification that has been used is related with the epoxidation of the UPs double bonds, as already seen in Section 2.3. Roumanet and co-workers [91] synthesized oleic acid based UPs via bulk polycondensation of 1,18-(Z)-octadec-9enedioic acid (D18:1) with different glycols (1,3-propanediol, 1,8-octanediol, 1,9nonanediol, 1,10-decanediol, 1,12-dodecanediol). UPs with molecular weights ranging from 7000 to $20000 \mathrm{~g} / \mathrm{mol}$ were obtained, with $T_{\mathrm{m}}$ ranging from $21{ }^{\circ} \mathrm{C}$ to $45^{\circ} \mathrm{C}$, being the lowest and highest value registered for the UPs with 1,6-hexanediol and 1,12dodecanediol in the structure, respectively. The double bonds of the UP were then modified with epoxy groups through the reaction of the UP with m-chloroperbenzoic acid (mCPBA). The crosslinking reaction was then performed (by the formation of ether bridges), using UV light (photocrosslinking) and an iodonium salt as the photoinitiator. Transparent and highly cured films ( $<5 \%$ of extractables) were obtained. The films were subjected to enzymatic degradation $\left(\mathrm{pH}=7.4,37^{\circ} \mathrm{C}\right)$ in the presence of Rhizopus Arrhizus lipase. Results showed no significant degradation after 8 weeks which could be attributed to the highly hydrophobic nature of the films.

Kolb and Meier reported some interesting data related to the modification of saturated fatty acid methyl esters (FAMEs) [92] and proposed new methodologies for the modification of polyesters bearing pendant double bonds (Fig. 23) [93] via crossmetathesis with acrylates or via thiol-ene coupling modifications. The results proved that the methods used were efficient to introduce new functional groups on the structure of the polyester that could be used to tune their thermophysical properties.

\section{<Insert Figure 23>}

Regarding the development of partially biobased UPRs, some contributions are also presented in the literature. Olson and co-workers [94] prepared unsaturated poly(ester ether)s, using the methodology previously presented by Olson and Shears [12], and used the ensuing polymers in the preparation of biodegradable elastomers. The unsaturated polymers were thermally crosslinked in the presence of BPO and $\mathrm{N}$ vinylpyrrolidone (NVP) as UM, to yield elastomeric films. Additionally, the materials were also fabricated into more complex forms with micropatterned surfaces making use of the lithography techniques. Overall, the results indicated that, depending on their composition, the crosslinked structures can be obtained with different in vitro 
degradation profiles (from 30 days to 6 months) and also with a vast range of mechanical properties (Young modulus' ranged from 0.2 to $20 \mathrm{MPa}$ ).

In another contribution, Tang and Takasu [95] developed UPs bearing itaconate and maleate moieties through bulk polycondensation of maleic anhydride and itaconic anhydride with 3-methyl-1,5-pentanediol, in the presence of bis(nonafluorobutanesulfonyl)imide, under mild conditions $\left(60^{\circ} \mathrm{C}, 12 \mathrm{~h}\right.$, vacuum). The preparation of UPRs from the UPs encompassed two steps. First, a diamine was added to a mixture containing the UP, methyl methacrylate (MMA) and a UV-initiator. By means of Michael addition reaction, in particular through the reaction of the maleate units in the UP with the diamine, it was possible to obtain a single gel network ( $\mathrm{SN}$ ). Interestingly, it was found that the itaconate moieties did not participate in this reaction. Next, the mixture was subjected to UV irradiation, and the reaction of the itaconate moieties with MMA led to the formation of the UPR (DN gel) (Fig. 24). It was found that the ensuing UPR had high mechanical strength and exhibited shape memory properties. The authors suggested that this material could be useful in different areas but did not reference any specific application.

$<$ Insert Figure 24>

Jasinska and Koning [96] prepared UPs from IS, SA and MA via thermal polycondensation in the presence of titanium(IV) n-butoxide [79]. The UPs showed a slightly branched structure that could result from the reaction of IS hydroxyl groups with the double bonds. The UPs, however, showed good thermal stability ( $T_{5} \%$ above $260{ }^{\circ} \mathrm{C}$ ) and high $T_{\mathrm{g}}$ values $\left(52\right.$ to $\left.76{ }^{\circ} \mathrm{C}\right)$. The UPs were further crosslinked in the presence of 2-butanone peroxide as initiator and cobalt (II) 2-ethylhexanoate as accelerator; styrene was replaced for less toxic monomers, viz. 2-hydroxyethyl methacrylate (HEMA), NVP, methacrylamide and AcA. UPRs with high $T_{\mathrm{g}}$ (60 to 103 ${ }^{\circ} \mathrm{C}$ ) were obtained and it was found that those were thermally stable up to $200^{\circ} \mathrm{C}$.

In another work, UPs with 'high green content', making use of different biobased monomers (e.g., IA, FA, IS, SebA) were prepared by Fonseca and co-workers [17] and their crosslinking reactions with HEMA studied. The UPs were prepared through bulk polycondensation in the absence of catalysts. The cure reaction was carried out at $80^{\circ} \mathrm{C}$, using BPO as initiator. It was found that when IA was used as the unsaturated diacid, UPs with branched structures were obtained, as inferred by the high values of $Ð(>4)$. 
The UPRs presented high gel contents $(>70 \%)$, being the highest values obtained for the formulations with higher amounts of HEMA. The DMTA showed the existence of two transitions, indicating the presence of different domains within the UPR structure. Swelling tests were also carried out, and it was found that $20 \%$ was the maximum value attained, indicating that the UPRs have a highly hydrophobic nature. Additionally, the in vitro degradation tests $\left(\mathrm{pH}=7.4,37^{\circ} \mathrm{C}\right)$ showed that the UPRs are hardly degraded under the tested conditions. The maximum weight loss was $9 \%$, after 50 days.

In the last years, the use of vegetable oils, or their derivatives, in the preparation of new UPs and UPRs has gained significant interest in the scientific community. The oils were used both as monomers in the preparation of the UPs [72, 73, 97, 98] or in blends with commercial UPRs to increase their biobased content $[74,99]$. To be used as monomers in the UPs synthesis', the vegetable oils primarily undergo an alcoholysis reaction (Fig. $25)$ with glycerol $[72,73,98,97]$, to yield a monoglyceride that is subsequently used in the polycondensation reactions.

$<$ Insert Figure 25>

In a study by Mahmoud and co-workers [73], palm oil (PO) based UPRs were prepared and characterized. The PO based monoglyceride was made to react with MA, in the presence of 2-methylimidazole. The ensuing UP was then mixed with styrene (30\%wt) and UV-crosslinked, using Irgacure 184 as the photoinitiator. The results showed that the UPRs prepared from the UPs with 3 eq. of MA relatively to the monoglyceride showed the highest value of gel content and the best mechanical performance (high values of tensile strength and toughness).

In another interesting contribution, UPs made from glycerol, 1,4-butanediol and IA were prepared and were mixed with acrylated epoxidized soybean oil and water, in order to obtain stable waterborne dispersions [100]. The dispersions were then photocrosslinked in the presence of Irgacure 2959 and triethanolamine, as the initiator and accelerator, respectively. The authors tested the potential of the material to be used as a coating and the overall results showed that the crosslinked UPs presented excellent adhesion, high flexibility, and improved solvent resistance.

\subsection{UPs and UPRs directed to biomedical applications}


The double bonds in the UPs' structure, as previously discussed, can be easily modified using different approaches. This particularity is very advantageous in the biomedical context because it enables the attachment of specific moieties that could enhance the properties of the final material. The fact that some UPs can be crosslinked in the absence of UMs is also very promising, since the use of hazardous UMs is avoided. Nevertheless, and as it will be described in this section, efforts have been made to produce UPRs with less toxic monomers or with macromers based on materials with recognized biocompatibility. This subsection aims to present the most relevant works related with the use of UPs and UPRs in biomedical applications (e.g., tissue engineering or drug delivery systems).

Kharas and co-workers reported the synthesis of fumarate-based UP to be used in bioresorbable bone cement composites, replacing poly(methyl methacrylate) (PMMA), which is currently used in clinical practice [101]. The UPs were prepared by polycondensation of diethyl fumarate and different diols, namely 1,2-propanediol (PD), (S)-(+)-1,2-propanediol (SPD), 2-methyl-1,3-propanediol (MPD) and 2,2-dimethyl-1,3propanediol (DMD). Different catalysts, namely PTSA, $\mathrm{AlCl}_{3}, \mathrm{TiCl}_{4}, \mathrm{Ti}\left(\mathrm{OC}_{4} \mathrm{H}_{9}\right)_{4}$, and $\mathrm{ZnCl}_{2}$, were also tested. The results suggested the possibility of controlling the UP structure and the extent of the side reactions by choosing the proper catalyst. For instance, the polycondensation of the monomers in the presence of PTSA led to branched UPs due to the occurrence of side reactions (between the hydroxyl groups and the double bonds), whereas in the presence of metallic catalysts an UP with a more regular structure and with high amounts of double bonds was obtained. After the polycondensation, the UPs were mixed with NVP, BPO and inorganic filler, $\mathrm{CaSO}_{4} \cdot 2 \mathrm{H}_{2} \mathrm{O}$, and cured in order to obtain a composite able to be used as a bone replacement material. The results showed that the composite presenting higher compressive strength and modulus was the one obtained based on the UP synthesized from $\mathrm{PD}$ in the presence of $\mathrm{ZnCl}_{2}$. This fact was ascribed to the higher content of double bonds of this UP, that led to a more crosslinked composite, and also to the unbranched nature of the glycol used. The in vitro degradation tests $\left(\mathrm{pH}=7.4,37^{\circ} \mathrm{C}\right)$ revealed that both the UPs obtained from branched glycols and the unbranched UPs (based on the polycondensation in the presence of metallic catalysts) are less susceptible to hydrolysis. Regarding the composites, it was found that those are less susceptible to hydrolysis than the corresponding uncrosslinked UPs. Nevertheless, the mass loss 
tendency observed, was the same both for composites and their uncrosslinked counterparts.

Recently, Śmiga-Matuszowicz and co-workers [19] also reported a work in the field of UPRs as bone substitutes. The authors prepared porous scaffolds from the crosslinking reaction of poly(3-allyloxy-1,2-propylene succinate) (PSAGE) with oligo(isosorbide maleate) (OMIS) and a small amount of MMA, in the presence of BPO and $N, N^{\prime}-$ dimethyl-p-toluidine, as the initiator and accelerator, respectively. The foaming system used comprised calcium carbonate and L-LA or pyruvic acid. The results showed that the maximum temperature observed during the crosslinking reaction was $43{ }^{\circ} \mathrm{C}$, and the crosslinked porous structure was able to be formed within 15 minutes. It was found that the scaffolds exhibited mechanical properties (e.g., compressive modulus and strength) similar to the trabecular bone. The in vitro cytotoxicity tests carried out with human fetal osteoblasts (hFOB1.19) cell line revealed that, after $24 \mathrm{~h}$, the percentage of viable cells was between 77 and $99 \%$. Upon incubation in a phosphate buffered saline solution $\left(\mathrm{pH}=7.4,37^{\circ} \mathrm{C}\right.$ ) it was found that the porous scaffolds lose $40 \%$ of their initial weight after 26 weeks of degradation. Additionally, the scanning electron microscopy (SEM) analysis revealed that, after 3 hours of incubation, a crystal layer resembling apatite was formed at the surface of the scaffold. Taking into account the obtained results, the authors suggested that these materials can be used as fillers for bone voids.

Guo and co-workers [102] developed new UPs viz. poly(fumaric acid-glycoldodecanedioic acid) (P(FA-GLY-DDDA)) copolymers, poly(fumaric acid-glycolbrassylic acid) (P(FA-GLY-BA)) copolymers, poly(fumaric acid-glycoltetradecanedioic acid) (P(FA-GLY-TA)) copolymers and poly(fumaric acid-glycolpentadecanedioic acid) (P(FA-GLY-PA)) copolymers. These were prepared in high yields by melt polycondensation of the corresponding monomers. The UPs were subsequently mixed with MMA, a dimer acid, and with BPO-triethylamine system, and it was found that the ensuing formulation was able to gel at temperatures close to human body temperatures. In terms of application in the biomedical field, the gels obtained from $\mathrm{P}$ (FA-GLY-BA) have shown to be the most promising taking into account its degradation profile $\left(\mathrm{pH}=7.4,37^{\circ} \mathrm{C}\right)$, its lack of toxicity when implanted in mice, and the release profile of hydrophilic drugs. Additionally, it was also found that the gels obtained from this UP (with a specific molar composition of 1.75FA/2.20 GLY/0.25BA) when used to encapsulate adriamycin hydrochloride were able to enhance the anti-tumor efficacy of the drug, as revealed by the in vivo tests carried out 
on mice bearing Sarcoma-180 tumor. In a subsequent work, Guo and co-workers [103] reported the use of poly(fumaric acid-glycol-sebacic acid) (P(FA-GLY-SA)) copolymers and poly(maleic anhydride-glycol-sebacic acid) (P(MA-GLY-SA)) for the same purpose. The gels of both UPs have shown to be biocompatible and suitable for applications related with the drug delivery for cancer therapy.

Doulabi and co-workers [8] developed poly(ethylene glycol-co-fumarate) (PEGF) macromers to be used in the preparation of hydrogels. The macromers were prepared from PEG (1000 g/mol and $4000 \mathrm{~g} / \mathrm{mol})$ and fumaric acid, at $50{ }^{\circ} \mathrm{C}$, in the presence of the system dicyclohexylcarbodiimide (DCC)/dimethylaminopyridine (DMAP) as the condensation promoter (Fig. 26). The crystallinity and $T_{\mathrm{m}}$ were shown to be higher for the macromers prepared from PEG with high molecular weight.

$<$ Insert Figure 26>

The hydrogels were prepared in the presence of a crosslinking agent, NVP, using a water soluble redox system comprising ammonium persulphate $N, \quad N, \quad N^{\prime}, N^{\prime}-$ tetramethylethylenediamine as initiator. It was found that the gelation time to produce the hydrogels decreased with the increase in the PEG molecular weight. The swelling capacity was also higher for the hydrogels prepared from the macromers with PEG of high molecular weight.

In a different approach, Wang and co-workers [104] prepared a set of self-crosslinkable and biodegradable UPs from poly( $\varepsilon$-caprolactone-co-fumarate) (PCLF), poly(ethylene glycol-co-fumarate) (PEGF) and their copolymer PEGF-co-PCLF. The PCLF and PEGF were prepared from the reaction of the PCL-diol or PEG with fumaryl chloride, in the presence of $\mathrm{K}_{2} \mathrm{CO}_{3}$, as the proton scavenger. The copolymer was prepared in the same way, making use of the PCLF and PEGF macrodiols previously obtained (Fig. 27).

$<$ Insert Figure 27>

The prepared UPs were able to be thermally or photocrosslinked, without the addition of a crosslinking agent. The authors suggested that these UP could be useful in the preparation of diverse materials for biomedical applications.

PCLF was used by Sharifi and co-workers [105] in the development of an in situ forming drug delivery system for tamoxifen citrate (TC), an anti-cancer drug. The networks were prepared via photocrossliking using camphorquinone (CQ) and 
dimethyl-p-toluidine as the initiator and accelerator, respectively, and NVP as the crosslinking agent. Increasing the NVP content up to $16 \%$ wt, led to an increase in the gel yield and a decrease in the swelling capacity. Above this value, the increment of the NVP concentration in the formulation did not translate in an increase of the gel yield, remaining some of the monomer unreacted. The in vitro cytotoxicity tests carried out on MCF-7 and L929 cell lines showed that the PCLF based networks containing $10 \% \mathrm{wt}$ NVP had no adverse effects on the cells. However, when PCLF/10\%NVP networks were loaded with TC, it was observed that $40-60 \%$ of the cells were killed after $72 \mathrm{~h}$ of incubation.

In another approach, Sharifi and co-workers [106] synthesized novel self-crosslinkable and biodegradable polymers, namely poly(hexamethylene carbonate-fumarate) (PHMCF) and poly(hexamethylene carbonate) diacrylate (PHMCA), and their amphiphilic copolymers with PEG, poly(ethylene glycol fumarate-co-hexamethylene carbonate-fumarate) (PEGF-co-PHMCF). The synthetic route for the obtainment of the polymers was similar to that proposed by Wang and co-workers [104], but, in this case, instead of $\mathrm{K}_{2} \mathrm{CO}_{3}$, propylene oxide was used as the proton scavenger. The developed materials were able to be photocrosslinked, without the addition of a crosslinker or accelerator, and in the presence of camphorquinone (CQ). The in vitro cytotoxicity tests showed that the materials did not evoke any cytotoxic effect. The optimization of the photocuring parameters of PHMCF (Fig. 28A) were reported by Mohtaram and coworkers [107]. The photocrosslinking reaction was studied in the presence of CQ ( 0.5 to $1.5 \% \mathrm{wt}$ ) and also in the presence of CQ and an amine accelerator, viz. dimethylamino methyl ethylacrylate (DMAMEA) (0.5 to $1.5 \%$ wt) (Fig. 28B). The PHMCF has shown to be able to be photocrosslinked with a high degree of conversion (ca. $75 \%$ ), in the presence of CQ $(1 \% \mathrm{wt})$ and without DMAMEA. The network obtained from this specific photocrosslinking reaction showed the lowest swelling ratio and a total absence of cytotoxicity.

<Insert Figure 28>

UPs based on itaconic acid (IA), and the corresponding diester (dimethyl itaconate, DMI), AA, SA, and different diols, viz. sorbitol (Sorb), TMP, 1,4cyclohexanedimethanol (CHDM), PEG and 3-methyl-1,5-pentanediol (MPDO) were prepared by Barret and co-workers [108]. Thermal and enzymatic polycondensation (mediated CALB) were used as the polymerization methods with IA and DMI, 
respectively. Both branched and linear UPs were prepared (Fig. 29); the first ones were prepared from the copolymerization of IA with AA and TMP and from the copolymerization of SA Sorb, whereas the second ones resulted from the copolycondensation of DMI with CHDM, PEG and MPDO. The UPs were then photocrosslinked using 2,2-diethoxyacetophenone as the photoinitiator, and poly(ethylene glycol) methyl ether methacrylate $(475 \mathrm{~g} / \mathrm{mol})$, or 2(methacryloyloxy)ethyl acetoacetate as the UM. It was shown that the thermomechanical properties can be easily tuned by the choice of the monomers, being the best results obtained for the network based on the UP synthesized from DMI, AA, and MPDO. The materials have also shown to have low cytotoxicity, making them good candidates to be used in biomedical applications. Moreover, the suitability of the UPs to be used in imprint lithographic techniques was also shown.

\section{$<$ Insert Figure 29>}

In another approach, Brown and co-workers [109] reported the synthesis of aliphatic UPs with potential application in the biomedical field making use of a new dicarboxylic acids and anhydrides (Fig. 30A), obtained from the Diels-Alder reaction of fumaric acid and maleic anhydride with several dienes. This synthetic route allowed the obtainment of new monomers with diverse functionalities, viz. ether and amine, that were preserved in the UP structure, after the polycondensation reaction with 1,8octanediol, in the presence of $\mathrm{Sn}(\mathrm{Oct})_{2}$ (Fig. 30B). All the UPs were amorphous, with $T_{\mathrm{g}}$ ranging from -30 to $-15^{\circ} \mathrm{C}$. The UPs were liquid at room temperature, and were able to self-crosslink in the presence of $\alpha, \alpha^{\prime}$-azoisobutyronitrile (AIBN), at $130{ }^{\circ} \mathrm{C}$ (Fig. 30C), yielding degradable elastomeric materials. These structures were evaluated in terms of their in vitro cytotoxicity, and the results showed that only the elastomer prepared from the UP containing the anhydride III (Fig. 30A) evoked a cytotoxic response. The remaining elastomers have shown to be non-cytotoxic.

$<$ Insert Figure 30> 


\subsection{UPs, UPRs and additive manufacturing towards scaffold-based tissue engineering}

The previous sections of this manuscript described the different strategies available in the literature to afford UPs and UPRs with tunable properties (e.g., thermomechanical, biodegradability, etc) for biomedical applications. Despite their huge potential, the design and production of 3D scaffolds using these materials remains very limited due to the processing techniques employed. The introduction of AM in the field of TE opens the possibility to generate $3 \mathrm{D}$ matrices with complex shapes, reproducible internal/external architectures, interconnected network of pores and multiple materials. Knowing the potential of UPs and UPRs as materials for AM due to the possibility of fine tuning their properties as previously described, in the current section of this contribution, the rationale behind TE and AM processes is presented with special emphasis on SLA systems. In particular, the main SLA processes, principles and applications will be described, as well as the recent advances in micro- and multimaterial systems for the production of TE scaffolds.

As reported in the literature, TE represents an emerging multidisciplinary scientific field where principles of biology, medicine, materials and engineering are combined with the aim of developing artificial bio-implants for the regeneration/repair of damaged tissues and organs. The most common strategy in TE (scaffold-based TE strategy) comprises the combined use of cells and scaffolds to promote and enhance the healing process of the native tissues (Fig. 31).

$<$ Insert Figure 31>

Most of cell lines used in TE are anchorage dependent, which means they will need a support template. For this reason, scaffolds play a major role in TE acting as a temporary biomechanical support to accommodate cells and promote the guided regeneration of the neo tissue [110]. The capacity of scaffolds to retain and deliver cells and biological molecules, promote the adequate diffusion of cell nutrients, oxygen and vascularization are fundamental aspects inherent to the regeneration process of tissues [111-113]. Due to the multi-functionality of human tissues it becomes very complex, if not impossible, to define which are the parameters of an ideal scaffold, even for a single tissue [114]. The considerations are complex and include chemical, morphological, mechanical and biological aspects, as well their variation with time. Specifically, a 
scaffold must satisfy many requirements such as biocompatibility, controlled biodegradability and bioresorbability, interconnecting pores with specific size and geometry, appropriate mechanical and mass transport properties, as well as adequate surface topography and chemistry to promote cell adhesion, proliferation and differentiation [111-113, 115-127].

The mechanical, chemical and biological behavior of scaffolds are determined both by the intrinsic properties of the biomaterials as well the manufacturing processes used for their fabrication. In this sense, different technologies have been developed with the aim of producing scaffolds with optimized properties for TE applications.

Currently, it is possible to identify and classify the existing technologies into two major groups: conventional and non-conventional technologies.

Since the early days of TE, conventional technologies have been used extensively and with relative success in the fabrication of scaffolds. These methodologies include salt leaching, lyophilisation, supercritical fluids, moulding [111, 128-131].

These processes are generally quite simple from an implementation point of view enabling the production of highly porous structures. Despite this simplicity, they do not allow for a perfect control over the pore size, geometry and spatial distribution, leading to the generation of $3 \mathrm{D}$ structures with limited or inexistent pore channel interconnectivity. Besides the abovementioned limitations of these so called nonconventional techniques, the use of toxic organic solvents and long fabrication times are other drawbacks that have to be considered. Therefore additive manufacturing techniques are gaining increasing importance in the fabrication of 3D structures with customised external shape and predefined internal morphology, allowing good control of pore size and distribution.

Non-conventional or AM technologies represent a group of techniques recently introduced in the medical field. Besides the high reproducibility and elevated capacity to quickly produce very complex 3D shapes, these techniques enable the fabrication of scaffolds with good control over pore size and distribution increasing the vascularisation and mass transport of oxygen and nutrients throughout the scaffold [132-134]. The rationale behind AM technologies is based on the use of two dimensional data (2D) obtained from the slicing process of $3 \mathrm{D}$ models created via $\mathrm{CAD}$ (Computer Aided Manufacturing) systems to physically reproduce 3D objects in a 
layer-by-layer fashion [135]. Fig. 32 illustrates the main steps required for the production of TE scaffolds using AM techniques.

The first stage requires the generation of the $3 \mathrm{D}$ solid model to be produced. This model can either be obtained directly from 3D CAD software, imported from 3D scanners or from medical imaging data (computed tomography, magnetic resonance, ultra sounds, etc.) [136].

$<$ Insert Figure 32>

The CAD model is then tessellated into an STL model. This operation consists on the approximation of the model surfaces through a mesh of triangular elements. Finally the STL model is mathematically sliced into layers of homogeneous thickness (SLI file) and sent for production in one of the available AM techniques. The main advantages of AM techniques rely on the capacity of the systems to physically reproduce very complex 3D objects with relatively high speed and employing a wide range of materials. Through the combination of AM techniques with imaging data it becomes possible to produce personalized structures with optimal internal/external geometries, which will enhance the biomechanical coupling between the implant and the native tissue at the site of the defect. Fig. 33 illustrates some customized implants produced via AM techniques.

$<$ Insert Figure 33>

Some of these processes can operate at room temperature, with relatively low mechanical work hence enabling the production of 3D hydrogel-based constructs with embedded cells (Fig. 34).

$<$ Insert Figure 34>

Depending on the application, AM techniques allow for the direct or indirect production of $3 \mathrm{D}$ scaffolds. The last, requires the generation of a lost mould where the biomaterial can be deposited and give shape to the scaffold (Fig. 35). The existing or under development AM techniques employed in TE comprise SLA processes, sintering processes, extrusion, inkjet printing.

<Insert Figure 35> 
The SLA processes, initially proposed by Hull and Pomerantz, involve the selective solidification of photosensitive resins [146, 147]. Currently, SLA processes comprise two distinct irradiation methods, namely mask irradiation and direct irradiation (Fig. 36).

$<$ Insert Figure 36>

In the first method, each layer of the polymer is solidified via exposure to UV radiation, generated by a lamp and transmitted through a mask with transparent areas corresponding to the section of the model to be fabricated. This strategy can also be designated as integrative fabrication method as each layer is produced in full at once [148]. In the second method, also called vector photo-fabrication, a laser is employed to polymerize, point by point each layer of the polymer hence defining the cross section of the $3 \mathrm{D}$ object. The direct irradiation system is composed of a vat containing a photosensitive polymer, a movable platform where the model is built, a laser irradiating UV light and a dynamic optical system to direct the laser along the polymeric layer (Fig. 37). After the construction of each layer, the platform lowers inside the vat containing the polymer promoting the deposition of a non-reticulated polymeric film upon which the next layer will be generated.

\section{$<$ Insert Figure 37>}

The methods described above comprise polymerization mechanisms (solidification or cure of liquid resins) through the absorption of a single radiation photon. However, there are processes based on the use of femtosecond laser emitting IR, where the polymeric system is solidified through a reaction ignited by the absorption of two radiation photons. This process is designated two-photon polymerization and enables the curing process to occur inside the polymeric system with nanometric resolution. Independently from the adopted SLA strategy, two main events occur during the curing reaction, namely gelation and vitrification.

During the curing process, an increase in the $T_{\mathrm{g}}$ of the material may be observed, as a consequence of the increase in the molecular weight and cross-linking density. Generally, it is expected that by increasing the extent of cure, molecular weight and cross-linking will increase, thus removing free chain ends and reducing polymer chain 
motions [149]. Consequently, the specific volume should decrease with increasing the extent of cure [149], and it might be expected an increase in density and modulus of the material as the conversion increases [148, 150].The kinetics of the curing process is strongly affected by temperature, light intensity, and resin composition. As reported in the literature [148, 151-153], photoinitiated curing processes are characterized by high initiation rates. Accordingly, volume shrinkage is much slower than the rate of chemical reaction and the system cannot be in volume equilibrium. For this reason, a temporary excess of free-volume is generated, thus increasing the mobility of the reactive species in the system. This effect induces higher reaction rates and conversions. Hence, the higher the temperature, light intensity, or initiator concentration, the higher the rate of gel formation which leads to higher conversion [148].

A wide range of materials can be used to produce 3D structures via conventional SLA such as agarose, dextran, PEG, PVA, poly(2-hydroxyethyl methacrylate) (PHEMA), etc. In this case the photo initiators must possess low cytotoxicity, enabling the polymerization of polymeric suspensions containing cells.

Liu and Bhatia [154] have developed a mask irradiation process for the production of cell laden constructs with micrometric resolution. In this process, the polymeric solution containing the cells is deposited in the working platform using a syringe (Fig. 38).

$<$ Insert Figure 38>

Chan and co-workers [155] have developed a method to promote cell alignment on three dimensional hydrogel-based constructs through the combination of micro-contact printing and SLA (Fig. 39). Fibronectin was initially modified with acrylate groups and then used to pattern glass coverslips with acryl-fibronectin via micro patterning technique. Generated patterns were transferred to hydrogels produced via SLA and cell alignment investigated using NIH/3T3 mouse embryonic fibroblasts.

$<$ Insert Figure 39>

Microstereolithography (micro-SLA) has evolved from conventional SLA process and possesses the same operating principles. High resolution $3 \mathrm{D}$ objects are built by superimposition of layers, each being produced by a light-induced photopolymerization of a liquid resin $[133,146,156]$. 
Since 1993 different strategies have been adopted to improve both the vertical (along the building axis) and lateral (in-plane) resolution of the SLA process, thus resulting in the development of several machines that can be classified into three categories:

1) Scanning micro-SLA systems, which are based on a vector by vector tracing of every layer of the object with a light beam;

2) Integral micro-SLA processes, which are based on the projection of the image of the layer to be built on the surface of the resin with a high resolution;

3) Sub-micron micro-SLA systems, allowing the polymerization of the layers which compose the structure directly inside the reactive medium. The improvement of the resolution is basically related to the reduction of the light-material interaction $[157][$.

All micro-SLA machines are based on the use of a liquid resin that should possess specific characteristics, since it is directly related to the resolution of the object that will be manufactured. One important development in this area was the development of a novel integral SLA system by researchers from the Centre for Rapid and Sustainable Product Development (CDRSP), Portugal. This system comprises a light source consisting on a 200 Watts mercury lamp with 3 fundamental peaks of irradiation (320$390 \mathrm{~nm}$ with radiation intensity of 17 Watts $/ \mathrm{cm}^{2}, 390-450 \mathrm{~nm}$ with radiation intensity of $20 \mathrm{Watts} / \mathrm{cm}^{2}$ and 280-320 nm with radiation intensity of 7 Watts $/ \mathrm{cm}^{2}$ ), a shutter for the radiation on/off, a set of filters and collimating lenses which guarantee the adequate selection of the wave length, a UV radiation DMD (Digital Micro-Mirror Device DMD $0.7 \mathrm{XGA} 12^{\circ}$ DDR, $1024 \times 768$ pixel of $14 \mu \mathrm{m}$ dimension) which enables the micro definition of each cross section to be built, a reduction Zeiss lens (10X maximum reduction) and building moveable platform with a resin vat (Fig. 40).

$<$ Insert Figure 40>

This system allows for the production of hydrogel-based constructs for TE applications (Fig. 41). The structures are formed by physical or covalent reticulation of a liquid polymeric solution transforming it into a solid hydrogel.

$<$ Insert Figure 41>

In the TE field, micro-SLA has been used, for example, to produce customized poly(propylene fumarate) (PPF)/diethyl fumarate (DEF) photopolymer 3D scaffolds 
incorporating BMP-2 loaded PLGA microspheres [158]. In this case, PLGA microspheres were incorporated into a 3D scaffold which was fabricated through a micro-SLA system with a suspension of microspheres and a PPF/DEF photopolymer. The in vitro release profiles were assessed, and it was demonstrated that the produced microsphere-containing 3D scaffold was able to gradually release the growth factor. The biological performance of such multifunctional structures was analysed, confirming that scaffolds produced by micro-SLA were superior to traditional structures obtained using particulate leaching/gas foaming method.

However, as reported in the literature [159, 160], excimer-laser-based projection photocuring of liquid resins represents a promising method to increase the production efficiency of SLA, taking into consideration the well-shaped and high-power beams delivered by excimer lasers. In addition, such lasers may offer the possibility to process a wide range of materials for scaffold fabrication as the wavelengths can span all the deep-UV to UV range [159, 160].

For this reason, an excimer-laser-based SLA was also developed and proposed as a rapid process to fabricate PPF/DEF scaffolds for TE [160].

The results obtained from experimental analyses demonstrated that the proposed technique could be considered as an excellent tool for the development of biocompatible structures on a micrometre scale showing high-resolution and well-defined patterns in all the three spatial dimensions. Furthermore, the speed of the process was strongly increased, thus favoring a potential translation of this technology to clinical applications [160].

A scalable method to synthesize well-defined PPF was also reported by means of a ring opening polymerization of maleic anhydride and propylene oxide coupled with a post polymerization isomerization reaction [161]. The biological evaluation of these PPF oligomers was performed and their use to manufacture $3 \mathrm{D}$ printed scaffolds via established photochemical methods was assessed.

In particular, DEF was also added to the PPF in a specific mass ratio to reduce the viscosity of the polymer. The photoinitiators Irgacure 819 and Irgacure 784 together with oxybenzone and additional DEF were added to the PPF/DEF mixture to optimize the final composition of a suitable reactive solution for photo-cross-linking. Preliminary analyses showed that the 3D printed scaffolds were nontoxic to L929 mouse fibroblasts and human mesenchymal stem cells [161]. 
To manufacture multi-material functionally graded components, researchers from the CDRSP, Portugal, have developed a new SLA process, which is known as stereothermal-lithography (STLA) [148, 162]. This fabrication process uses UV radiation and thermal energy produced by IR radiation to initiate the polymerization in a medium which contains both photo- and thermal-initiators (Fig. 42) [148, 162].

\section{$<$ Insert Figure 42>}

The concentrations of these initiators must be properly selected and the curing process starts when there is a specific combination of thermal and UV radiation energy [148, 162]. Also, the amount of each initiator must be low to prevent the start of the polymerization by only one of these two effects.

In this fabrication process, temperature is used to produce radicals through the thermal decomposition of the initiators, simultaneously increasing the initiation and reaction rate of the photoinitiated curing reaction. Consequently, the extent of cure increases and no post-cure should be needed, thus producing high quality models [148]. If compared to conventional SLA, STLA presents several advantages, such as: a more efficient generation of radicals; the use of small concentrations of two different types of initiator which enables the radiation to penetrate deeper into the material; a faster reaction rate; a fractional conversion values due to the specific combination of UV radiation and temperature; and an improvement of the accuracy of the produced models as a consequence of a more localized curing reaction, a more tunable system [148].

In particular, the overall system may be divided into four subsystems:

Subsystem A employs UV radiation to solidify a liquid resin containing a specific amount of photoinitiator. It corresponds to an approach which is similar to conventional SLA.

$>$ Subsystem B uses thermal energy produced by infrared radiation for solidifying a liquid resin which contains a specific amount of thermal initiator.

$>$ Subsystem $\mathrm{C}$ employs both heat produced by infrared radiation and ultraviolet radiation in order to solidify a liquid resin which contains a certain amount of photoinitiator.

$>$ Subsystem D uses both heat produced using infrared radiation and ultraviolet radiation to solidify a liquid resin containing a certain amount of thermal initiator and photoinitiator [148]. 
Furthermore, the system also contains a rotating multi vat allowing the production of multi-material structures (Fig. 43).

$<$ Insert Figure 43>

This should represent an important advancement in developing multi-material functional graded scaffolds for tissue engineering, multi-material microscopic engineering prototypes through nanostructures for different applications in several fields, biomedical components, as well as functional metallic or ceramic parts [148]. In this context, our research group developed new bio UPs to be applied in SLA [18]. In particular, the different biobased UPs (Fig. 44) were used to prepare scaffolds by microSTLA, using HEMA as UM and Irgacure 651 as photoinitiator.

$<$ Insert Figure 44>

The obtained structures presented very accurate external geometries (Fig. 45), well defined internal pores and nano scale surface roughness, which is very important to promote cell adhesion and proliferation.

<Insert Figure 45>

Two-photon polymerization (TPP) may be considered as a useful SLA strategy to fabricate micro/nanoscale structures. Basically, femtosecond laser pulses are focused into the volume of a liquid resin transparent to the infrared radiation without using photomasks (Fig. 46) [148, 163-170].

<Insert Figure 46>

In this fabrication process, the reactive molecule should be able to simultaneously absorb two photons instead of one as it is excited to a higher singlet state. The process allows a submicron 3D resolution, also allowing 3D fabrication at greater depth and ultra-high speed [148].

With regard to the fabrication of $2 \mathrm{D}$ and $3 \mathrm{D}$ microstructures with TPP, a nanostereolithography (nano-SLA) system was also developed (Fig. 47) [148, 167]. 
It involves the use of a mode-locked Ti:sapphire laser as the light source, providing a wavelength of $780 \mathrm{~nm}$ and a pulse width of less than $100 \mathrm{fs}$ at a repetition rate of 80 $\mathrm{MHz}[107,172]$. The beam is scanned across the focal plane by employing a set of two Galvano-mirrors characterized by a resolution of approximately $2.5 \mathrm{~nm}$ per step, and along the vertical axis using a piezoelectric stage. The laser is closely focused into a volume of photocurable resin with an objective lens. In order to obtain exposure times less than $1 \mathrm{~ms}$, a Galvano-shutter combined with a pin-holed plate is applied [167]. A control program is used to control the shutter, scanner, and piezoelectric stage. A high magnification CCD camera is also employed to monitor the fabrication process [167]. The contour scanning method and the raster scanning method have been considered to produce micro-objects with TPP. In the contour scanning method, the contour profile of the microstructure is traced by the laser beam, whilst in the raster scanning method all of the cubic volume containing the microstructure is scanned. The contour scanning method improves the fabrication efficiency, requiring less processing time [167]. In the nano-SLA process, according to the scanning paths one sliced layer of the 3D microstructure is solidified. After translating the position of the beam spot along the zaxis, another layer is produced. The 3D structure is sequentially produced with this method [167]. TPP using resins which contain conventional initiators have been reported in the literature, even if such polymeric systems exhibit low photosensitivity [148, 169, 173]. Commonly used materials are inorganic-organic hybrid materials whose properties can be suitably tailored benefiting from a combination of the characteristics of their constituents, polymers and inorganic glasses [174, 175].

Even though TPP possesses many advantages, this technology still has some problems related to the fabrication of multi-material structures [176].

To sum up, SLA processes present significant advantages for the production of TE scaffolds, namely high dimensional accuracy, capability to generate very complex geometries, possibility to use multiple materials and ability to operate at room temperature (or above) for the encapsulation of cells and biological molecules. Significant advances are expected in the next few years with the integration of different technologies into a single hybrid system capable of replicating the nano, micro and macro features of the tissues, introducing biomimetic functional gradients and improving the overall regeneration process.

\subsection{Experimental design and theoretical concepts in SLA}


To develop scaffolds for TE using SLA process, the materials must fulfill some requirements such as biocompatibility, fast curing process and low viscosity.

In the SLA process, the UV radiation, which hits the surface of the liquid resin, is absorbed and dispersed.

Accordingly, the penetration of the radiation is limited and, hence, the depth of curing which may be defined as follows [148, 178]:

$$
C_{d}=D_{p} \ln \left[\frac{E_{\max }}{E_{c}}\right]
$$

where, $C_{d}$ represents the maximum curing (penetration) depth, $D_{d}$ is the penetration depth at which the beam intensity is reduced to 1/e of its surface value, Emax is the maximum energy value on the resin surface and $E_{c}$ is the critical energy value which is required for the liquid $\rightarrow$ solid phase transition of the resin. As a consequence, the depth of curing is a function of the exposure and may be controlled by varying the radiation level applied to the liquid resin. The maximum exposure energy on the resin surface may be written as follows [148, 178]:

$$
E_{\max }=\sqrt{\frac{2}{\pi}} \frac{P}{w_{0} v_{s}}
$$

where $\mathrm{P}$ represents the laser power within the vat of the stereolithography apparatus, w0 and $v_{\mathrm{s}}$ are the beam radius and the scanning speed, respectively [148].

An insufficient extent of cure means that it is necessary to perform a post-cure operation in an ultraviolet chamber [148].

Accordingly, the knowledge of the material and process parameters is crucial to further extend the use of SLA processes and to determine the suitable resin formulations.

The evaluation of the molecular mass and molecular mass distribution as well as of the calorimetric properties of the material (e.g., glass transition, thermal degradation...) represents an important step to optimize the SLA process.

The curing behavior can be properly optimized by analyzing the curing depth as a function of the irradiation dose or time. The effect of the light intensity on the curing process can be properly assessed, fractional conversion as a function of curing time provides an important information for the process optimization.

All of this may allow to tailor the reaction rate, as well as the induction time and vitrification. 
At different molecular mass levels, to assess the flow behavior measurements of intrinsic viscosity may be performed by a capillary viscosimeter, whereas steady shear tests may allow to analyze the viscosity as a function of the shear rate.

On the other hand, small amplitude oscillatory shear tests can be also carried out to evaluate the viscoelastic properties of the resin (e.g., storage modulus and loss modulus as a function of frequency).

In many cases, the evaluation of the viscosity may be difficult as a possible consequence of the high concentration of carbon-carbon bonds in the polymer backbone and eventual crosslinking reactions which can occur during the polymerization reaction [18].

Furthermore, rheological stability or instability may be evaluated by monitoring the viscosity as a function of the shear rate over time.

It is well known that high molecular mass polymers with high viscosity are usually not suitable for manufacturing 3D printed scaffolds [161].

For this reason, taking into account the above reported features, it is possible to define a scalable method to synthesize a material with well-defined molecular mass, narrow molecular mass distribution and viscosity properties suitable to manufacture 3D scaffolds using SLA processes.

As reported in the previous sections, our group focused on the development of different biobased UPs to be used in micro-SLA [18], trying to overcome the lack of proper biocompatible and photocurable polymers $[18,178]$.

Specifically, the viscosity values of UPs based on alkyl carboxylic acids were low (e.g., $0.24-0.58 \mathrm{~Pa} \mathrm{~s}$ ) in comparison with those based on isophthalic acid. This difference can be due to the higher mobility of the polymer chains incorporating a long alkyl chain backbone [18]. An extensive characterization showed that the properties of these UPs matched the micro-SLA requirements, thus opening the possibility to develop new biodegradable and tailor made scaffolds for TE [18].

\section{Conclusions and Outlook}

The introduction of AM technologies in the TE field brought an unprecedented toolbox of methods to produce tailor made 3D structures. In order to explore the full potential of 
these advanced methods it is crucial the development of suitable polymers that can fulfill some demanding requirements.

There are still many barriers to use innovative materials and advanced SLA processes in the mainstream clinical practice. For example, one of the main problems is related to the synthesis of low molecular weight polymers with reproducible properties and welldefined characteristics that could be used in SLA. Recently, the development of new UP based materials have received enormous interest for biomedical applications, particularly in the development of tailor made 3D structures. These polymers can be successfully used in AM due to several important features: biocompatibility, easy synthesis, functional side groups, large availability and fast UV/Vis curing. Although important developments have been made over the last years regarding the synthesis of UPs, their full use in AM requires important research efforts to overcome some existing issues that strongly affect the manufacturing process. Among them it is possible to stress: the rheological instability that leads to an increase of viscosity over time; nonreversible events; and phase transitions. The rigorous control over the structure of the polymer is also mandatory for the fine adjustment of the mechanical properties of the final 3D scaffolds aiming specific applications, the optimization of cell attachment, growth and proliferation. In this vein, it is frequently reported that poorly controlled manual cell seeding should be overcome by AM technologies that may allow the fabrication of cell-containing constructs in a computer controlled manner. However, most of the limitations are related to the discussed lack of polymers with appropriate properties and processability.

Regarding the SLA technologies, the developments achieved during the last decade are remarkable. The accuracy of most SLA systems is considerably higher compared to other AM techniques enabling the production of TE constructs with sub-micron resolutions. The flexibility of SLA, especially in terms of the light sources used, combined with the freedom of design that it offers, results in the ability to create highly detailed functional implants. However, the successful application of these light-based systems in TE is still hindered by some technological issues: 1) long printing time: this issue becomes especially relevant for the design and production of cell-laden constructs. The majority of SLA systems are still very slow hence affecting cell viability and proliferation after encapsulation; 2) multi-material printing: currently there are two approaches to produce multi-material scaffolds using SLA. The first implies the 
exchange of the entire material vat during fabrication and the second requires the exchange of the materials inside the single vat. Despite being possible to print multimaterial 3D constructs, more efforts will be needed to eliminate problems associated with cross contamination between different resins, uncured material that affects layer accuracy and layer interfaces. The last is particularly important for the design of 3D constructs with continuous functional gradients and improved mechanical stability; 3) gravitational settling of cells: if the printing speed is too low and the resin does not contain the adequate rheological properties, cells will not be homogenously distributed within the precursor solution. Thus, modifications in terms of the SLA apparatus (i.e. introducing centrifugational forces) and in the resins (i.e. including self-adhesive peptides in the cell solution) will be required to improve the design of cell-laden implants; 4) convergence of techniques: the integration of SLA with other AM techniques such as dispensing systems would enable, for example, to combine high accuracy (from SLA) with cell friendly processing (from dispensing) for the production of accurate and biologically viable 3D cell laden-constructs.

To sum up, the synthesis of novel materials and the ways to tune their performances together with the more advanced SLA processes (from micro-SLA and STLA to TPP and nano-SLA) will allow the fabrication of 3D constructs with tailored mechanical, chemical and biological functionality to improve cell-cell and cell-matrix interactions hence leading to a better understanding of the complex cellular mechanisms involved in the regeneration of tissues and organs. With a more synergetic approach between materials scientists, engineers and clinicians it will be possible to design and produce novel biomaterials for SLA opening avenues for effective solutions that can be translated to clinical practice.

Acknowledgements: F.A.M.M. Gonçalves acknowledges "Fundação para a Ciência e Tecnologia", Grant: SFRH/BD/71113/2010. A. C. Fonseca acknowledges "Fundação para a Ciência e Tecnologia", Grant: SFRH/BPD/99982/2014. 


\section{References}

[1] McIntyre JE. The historical development of polyesters. In: Scheirs J, Long TE, edtiors. Modern Polyesters: Chemistry and Technology of Polyesters and Copolyesters. Chichester: John Wiley \& Sons Ltd, 2003. p. 3-10.

[2] Odian G. Principles of Polymerization. New Jersey: John Wiley \& Sons Inc, 2004. p. 812.

[3] Rogers ME, Long TE. Synthetic methods in step-growth polymers. New Jersey: John Wiley \& Sons Inc, 2003. 605 pp.

[4] Krishnan PSG, Kulkarni ST. Polyester resins. In: Deopura BL, Alagirusamy R, Joshi M, Gupta B, edtiors. Polyesters and Polyamides, Boca Raton: CRC Press LLC, 2008. p. 3-35.

[5] Ferreira AB, Cardoso AL, Silva MJd. Tin-catalyzed esterification and transesterification reactions: A review. ISRN Renew Energy 2012;2012:142857/(1-13).

[6] Zeng Z, Cui L, Xue W, Chen J, Che Y. Recent developments on the mechanism and kinetics of esterification reaction promoted by various catalysts. In: Patel V, editor. Chemical Kinetics. Rijeka: InTech, 2012. p. 255-282.

[7] Varma IK, Albertsson AC, Rajkhowa R, Srivastava RK. Enzyme catalyzed synthesis of polyesters. Prog Polym Sci 2005;30:949-81.

[8] Doulabi ASH, Sharifi S, Imani M, Mirzadeh H. Synthesis and characterization of biodegradable in situ forming hydrogels via direct polycondensation of poly(ethylene glycol) and fumaric acid. Iran Polym J 2008;17:125-33.

[9] Doulabi ASH, Mirzadeh H, Imani M, Sharifi S, Atai M, Mehdipour-Ataei S. Synthesis and preparation of biodegradable and visible light crosslinkable unsaturated fumarate-based networks for biomedical applications. Polym Adv Technol 2008;19:1199-208.

[10] Taylor MS, Shalaby SW. Sutures. In: Ratner BD, Hoffman AS, Schoen FJ, Lemons JE, editors. Biomaterials Science: An Introduction to Materials in Medicine. Oxford: Academic Press, 2012. p. 1010-23.

[11] Fonseca AC, Ferreira P, Cordeiro RA, Mendonça PV, Góis JR, Gil MH, Coelho JFJ. Drug delivery systems for predictive medicine: Polymers as tools for advanced applications. In: Mozaffari MS, editor. New Strategies to Advance Pre/Diabetes Care: Integrative Approach by PPPM, Advances in Predictive, 
Preventive and Personalised Medicine 3. Dordrecht: Springer Science+Business Media, 2013. p. 399-455.

[12] Olson DA, Sheares VV. Preparation of unsaturated linear aliphatic polyesters using condensation polymerization. Macromolecules 2006;39:2808-14.

[13] Johnson KG, Yang LS. Preparation, properties and applications of unsaturated polyesters. In: Scheirs J, Long TE, edtiors. Modern Polyesters: Chemistry and Technology of Polyesters and Copolyesters. Chichester: John Wiley \& Sons Ltd, 2003. p. 699-714.

[14] Stevens MP. Polymer chemistry: an introduction. 3rd ed. New York: Oxford University Press Inc, 1999. 576 pp.

[15] Dholakiya B. Unsaturated polyester resin for specialty applications. In: Saleh HEDM, editor. Polyester. Rijeka: InTech, 2012. p. 167-202.

[16] Sousa AF, Fonseca AC, Serra AC, Freire CSR, Silvestre AJD, Coelho JFJ. New unsaturated copolyesters based on 2,5-furandicarboxylic acid and their crosslinked derivatives. Polym Chem 2016;7:1049-58.

[17] Fonseca AC, Lopes IM, Coelho JFJ, Serra AC. Synthesis of unsaturated polyesters based on renewable monomers: Structure/properties relationship and crosslinking with 2-hydroxyethyl methacrylate. React Funct Polym 2015;97:111.

[18] Gonçalves FAMM, Costa CSMF, Fabela IGP, Simões PN, Farinha D, Faneca H, Serra AC, Bartolo PJ, Coelho JFJ. 3D printing of new biobased unsaturated polyesters by microstereo-thermal-lithography. Biofabrication 2014;6:035024/(1-14).

[19] Śmiga-Matuszowicz M, Janicki B, Jaszcz K, Łukaszczyk J, Kaczmarek M, Lesiak M, Sieron AL, Simka W, Mierzwinski M, Kusz D. Novel bioactive polyester scaffolds prepared from unsaturated resins based on isosorbide and succinic acid. Mater Sci Eng C 2014;45:64-71.

[20] Chanda S, Ramakrishnan S. Poly(alkylene itaconate)s - an interesting class of polyesters with periodically located exo-chain double bonds susceptible to Michael addition. Polym Chem 2015;6:2108-14.

[21] Ates Z, Thornton PD, Heise A. Side-chain functionalisation of unsaturated polyesters from ring-opening polymerisation of macrolactones by thiol-ene click chemistry. Polym Chem 2011;2:309-12. 
[22] Fink JK. Reactive Polymers: Fundamentals and Applications. New York: William Andrew Publishing, 2005. p. 1-48.

[23] Dusek K, Duskov-Smrckova M. Network structure formation during crosslinking of organic coating systems. Prog Polym Sci 2000;25:1215-60.

[24] Lu MG, Shim MJ, Kim SW. Curing behavior of an unsaturated polyester system analyzed by Avrami equation. Thermochim Acta 1998;323:37-42.

[25] Yang YS, Lee LJ. Microstructure formation in the cure of unsaturated polyester resins. Polymer 1988;29:1793-800.

[26] Penczek P, Czub P, Pielichowski J. Unsaturated polyester resins: Chemistry and technology. Crosslinking in Materials Science. Adv Polym Sci 2005;184:1-95.

[27] Martin JL. Kinetic analysis of two DSC peaks in the curing of an unsaturated polyester resin catalyzed with methylethylketone peroxide and cobalt octoate. Polym Eng Sci 2007;47:62-70.

[28] Hsu CP, Lee LJ. Structure formation during the copolymerization of styrene and unsaturated polyester resin. Polymer 1991;32:2263-71.

[29] Hong C, Wang X, Pan Z, Zhang Y. Curing thermodynamics and kinetics of unsaturated polyester resin with different chain length of saturated aliphatic binary carboxylic acid. J Therm Anal Calorim 2015;122:427-36.

[30] Morel M, Lacoste J, Baba M. Photo-DSC I: A new tool to study the semicrystalline polymer accelerated photo-ageing. Polymer 2005;46:9274-82.

[31] Lee SS, Luciani A, Månson JAE. A rheological characterisation technique for fast UV-curable systems. Prog Org Coat 2000;38:193-7.

[32] Claesson H, Malmström E, Johansson M, Hult A, Doyle M, Månson JAE. Rheological behaviour during UV-curing of a star-branched polyester. Prog Org Coat 2002;44:63-7.

[33] Castell P, Wouters M, Fischer H, de With G. Kinetic studies of a UV-curable powder coating using photo-DSC, real-time FTIR and rheology. J Coat Technol Res 2007;4:411-23.

[34] Worzakowska M. Chemical modification of unsaturated polyesters influence of polyester's structure on thermal and viscoelastic properties of low styrene content copolymers. J Appl Polym Sci 2009;114:720-31.

[35] Sanchez EMS, Zavaglia CAC, Felisberti MI. Unsaturated polyester resins: influence of the styrene concentration on the miscibility and mechanical properties. Polymer 2000;41:765-9. 
[36] Matynia T, Worzakowska M, Tamawski W. Synthesis of unsaturated polyesters of increased solubility in styrene. J Appl Polym Sci 2006;101:3143-50.

[37] Cherian AB, Thachil ET. Block copolymers of unsaturated polyesters and functional elastomers. J Appl Polym Sci 2004;94:1956-64.

[38] Cherian AB, Thachil ET. Modification of unsaturated polyesters using polyethylene glycol. Plast, Rubber Compos 2007;36:128-33.

[39] Cherian AB, Abraham BT, Thachil ET. Modification of unsaturated polyester resin by polyurethane prepolymers. J Appl Polym Sci 2006;100:449-56.

[40] Rosa VM, Felisberti MI. Unsaturated polyester resin modified with poly(organosiloxanes). I. Preparation, dynamic mechanical properties, and impact resistance. J Appl Polym Sci 2001;81:3272-9.

[41] Abbate M, Martuscelli E, Musto P, Ragosta G. A polymer network of unsaturated polyester and bismaleimide resins: Yielding and fracture behaviour. Angew Makromol Chem 1996;241:11-29.

[42] Gawdzik B, Matynia T, Chmielewska E. Modification of unsaturated polyester resin with bismaleimide. J Appl Polym Sci 2001;82:2003-7.

[43] Cherian B, Thachil ET. Synthesis of unsaturated polyester resin - Effect of sequence of addition of reactants. Polym Plast Technol Eng 2005;44:931-8.

[44] Messori M, Toselli M, Pilati F, Tonelli C. Unsaturated polyester resins modified with poly(epsilon-caprolactone)-perfluoropolyethers block copolymers. Polymer 2001;42:9877-85.

[45] Nebioglu A, Soucek MD. Investigation of the properties of UV-curing acrylateterminated unsaturated polyester coatings by utilizing an experimental design methodology. J Coat Technol Res 2007;4:425-33.

[46] Nebioglu A, Soucek MD. Microgel formation and thermo-mechanical properties of UV-curing unsaturated polyester acrylates. J Appl Polym Sci 2008;107:236474.

[47] Tawfik SY. Preparation and characterization of some new unsaturated polyesters based on 3,6-bis(methoxymethyl)durene. J Appl Polym Sci 2001;81:3388-98.

[48] Tibiletti L, Longuet C, Ferry L, Coutelen P, Mas A, Robin JJ, Lopez-Cuesta JM. Thermal degradation and fire behaviour of unsaturated polyesters filled with metallic oxides. Polym Degrad Stab 2011;96:67-75. 
[49] Alkskas IA, El-Gnidi BA, Azam F. Synthesis and characterization of new unsaturated polyesters containing cyclopentapyrazoline moiety in the main chain. J Appl Polym Sci 2010;115:3727-36.

[50] Chiu YY, Saito R, Lee LJ. Modification of unsaturated polyester resins for viscosity control. Polymer 1996;37:2179-90.

[51] Zhang D, Wang J, Li T, Zhang A, Jia D. Synthesis and characterization of a novel low-viscosity unsaturated hyperbranched polyester resin. Chem Eng Technol 2011;34:119-26.

[52] Shenoy MA, D'Mello D, Patil M. Effect of the addition of depolymerised ethylene vinyl acetate on the mechanical, thermal, chemical and shrinkage properties of cured unsaturated polyester resins. Polym Int 2010;59:867-74.

[53] Huang YJ, Liang CM. Volume shrinkage characteristics in the cure of lowshrink unsaturated polyester resins. Polymer 1996;37:401-12.

[54] Saito R, Kan WMJ, Lee LJ. Thickening behaviour and shrinkage control of low profile unsaturated polyester resins. Polymer 1996;37:3567-76.

[55] Cao X, Lee LJ. Control of shrinkage and residual styrene of unsaturated polyester resins cured at low temperatures: I. Effect of curing agents. Polymer 2003;44:1893-902.

[56] Duliban J. Novel amine modifiers for unsaturated polyester resins. Macromol Mater Eng 2001;286:624-33.

[57] Duliban J. Amine modifiers with an s-triazine ring for unsaturated polyester resins, 2. Macromol Mater Eng 2007;292:1126-39.

[58] Duliban J. Amine modifiers with an s-triazine ring for unsaturated polyester resins, 1. Macromol Mater Eng 2006;291:137-47.

[59] Kucharski M, Duliban J, Chmiel-Szukiewicz E. Novel amine preaccelerators for polyester resins. J Appl Polym Sci 2003;89:2973-6.

[60] Alemdar N, Erciyes AT, Bicak N. Preparation of unsaturated polyesters using boric acid as mild catalyst and their sulfonated derivatives as new family of degradable polymer surfactants. Polymer 2010;51:5044-50.

[61] Lou X, Detrembleur C, Lecomte P, Jerome R. Living ring-opening (co)polymerization of 6,7-dihydro-2 $(5 \mathrm{H})$-oxepinone into unsaturated aliphatic polyesters. Macromolecules 2001;34:5806-11. 
[62] Cousinet S, Ghadban A, Fleury E, Lortie F, Pascault JP, Portinha D. Toward replacement of styrene by bio-based methacrylates in unsaturated polyester resins. Eur Polym J 2015;67:539-50.

[63] La Scala JJ, Sands JM, Orlicki JA, Robinette EJ, Palmese GR. Fatty acid-based monomers as styrene replacements for liquid molding resins. Polymer 2004;45:7729-37.

[64] Straub T, Brunner M, Koskinen AMP. Model studies towards alternative crosslinking of unsaturated polyesters. Lett Org Chem 2005;2:74-6.

[65] Cinar H, Tabatabai M, Ritter H. Bis(nitrone) as crosslinking agent for unsaturated polyesters via 1,3-dipolaric cycloaddition. Polym Int 2012;61:692-5.

[66] Worzakowska M. Synthesis and characterization of the new unsaturated epoxyoligoester suitable for further modification. J Appl Polym Sci 2008;109:2973-8.

[67] Vilela C, Sousa AF, Fonseca AC, Serra AC, Coelho JFJ, Freire CSR, Silvestre AJD. The quest for sustainable polyesters - insights into the future. Polym Chem 2014;5:3119-41.

[68] Farmer T, Castle R, Clark J, Macquarrie D. Synthesis of unsaturated polyester resins from various bio-derived platform molecules. Int $\mathrm{J}$ Mol Sci 2015;16:14912-32.

[69] Jiang Y, Woortman AJJ, van Ekenstein GORA, Loos K. Environmentally benign synthesis of saturated and unsaturated aliphatic polyesters via enzymatic polymerization of biobased monomers derived from renewable resources. Polym Chem 2015;6:5451-63.

[70] Jiang Y, Woortman A, van Ekenstein G, Loos K. Enzyme-catalyzed synthesis of unsaturated aliphatic polyesters based on green monomers from renewable resources. Biomolecules 2013;3:461-80.

[71] Jiang Y, van Ekenstein GORA, Woortman AJJ, Loos K. Fully biobased unsaturated aliphatic polyesters from renewable resources: Enzymatic synthesis, characterization, and properties. Macromol Chem Phys 2014;215:2185-97.

[72] Lai CM, Rozman HD, Tay GS. Palm oil-based unsaturated polyester: Activation energy and swelling properties. Polym Eng Sci 2013;53:1138-45.

[73] Mahmoud AH, Tay GS, Rozman HD. A preliminary study on ultraviolet radiation-cured unsaturated polyester resin based on palm oil. Polym Plast Technol Eng 2011;50:573-80. 
[74] Miyagawa H, Mohanty AK, Burgueño R, Drzal LT, Misra M. Development of biobased unsaturated polyester containing functionalized linseed oil. Ind Eng Chem Res 2006;45:1014-8.

[75] Takenouchi S, Takasu A, Inai Y, Hirabayashi T. Effects of geometric structure in unsaturated aliphatic polyesters on their biodegradability. Polym $\mathbf{J}$ 2001;33:746-53.

[76] Zheng L, Wang Z, Li C, Zhang D, Xiao Y. Novel unsaturated aliphatic polyesters: Synthesis, characterization, and properties of multiblock copolymers composing of poly(butylene fumarate) and poly(1,2-propylene succinate). Ind Eng Chem Res 2012;51:14107-14.

[77] Najafi F, Sarbolouki MN. Synthesis and characterization of block copolymers from aromatic diols, fumaric acid, sebacic acid and PEG. J Appl Polym Sci 2003;90:2358-63.

[78] Najafi F, Sarbolouki MN. Synthesis and characterization of biodegradable block copolymers of poly(propylene fumarate-co-sebacate)-copoly(ethylene glycol) and poly(ethylene fumarate-cosebacate)-co-poly(ethylene glycol). J Appl Polym Sci 2004;92:295-300.

[79] Jasinska L, Koning CE. Waterborne polyesters partially based on renewable resources. J Polym Sci Part A Polym Chem 2010;48:5907-15.

[80] Naves AF, Fernandes HTC, Immich APS, Catalani LH. Enzymatic syntheses of unsaturated polyesters based on isosorbide and isomannide. J Polym Sci Part A Polym Chem 2013;51:3881-91.

[81] Tsujimoto T, Uyama H, Kobayashi S. Enzymatic synthesis and curing of biodegradable crosslinkable polyesters. Macromol Biosci 2002;2:329-35.

[82] Uyama H, Kuwabara M, Tsujimoto T, Kobayashi S. Enzymatic synthesis and curing of biodegradable epoxide-containing polyesters from renewable resources. Biomacromolecules 2003;4:211-5.

[83] Goerz O, Ritter H. N-Alkylated dinitrones from isosorbide as cross-linkers for unsaturated bio-based polyesters. Beilstein J Org Chem 2014;10:902-9.

[84] Jiang HY, Kelch S, Lendlein A. Polymers move in response to light. Adv Mater 2006;18:1471-5.

[85] Lendlein A, Jiang H, Junger O, Langer R. Light-induced shape-memory polymers. Nature 2005;434:879-82. 
[86] Dong W, Ren J, Lin L, Shi D, Ni Z, Chen M. Novel photocrosslinkable and biodegradable polyester from bio-renewable resource. Polym Degrad Stab 2012;97:578-83.

[87] Matsusaki M, Kishida A, Stainton N, Ansell CWG, Akashi M. Synthesis and characterization of novel biodegradable polymers composed of hydroxycinnamic acid and D,L-lactic acid. J Appl Polym Sci 2001;82:2357-64.

[88] Thi TH, Matsusaki M, Akashi M. Thermally stable and photoreactive polylactides by the terminal conjugation of bio-based caffeic acid. Chem Commun 2008:3918-20.

[89] Nagata M, Inaki K. Synthesis and characterization of photocrosslinkable poly(1lactide)s with a pendent cinnamate group. Eur Polym J 2009;45:1111-7.

[90] Kim YB, Kim HK, Choi HC, Hong JW. Photocuring of a thiol-ene system based on an unsaturated polyester. J Appl Polym Sci 2005;95:342-50.

[91] Roumanet PJ, Laflèche F, Jarroux N, Raoul Y, Claude S, Guégan P. Novel aliphatic polyesters from an oleic acid based monomer. Synthesis, epoxidation, cross-linking and biodegradation. Eur Polym J 2013;49:813-22.

[92] Kolb N, Meier MAR. Monomers and their polymers derived from saturated fatty acid methyl esters and dimethyl carbonate. Green Chem 2012;14:2429-35.

[93] Kolb N, Meier MAR. Grafting onto a renewable unsaturated polyester via thiolene chemistry and cross-metathesis. Eur Polym J 2013;49:843-52.

[94] Olson DA, Gratton SEA, DeSimone JM, Sheares VV. Amorphous linear aliphatic polyesters for the facile preparation of tunable rapidly degrading elastomeric devices and delivery vectors. J Am Chem Soc 2006;128:13625-33.

[95] Tang T, Takasu A. Facile synthesis of unsaturated polyester-based doublenetwork gels via chemoselective cross-linking using Michael addition and subsequent UV-initiated radical polymerization. RSC Adv 2015;5:819-29.

[96] Jasinska L, Koning CE. Unsaturated, biobased polyesters and their cross-linking via radical copolymerization. J Polym Sci Part A Polym Chem 2010;48:288595.

[97] Li J, Qin Y, Zhao L. Mechanical Properties of UP Resin from Soybean Oil. Appl Mech Mater 2011;55-57:443-6.

[98] Qin Y, Jia JR, Zhao L, Huang ZX, Zhao SW, Zhang GW, Dai B. Synthesis and characterization of soybean oil based unsaturated polyester resin. Adv Mater Res 2011;393-395:349-53. 
[99] Miyagawa H, Mohanty AK, Burgueno R, Drzal LT, Misra M. Novel biobased resins from blends of functionalized soybean oil and unsaturated polyester resin. J Polym Sci Part B Polym Phys 2007;45:698-704.

[100] Dai J, Ma S, Wu Y, Zhu J, Liu X. High bio-based content waterborne UVcurable coatings with excellent adhesion and flexibility. Prog Org Coat 2015;87:197-203.

[101] Kharas GB, Kamenetsky M, Simantirakis J, Beinlich KC, Rizzo AMT, Caywood GA, Watson K. Synthesis and characterization of fumarate-based polyesters for use in bioresorbable bone cement composites. J Appl Polym Sci 1997;66:1123-37.

[102] Guo WX, Huang KX, Tang R, Xu HB. Synthesis, characterization of novel injectable drug carriers and the antitumor efficacy in mice bearing Sarcoma-180 tumor. J Controlled Release 2005;107:513-22.

[103] Guo WX, Shi ZL, Liang K, Liu YL, Chen XH, Li W. New unsaturated polyesters as injectable drug carriers. Polym Degrad Stab 2007;92:407-13.

[104] Wang SF, Lu LC, Gruetzmacher JA, Currier BL, Yaszemski MJ. Synthesis and characterizations of biodegradable and crosslinkable poly(epsilon-caprolactone fumarate), poly(ethylene glycol fumarate), and their amphiphilic copolymer. Biomaterials 2006;27:832-41.

[105] Sharifi S, Mirzadeh H, Imani M, Rong Z, Jamshidi A, Shokrgozar M, Atai M, Roohpour N. Injectable in situ forming drug delivery system based on poly(epsilon-caprolactone fumarate) for tamoxifen citrate delivery: Gelation characteristics, in vitro drug release and anti-cancer evaluation. Acta Biomater 2009;5:1966-78.

[106] Sharifi S, Imani M, Mirzadeh H, Atai M, Ziaee F, Bakhshi R. Synthesis, characterization, and biocompatibility of novel injectable, biodegradable, and in situ crosslinkable polycarbonate-based macromers. J Biomed Mater Res Part A 2009;90:830-43.

[107] Mohtaram NK, Imani M, Sharifi S, Mobedi H, Atai M. Novel, Biocompatible and Photo Crosslinkable Polymeric Networks based on Unsaturated Polyesters: Optimization of the Network Properties. In: Sloten JV, Verdonck P, Nyssen M, Haueisen J, edtiors. IFMBE Proceedings, Vol 22. Belgium: Springer, 2009. p. 2182-5. 
[108] Barrett DG, Merkel TJ, Luft JC, Yousaf MN. One-step syntheses of photocurable polyesters based on a renewable resource. Macromolecules 2010;43:9660-7.

[109] Brown AH, Sheares VV. Amorphous unsaturated aliphatic polyesters derived from dicarboxylic monomers synthesized by Diels-Alder chemistry. Macromolecules 2007;40:4848-53.

[110] Landers R, Pfister A, Hubner U, John H, Schmelzeisen R, Mulhaupt R. Fabrication of soft tissue engineering scaffolds by means of rapid prototyping techniques. J Mater Sci 2002;37:3107-16.

[111] Bártolo PJ, Almeida H, Rezende R, Laoui T, Bidanda B. Advanced processes to fabricate scaffolds for tissue engineering. In: Bidanda B, Bártolo PJ, edtiors. Virtual prototyping \& bio manufacturing in medical applications. New York: Springer, 2008. p. 149-70.

[112] Bártolo PJ, Chua CK, Almeida HA, Chou SM, Lim ASC. Biomanufacturing for tissue engineering: Present and future trends. Virtual Phys Prototyp 2009;4:20316.

[113] Holtorf H, Jansen J, Mikos A. Modulation of cell differentiation in bone tissue engineering constructs cultured in a bioreactor. In: Fisher J, editor. Tissue Engineering. New York: Springer, 2007. p. 225-41.

[114] Hutmacher DW, Schantz JT, Lam CXF, Tan KC, Lim TC. State of the art and future directions of scaffold-based bone engineering from a biomaterials perspective. J Tissue Eng Regener Med 2007;1:245-60.

[115] Anderson JM. Mechanisms of inflammation and infection with implanted devices. Cardiovasc Pathol 1993;2:33-41.

[116] Anderson JM. Inflammatory response to implants. ASAIO Trans 1988;34:101-7.

[117] Anderson JM. Biocompatibility of Tissue Engineered Implants. In: Mikos CWPG, Langer LVMS, edtiors. Frontiers in Tissue Engineering. Oxford: Pergamon, 1998. p. 152-65.

[118] Gilbert TW, Stewart-Akers AM, Badylak SF. A quantitative method for evaluating the degradation of biologic scaffold materials. Biomaterials 2007;28:147-50.

[119] Sung HJ, Meredith C, Johnson C, Galis ZS. The effect of scaffold degradation rate on three-dimensional cell growth and angiogenesis. Biomaterials 2004;25:5735-42. 
[120] Domingos M, Chiellini F, Cometa S, De Giglio E, Grillo-Fernandes E, Bártolo P, Chielline E. Evaluation of in vitro degradation of PCL scaffolds fabricated via BioExtrusion. Part 1: Influence of the degradation environment. Virtual Phys Prototyp 2010;5:65-73.

[121] Kuboki Y, Takita H, Kobayashi D, Tsuruga E, Inoue M, Murata M, Nagai N, Dohi Y, Ohgushi H. BMP-Induced osteogenesis on the surface of hydroxyapatite with geometrically feasible and nonfeasible structures: Topology of osteogenesis. J Biomed Mater Res 1998;39:190-9.

[122] Story BJ, Wagner WR, Gaisser DM, Cook SD, Rust-Dawicki AM. In vivo performance of a modified CSTi dental implant coating. Int J Oral Maxillofac Implants 1998;13:749-57.

[123] Oh SH, Park IK, Kim JM, Lee JH. In vitro and in vivo characteristics of PCL scaffolds with pore size gradient fabricated by a centrifugation method. Biomaterials 2007;28:1664-71.

[124] Yang S, Leong KF, Du Z, Chua CK. The design of scaffolds for use in tissue engineering. Part I. Traditional factors. Tissue Eng 2001;7:679-89.

[125] Wang H, Pieper J, Péters F, van Blitterswijk CA, Lamme EN. Synthetic scaffold morphology controls human dermal connective tissue formation. J Biomed Mater Res Part A 2005;74:523-32.

[126] Price RL, Ellison K, Haberstroh KM, Webster TJ. Nanometer surface roughness increases select osteoblast adhesion on carbon nanofiber compacts. J Biomed Mater Res Part A 2004;70:129-38.

[127] Curtis ASG, Gadegaard N, Dalby MJ, Riehle MO, Wilkinson CDW, Aitchison G. Cells react to nanoscale order and symmetry in their surroundings. IEEE Trans Nanobiosc 2004;3:61-5.

[128] Reignier J, Huneault MA. Preparation of interconnected poly( $\varepsilon$-caprolactone) porous scaffolds by a combination of polymer and salt particulate leaching. Polymer 2006;47:4703-17.

[129] Gomes ME, Reis RL. Biodegradable polymers and composites in biomedical applications: from catgut to tissue engineering. Part 2 Systems for temporary replacement and advanced tissue regeneration. Int Mater Rev 2004;49:274-85.

[130] Ho MH, Kuo PY, Hsieh HJ, Hsien TY, Hou LT, Lai JY, Wang DM. Preparation of porous scaffolds by using freeze-extraction and freeze-gelation methods. Biomaterials 2004;25:129-38. 
[131] Whang K, Thomas CH, Healy KE, Nuber G. A novel method to fabricate bioabsorbable scaffolds. Polymer 1995;36:837-42.

[132] Hoque ME, Hutmacher DW, Feng W, Li S, Huang MH, Vert M, Wong YS. Fabrication using a rapid prototyping system and in vitro characterization of PEG-PCL-PLA scaffolds for tissue engineering. J Biomater Sci Polym Ed 2005; 16:1595-610.

[133] Woodruff MA, Hutmacher DW. The return of a forgotten polymerPolycaprolactone in the 21st century. Prog Polym Sci 2010;35:1217-56.

[134] Peltola SM, Melchels FPW, Grijpma DW, Kellomäki M. A review of rapid prototyping techniques for tissue engineering purposes. Ann Med 2008;40:26880.

[135] Bártolo PJdS. Optical approaches to macroscopic and microscopic engineering. PhD Thesis. University of Reading, 2001. 321 pp.

[136] Bártolo PJ, Mendes A, Jardini A. Bio-prototyping. In: Collins MW, Brebbia CA, edtiors. Design and Nature II Comparing design in nature with science and engineering. Southampton: WIT Press, 2004. p. 535-44.

[137] Ritman EL. Micro-computed tomography-Current status and developments. Annu Rev Biomed Eng 2004;6:185-208.

[138] Potter HG, Nestor BJ, Sofka CM, Ho ST, Peters LE, Salvati EA. Magnetic resonance imaging after total hip arthroplasty: evaluation of periprosthetic soft tissue. J Bone Joint Surg Am 2004;86-A:1947-54.

[139] Fenster A, Downey DB. 3-D ultrasound imaging: a review. IEEE Eng Med Biol Mag 1996;15:41-51.

[140] McElroy DP, MacDonald LR, Beekman FJ, Wang Y, Patt BE, Iwanczyk JS, Tsui BMW, Hoffman EJ. Performance evaluation of A-SPECT: a high resolution desktop pinhole SPECT system for imaging small animals. IEEE Trans Nucl Sci 2002;49:2139-47.

[141] Edinger M, Cao Ya, Hornig YS, Jenkins DE, Verneris MR, Bachmann MH, Negrin RS, Contag CH. Advancing animal models of neoplasia through in vivo bioluminescence imaging. Eur J Cancer 2002;38:2128-36.

[142] Melchels FPW, Domingos MAN, Klein TJ, Malda J, Bartolo PJ, Hutmacher DW. Additive manufacturing of tissues and organs. Prog Polym Sci 2012;37:1079-104. 
[143] Arcaute K, Mann B, Wicker R. Stereolithography of three-dimensional bioactive poly(ethylene glycol) constructs with encapsulated cells. Ann Biomed Eng 2006;34:1429-41.

[144] Elomaa L, Pan CC, Shanjani Y, Malkovskiy A, Seppala JV, Yang Y. Threedimensional fabrication of cell-laden biodegradable poly(ethylene glycol-codepsipeptide) hydrogels by visible light stereolithography. J Mater Chem B 2015;3:8348-58.

[145] He J, Li D, Liu Y, Gong H, Lu B. Indirect fabrication of microstructured chitosan-gelatin scaffolds using rapid prototyping. Virtual Phys Prototyp 2008;3:159-66.

[146] Hull CW. Method for production of three-dimensional objects by stereolithography. US 4929402 A, 1990.

[147] Pomerantz I, Gilad S, Dollberg Y, Ben-Ezra B, Sheinman Y, Barequet G, Katz M. Three dimensional modeling apparatus. US 5386500 A, 1995.

[148] Bártolo PJ. Stereolithographic Processes. In: Bártolo PJ, editor. Stereolithography: Materials, Processes and Applications. Berlin: Springer Science \& Business Media, 2011. p. 1-36.

[149] Pang KP, Gillham JK. Anomalous behavior of cured epoxy resins: Density at room temperature versus time and temperature of cure. J Appl Polym Sci 1989;37:1969-91.

[150] Ferry JD. Viscoelastic Properties of Polymers. New York: John Wiley \& Sons Inc, 1980. 672 pp.

[151] Simon SL, Gillham JK. Conversion-temperature-property diagram for a liquid dicyanate ester/high-Tg polycyanurate thermosetting system. J Appl Polym Sci 1994;51:1741-52.

[152] Fouassier JP. Photoinitiation, photopolymerization, and photocuring: Fundamentals and Applications. Munich: Carl Hanser Verlag GmbH \& Co, 1995. $388 \mathrm{pp}$.

[153] Decker C. New developments in UV-curable acrylic monomers. In: Fouassier J$\mathrm{P}$, editor. Radiation curing in polymer science and technology. London: Kluwer Academic Publishers, 1993. p. 33-63.

[154] Liu V, Bhatia S. Three-Dimensional Photopatterning of Hydrogels Containing Living Cells. Biomed Microdevices 2002;4:257-66. 
[155] Chan V, Collens MB, Jeong JH, Park K, Kong H, Bashir R. Directed cell growth and alignment on protein-patterned 3D hydrogels with stereolithography. Virtual Phys Prototyp 2012;7:219-28.

[156] Andre JC, Mehaute AL, Witte OD. Dispositif pour realiser un modele de piece industrielle. FR 84411241, 1984.

[157] Bertsch A, Renaud P. Microstereolithography. In: Bártolo PJ, editor. Stereolithography: Materials, Processes and Applications. Berlin: Springer Science \& Business Media, 2011. p. 81-112.

[158] Lee JW, Kang KS, Lee SH, Kim JY, Lee BK, Cho DW. Bone regeneration using a microstereolithography-produced customized poly(propylene fumarate)/diethyl fumarate photopolymer 3D scaffold incorporating BMP-2 loaded PLGA microspheres. Biomaterials 2011;32:744-52.

[159] Brandi F, Anjum F, Ceseracciu L, Barone AC, Athanassiou A. Rigid biodegradable photopolymer structures of high resolution using deep-UV laser photocuring. J Micromech Microeng 2011;21:054007/(1-8).

[160] Beke S, Anjum F, Tsushima H, Ceseracciu L, Chieregatti E, Diaspro A, Athanassiou A, Brandi F. Towards excimer-laser-based stereolithography: a rapid process to fabricate rigid biodegradable photopolymer scaffolds. J R Soc Interface 2012;9:3017-26.

[161] Luo Y, Dolder CK, Walker JM, Mishra R, Dean D, Becker ML. Synthesis and biological evaluation of well-defined poly(propylene fumarate) oligomers and their use in 3D Printed Scaffolds. Biomacromolecules 2016;17:690-7.

[162] Bártolo PJ, Mitchell G. Stereo-thermal-lithography: a new principle for rapid prototyping. Rapid Prototyp J 2003;9:150-6.

[163] Stratakis E, Ranella A, Farsari M, Fotakis C. Laser-based micro/nanoengineering for biological applications. Prog Quantum Electron 2009;33:127-63.

[164] Schafer KJ, Hales JM, Balu M, Belfield KD, Van Stryland EW, Hagan DJ. Twophoton absorption cross-sections of common photoinitiators. J Photochem Photobiol A 2004;162:497-502.

[165] Kawata S, Sun HB. Two-photon photopolymerization as a tool for making micro-devices. Appl Surf Sci 2003;208-209:153-8.

[166] Miwa M, Juodkazis S, Kawakami T, Matsuo S, Misawa H. Femtosecond twophoton stereo-lithography. Appl Phys A 2001;73:561-6. 
[167] Lee KS, Yang DY, Park SH, Kim RH. Recent developments in the use of twophoton polymerization in precise $2 \mathrm{D}$ and $3 \mathrm{D}$ microfabrications. Polym Adv Technol 2006;17:72-82.

[168] Lim TW, Park SH, Yang DY. Contour offset algorithm for precise patterning in two-photon polymerization. Microelectron Eng 2005;77:382-8.

[169] Wu S, Serbin J, Gu M. Two-photon polymerisation for three-dimensional microfabrication. J Photochem Photobiol A 2006;181:1-11.

[170] Zhou M, Yang HF, Kong JJ, Yan F, Cai L. Study on the microfabrication technique by femtosecond laser two-photon photopolymerization. J Mater Process Technol 2008;200:158-62.

[171] Tayalia P, Mendonca CR, Baldacchini T, Mooney DJ, Mazur E. 3D CellMigration Studies using Two-Photon Engineered Polymer Scaffolds. Adv Mater 2008;20:4494-8.

[172] Landers R, Hübner U, Schmelzeisen R, Mülhaupt R. Rapid prototyping of scaffolds derived from thermoreversible hydrogels and tailored for applications in tissue engineering. Biomaterials 2002;23:4437-47.

[173] Belfield KD, Schafer KJ, Liu Y, Liu J, Ren X, Stryland EWV. Multiphotonabsorbing organic materials for microfabrication, emerging optical applications and non-destructive three-dimensional imaging. J Phys Org Chem 2000;13:83749.

[174] Schlie S, Ngezahayo A, Ovsianikov A, Fabian T, Kolb HA, Haferkamp H, Chichkov BN. Three-dimensional cell growth on Structures Fabricated from ORMOCER $®$ by Two-Photon Polymerization Technique. J Biomater Appl 2007;22:275-87.

[175] Doraiswamy A, Jin C, Narayan RJ, Mageswaran P, Mente P, Modi R, Auyeung R, Chrisey DB, Ovsianikov A, Chichkov B. Two photon induced polymerization of organic-inorganic hybrid biomaterials for microstructured medical devices. Acta Biomater 2006;2:267-75.

[176] Pereira RF, Bártolo PJ. 3D Photo-Fabrication for Tissue Engineering and Drug Delivery. Engineering 2015;1:090-112.

[177] Lee JH, Prud'homme RK, Aksay IA. Cure depth in photopolymerization: Experiments and theory. J Mater Res 2001;16:3536-44.

[178] Melchels FPW, Feijen J, Grijpma DW. A review on stereolithography and its applications in biomedical engineering. Biomaterials 2010;31:6121-30. 
(A)<smiles>[CH2+]OCC(C)O</smiles>

Propylene glycol

Isophthalic acid

Maleic anhydride<smiles>CCC(C)OCC(C)OC(=O)/C=C\C(=O)OCC(C)OC(=O)c1cccc(C(=O)O[Na])c1</smiles>

(B)<smiles>CCC(=O)c1cccc(C(=O)OC(C)COC(=O)/C=C\C(=O)OCC(C)OC(C)C)c1</smiles><smiles>C=Cc1ccccc1</smiles>

Styrene

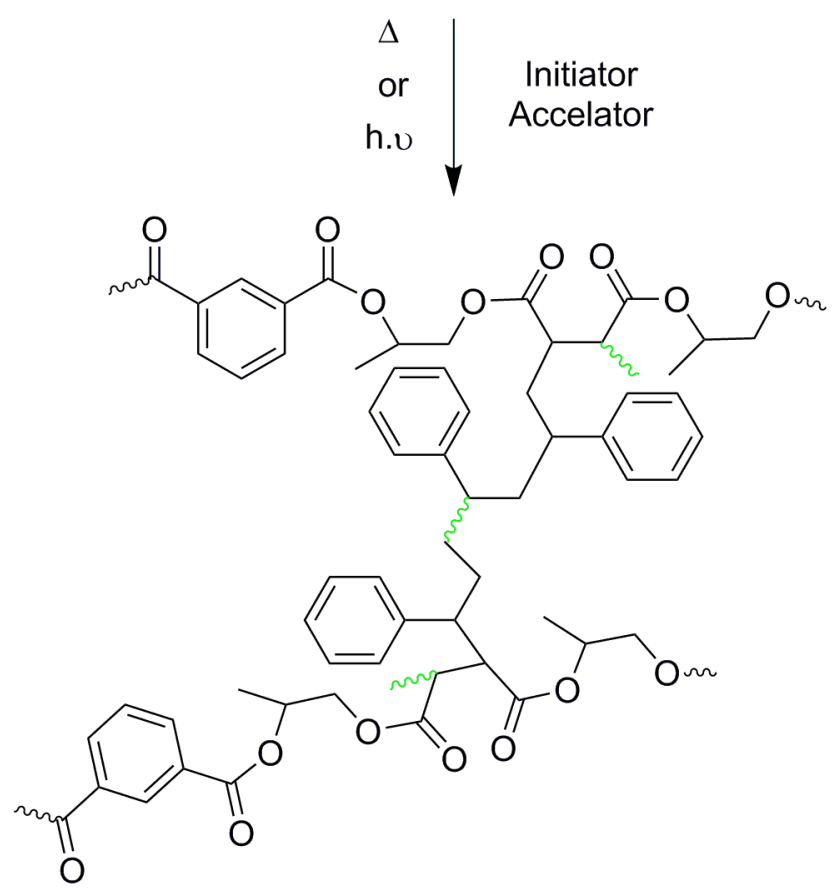

Fig. 1. Path for the development of UPRs: (A) Polycondensation reaction, and (B) cure reaction. 

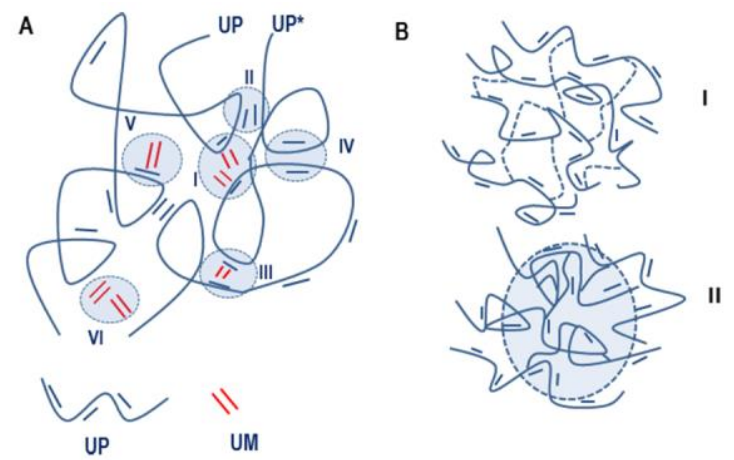

Fig. 2. A) Schematic representation of the possible reactions in the UM-UP cure reaction: (I) intermolecular crosslinking UP-UM-UP*; (II) intermolecular crosslinking UP-UP*; (III) intramolecular crosslinking UP-UM-UP (or UP*UM-UP*); (IV) intramolecular crosslinking UP-UP (or UP*-UP*); (V) branching growth UP-UM (or UP*-UM); (VI) UM homopolymerization. B) Formation of microgel particles through the growth of free radicals: (I) growth of free radicals; (II) formation of microgel particles. [25], Copyright 1988. Adapted with permission from Elsevier Ltd. 
<smiles>O=C1C=CC(=O)N1c1ccc(Cc2ccc(N3C(=O)C=CC3=O)cc2)cc1</smiles>

(A)

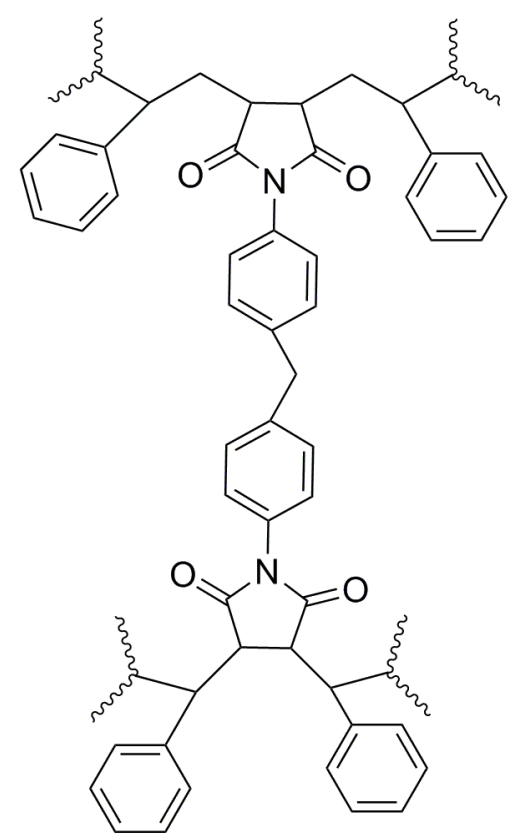

(B)

Fig. 3. Structures of : (A) BM, and (B) BM-styrene bridges [42]. 
(A)<smiles>COCc1c(C)c(C)c(COC)c(C)c1C</smiles>

3,6-bis(methoxymethyl)durene<smiles>Cc1c(C)c(COCc2ccccc2)c(C)c(C)c1COCc1ccccc1</smiles>

3,6-bis(benzyloxymethyl)durene

(B)<smiles>COC(C)c1c(C)c(C)c(COC(=O)c2ccccc2C(=O)OCC(C)OC(=O)/C=C/C(=O)OC(C)C)c(C)c1C</smiles><smiles>COC(C)c1c(C)c(C)c(COC(=O)CCC(=O)OCC(C)OC(=O)/C=C/C(=O)OC(C)C)c(C)c1C</smiles>

II<smiles>COC(=O)/C=C/C(=O)OCCOC(=O)c1ccccc1C(=O)OCc1c(C)c(C)c(C(C)OC)c(C)c1C</smiles>

III<smiles>COC(C)c1c(C)c(C)c(COC(=O)CCC(=O)OC(C)(C)CCOC(=O)/C=C/C(=O)OC(C)C)c(C)c1C</smiles><smiles>COC(C)c1c(C)c(C)c(COC(=O)c2ccccc2C(=O)OCc2c(C)c(C)c(COC(=O)/C=C/C(=O)OC(C)C)c(C)c2C)c(C)c1C</smiles>

$\mathrm{v}$

Fig. 4. Monomers used for the preparation of durene based polyesters (A), and structure of the UPs (B) [47]. 
<smiles>[R]c1cc(/C=C2\CCC3C2=NNC3c2ccc(O)c([R])c2)ccc1O</smiles><smiles>[R]C(=O)Oc1ccc([C@@H]2NN=C3/C(=C/c4ccc(OC)c([R])c4)CC[C@@H]32)cc1[R]</smiles>

$\mathrm{R}: \mathrm{H} ; \mathrm{OCH}_{3}$<smiles>[R]Cc1ccc(I)cc1</smiles>

Fig. 5. UPs synthesis through interfacial polycondensation technique. [49], Copyright 2010. Reproduced with permission from John Wiley \& Sons Inc. 


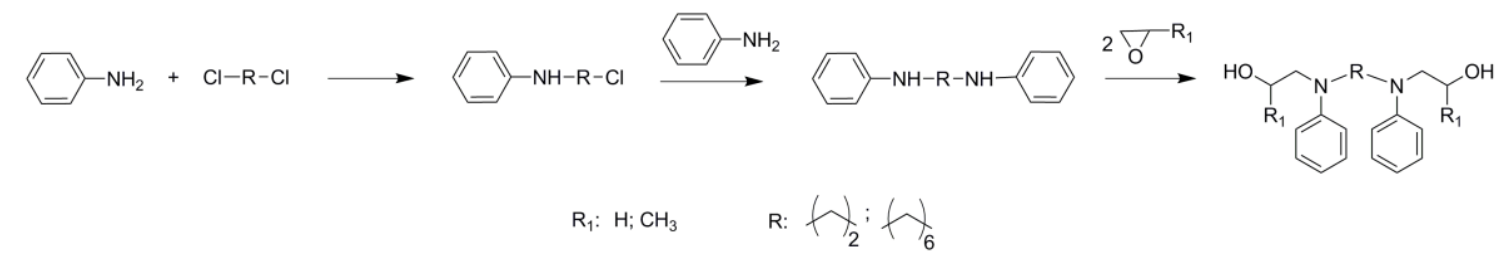

Fig. 6. Scheme of preparation in two steps of amine glycol modifiers for UP resin, i.e., 3,6-diaza-3,6-diphenyloctane-1,8-diol $\left(\mathrm{R}=-\left(\mathrm{CH}_{2}\right)_{2}-; \mathrm{R}_{1}=-\mathrm{H}\right), 4$, 7-diaza4,7-diphenyldecane-2,9-diol $\left(\mathrm{R}=-\left(\mathrm{CH}_{2}\right)_{2}-; \mathrm{R}_{1}=-\mathrm{CH}_{3}\right)$ and 3,10-diaza-3,10diphenyldodecane-1,12-diol ( $\left.\mathrm{R}=-\left(\mathrm{CH}_{2}\right)_{6-} ; \mathrm{R} 1=-\mathrm{H}\right)$. [56], Copyright 2001. Reproduced with permission from John Wiley \& Sons Inc. 
<smiles>COc1nc(OC)nc(N(CCO)CCO)n1</smiles>

(A)<smiles>COc1nc(N(CCO)CCO)nc(N(CCO)CCO)n1</smiles>

(B)<smiles>OCCN(CCO)c1nc(N(CCO)CCO)nc(N(CCO)CCO)n1</smiles>

(C)<smiles>COc1nc(OC)nc(N(CCO)c2ccccc2)n1</smiles>

(D)<smiles>COc1nc(N(CCO)c2ccccc2)nc(N(CCO)c2ccccc2)n1</smiles>

(E)<smiles>OCCN(c1ccccc1)c1nc(N(CCO)c2ccccc2)nc(N(CCO)c2ccccc2)n1</smiles>

$(\mathrm{F})$

Fig. 7. Structures of the amine diols and polyols bearing $s$-triazine rings: (A) 2-[N,Nbis(2-hydroxyethyl)amine]-4,6-dimethoxy-1,3,5-triazine; (B) 2,4-[N,N-bis(2hydroxyethyl)amine]-6-methoxy-1,3,5-triazine; (C) 2,4,6-tris[N,N-bis(2hydroxyethyl)amine]-1,3,5-triazine; (D) 2-[N-phenyl-(2-hydroxyethyl)amine4,6-dimethoxy-1,3,5-triazine; (E) 2,4-bis[N-phenyl-(2-hydroxyethyl)amine]6-methoxy-1,3,5-triazine; and (F) 2,4,6-tris[N-phenyl-(2hydroxyethyl)amine]-1,3,5-triazine $[57,58]$. 


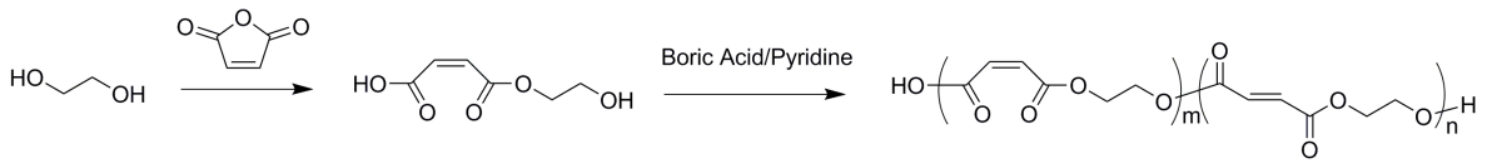

Fig. 8. Polyesterification of the monohydroxyethyl esters of maleic acids with boric acid-pyridine mixture as mild catalyst. [60], Copyright 2010. Adapted with permission from Elsevier Ltd. 


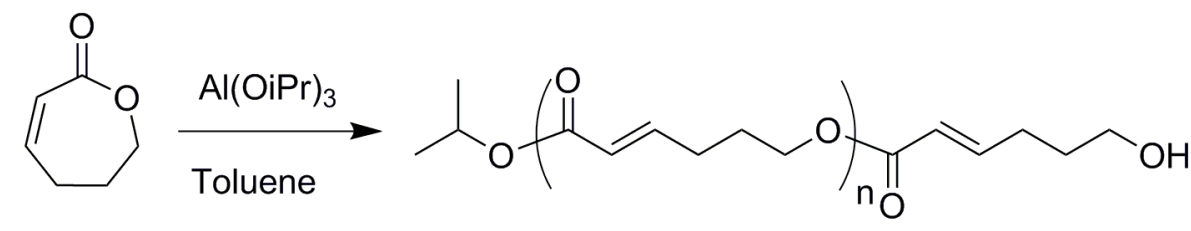

$\mathrm{DHO}$

Poly(DHO)

Fig. 9. ROP of DHO to give the poly(DHO) [61]. 


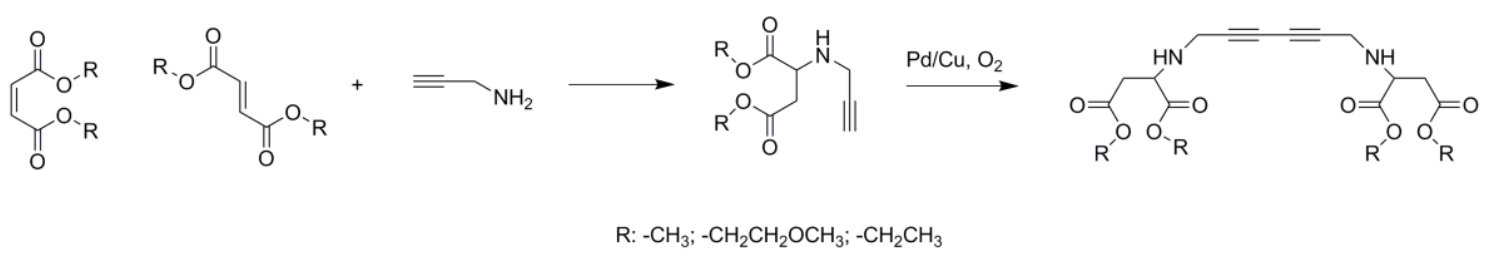

Fig. 10. Metal-mediated reaction of UP via functionalization of maleic or fumaric diesters, followed by oxidative homo-coupling of the introduced alkyne moieties [64]. 


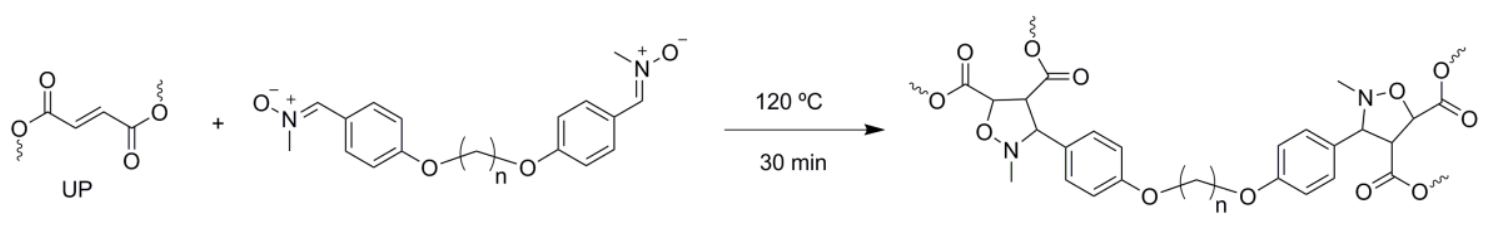

Fig. 11. Crosslinking reaction between the UP and a polynitrone, leading to a 3D network [65]. 
<smiles>O=C(/C=C/C(=O)OCCOC(=O)C1CC=CCC1C(=O)OCCO)OCCOC(=O)C1CC=CCC1C(=O)OCCO</smiles>

(A)<smiles>O=C(/C=C/C(=O)OCCOC(=O)C1CC2OC2CC1C(=O)OCCO)OCCOC(=O)C1CC2OC2CC1C(=O)OCCO</smiles>

(B)

Fig. 12. Structures of: (A) unsaturated oligoester; and (B) unsaturated epoxyoligoester, using EG as the diol. 

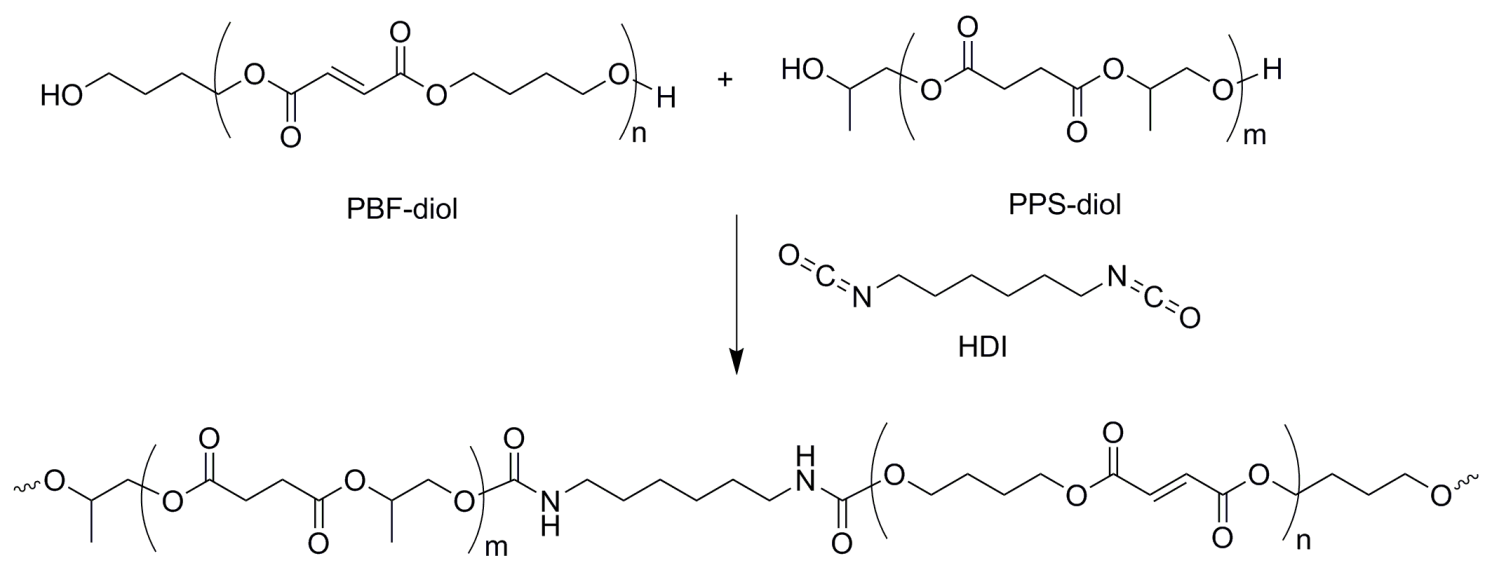

Fig. 13. Chain extension reaction of PPS-diol and PBF-diol mediated by HDI. 


$$
\text { (II) }
$$

Fig. 14. Synthesis of HMA homopolymers, HMA-adipic acid copolymers and of HMA and diethylene glycol poly(ester ether)s [12]. 
<smiles>CCOC(=O)CCCCC(=O)OCC</smiles>

Diethyl adipate<smiles>CCOC(=O)/C=C/C(=O)OCC</smiles>

Diethyl fumarate<smiles>C=C(CC(=O)OCC)C(=O)OCC</smiles>

Diethyl itaconate<smiles>CCOC(=O)/C=C/CC(=O)OCC</smiles>

Diethyl trans-glutaconate<smiles>CCOC(=O)C/C=C/CC(=O)OCC</smiles>

Diethyl trans- $\beta$-hydromuconate

Fig. 15. Structures of the synthesized diesters, diethyl adipate, diethyl fumarate, diethyl itaconate, diethyl trans-glutaconate and diethyl trans- $\beta$ hydromuconate used for further transesterification reaction with isosorbide or isomannide. 


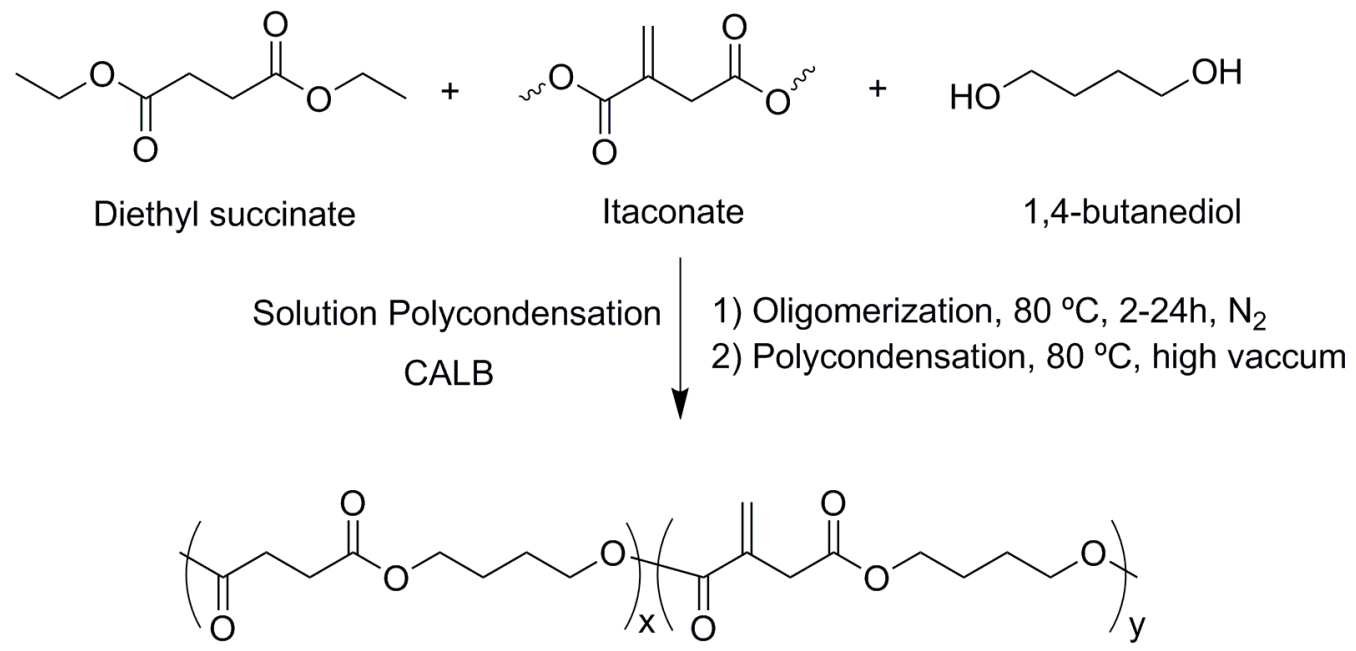

Fig. 16. Preparation of the UPs by the two-step solution polycondensation [70]. 


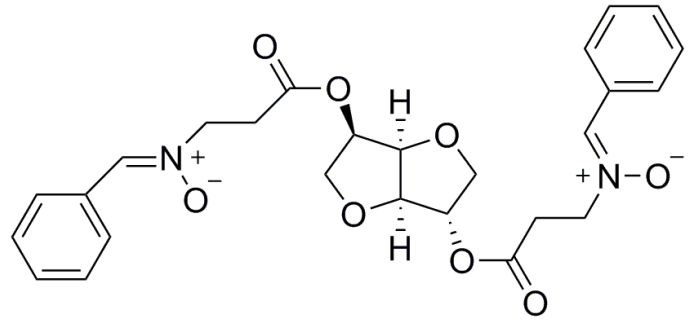

(A)

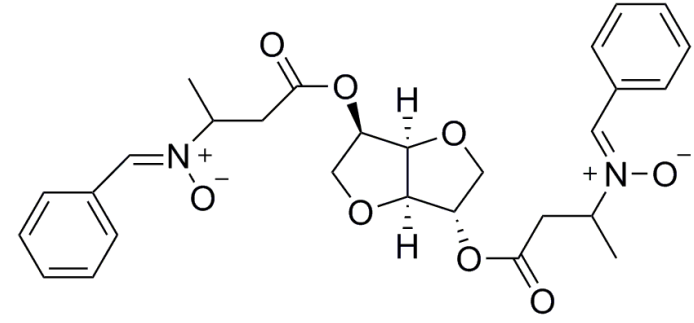

(B)

Fig. 17. Structures of the $N$-alkylated dinitrones based on IS [76]. 


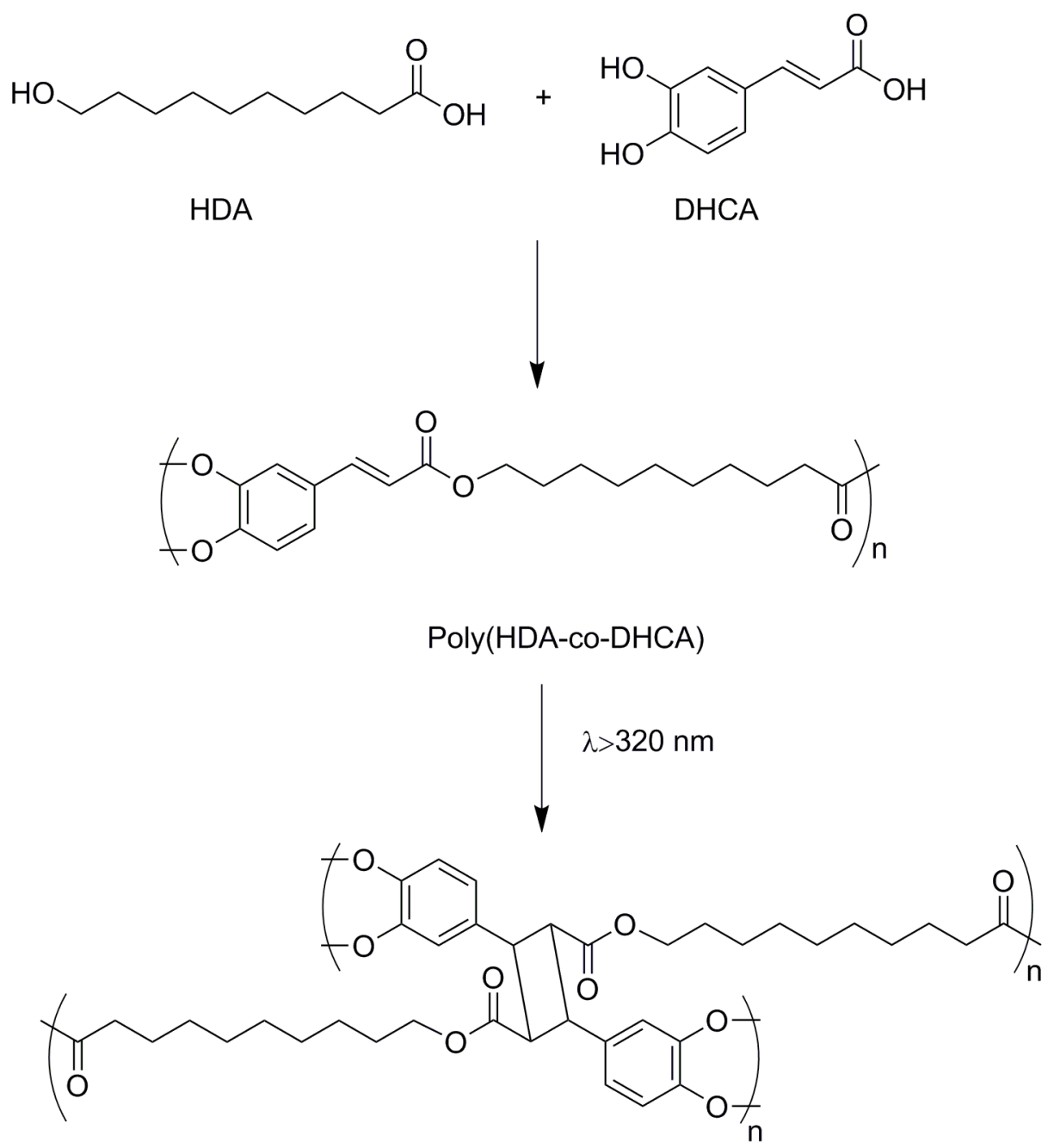

Fig. 18. Scheme of the synthesis of poly (DHCA-HDA) and photoreaction of the DHCA moiety promoted by UV irradiation [86]. 

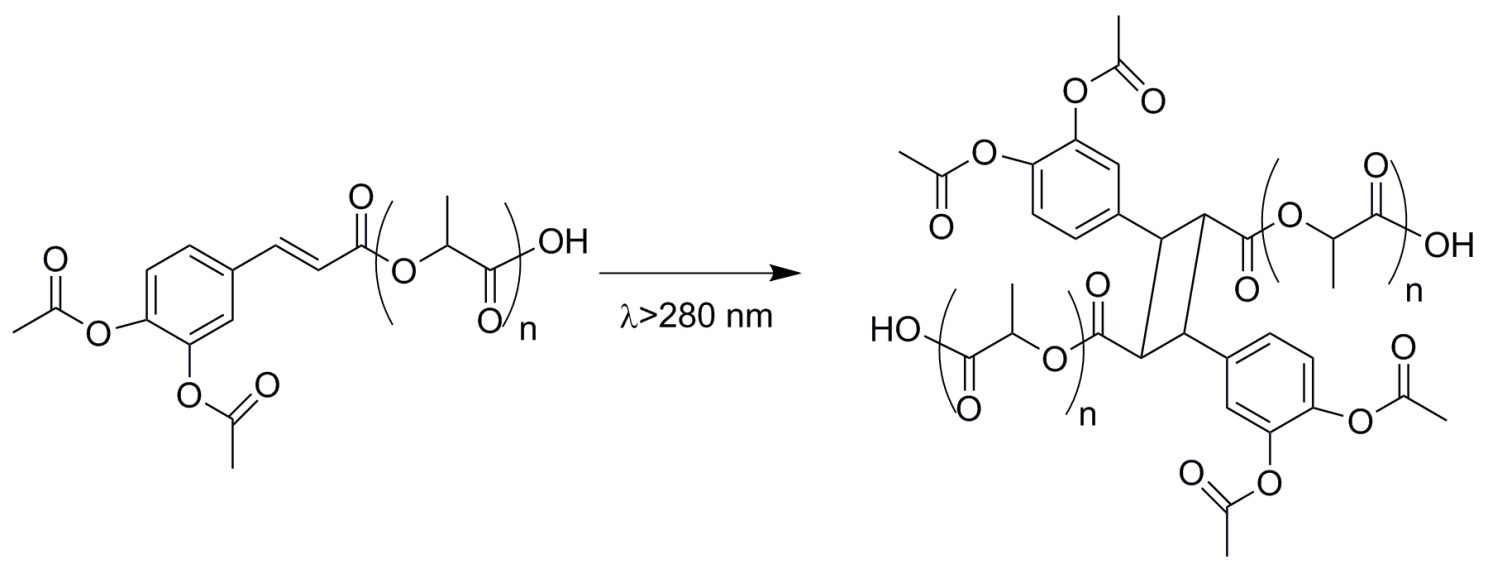

Fig. 19. Photoreaction scheme of DACA-PLLA by UV irradiation at $\lambda>280 \mathrm{~nm}$. [88], Copyright 2008. Reproduced with permission from the Royal Chemistry Society. 


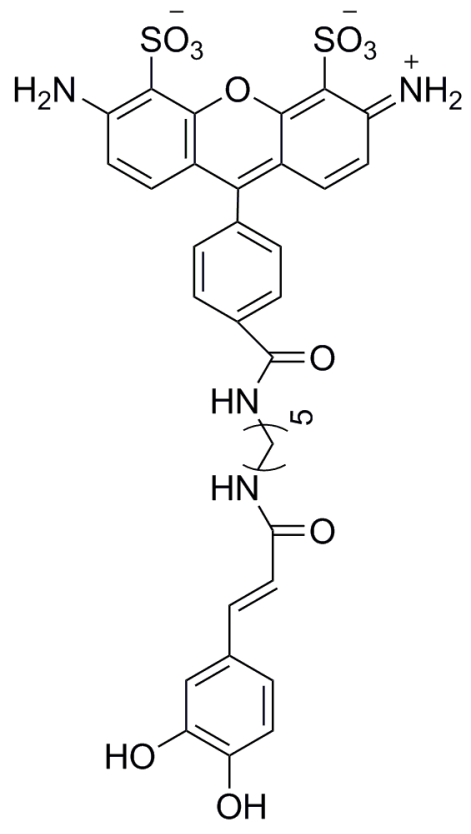

Fig. 20. Structure of the fluorescent dye. 
<smiles>O=C1CCCCCCCCC/C=C/CCCO1</smiles>

$\mathrm{GI}$<smiles>COC(C)(O)CCCCCCCCCCC=CCCCOC(C)C</smiles>

$P G I$

AIBN

$\mathrm{R}-\mathrm{SH}$

$\mathrm{R}:$

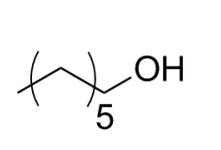

$\mathrm{MH}$

Fig. 21. ROP of globalide and thiol-ene reaction of PGl with MH, BMP and nACA.

[21], Copyright 2011. Reproduced with permission from the Royal Chemistry Society. 

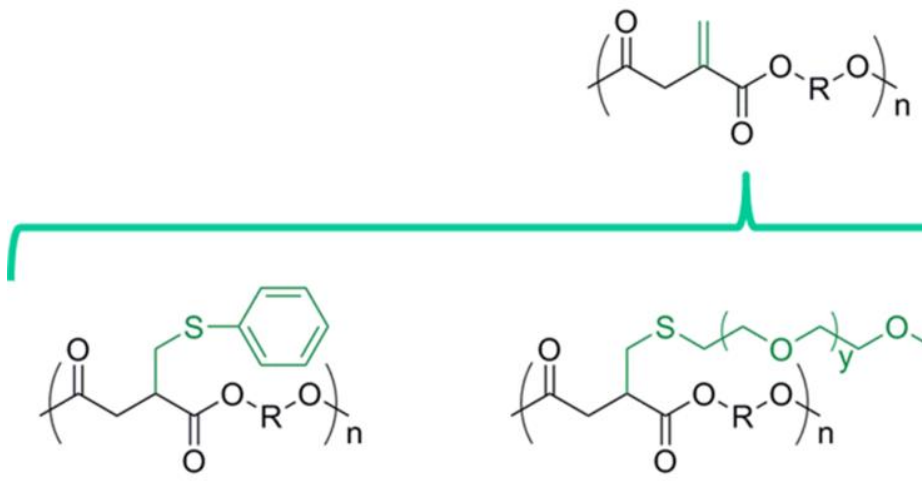<smiles>[R]OC(=O)C(CSCCOCC(C)(C)C)CC(C)=O</smiles><smiles>[R]OC(=O)C(CN(C)Cc1ccccc1)CC(C)(C)OC(C)(C)C</smiles><smiles>[R]OC(=O)C(CSCC(O)CO)CSCC(C)C(C)=O</smiles><smiles>[R]OC(=O)C(CSCCO)CC(C)(C)C(C)=O</smiles><smiles>[R]OC(=O)C(CC(=O)COCC)CN1CCCC1C(=O)OCC</smiles><smiles>[R]OC(=O)C(CSCC(CC(=O)CC)NC(=O)OC(C)(C)C)C(=O)OC(C)(C)C</smiles><smiles>[R]OC(=O)C(CC(C)=O)CN(CC=C)C/C=C\C(C)(C)C</smiles>

Fig. 22. Structures of the derivatives prepared using Michael addition reactions. [20], Copyright 2015. Reproduced with permission from the Royal Chemistry Society. 


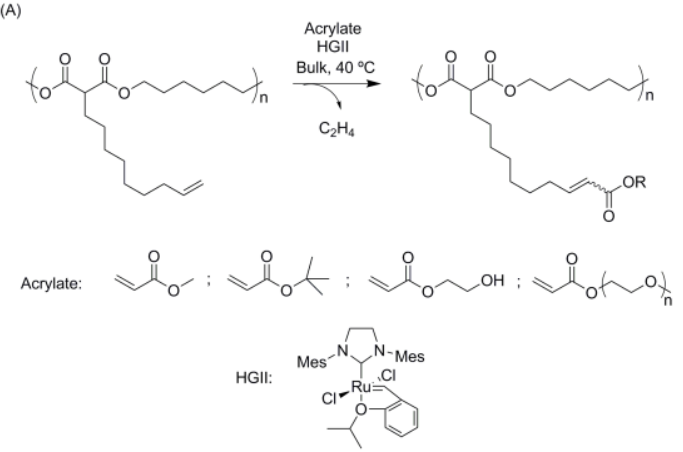

(B)

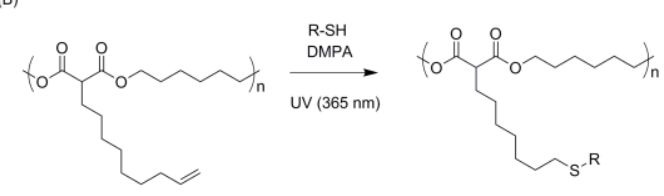

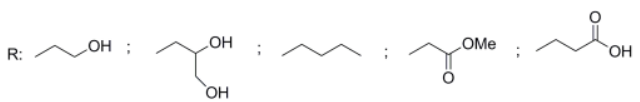

Fig. 23. Polymer-functionalization via ruthenium-catalyzed olefin-metathesis (A), and via thiol-ene addition reaction (B) [93]. 


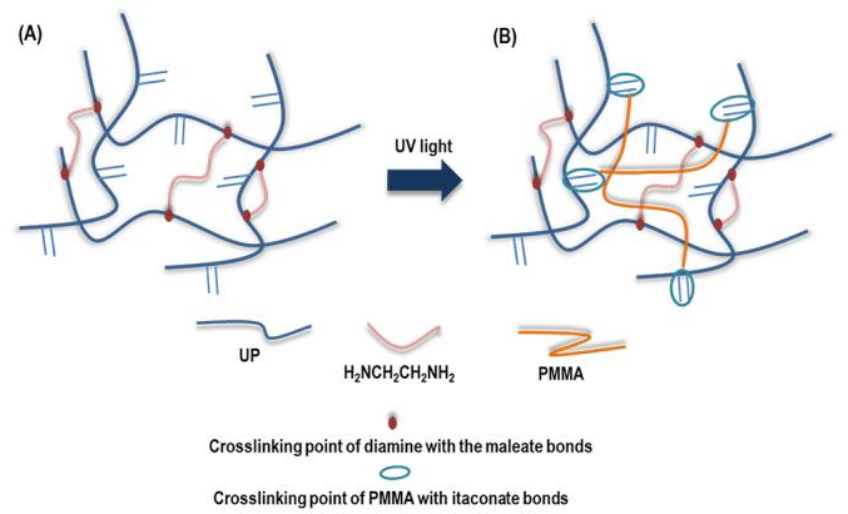

Fig. 24. Representation of the SN (A), and of the DN (B). [95], Copyright 2015. Reproduced with permission from the Royal Chemistry Society. 


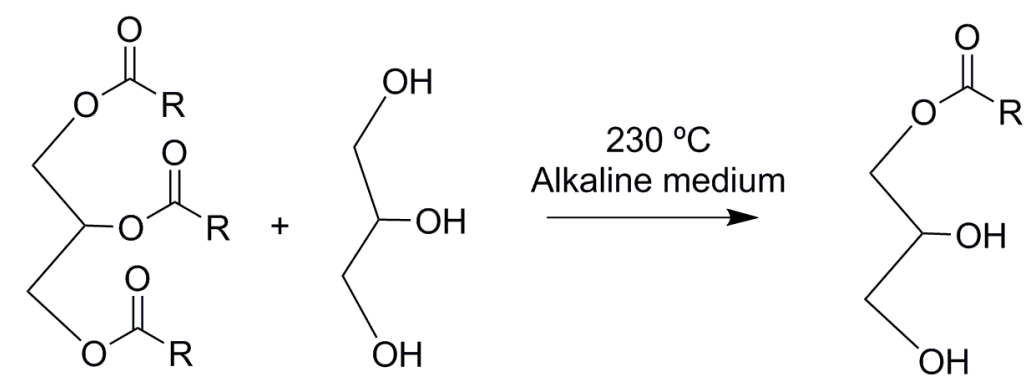

Fig. 25. Alcoholysis reaction to yield a polyol based on vegetable oils. 


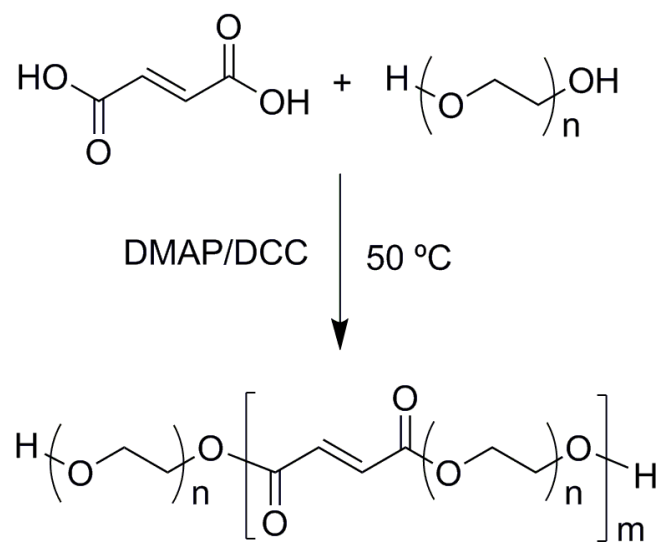

Fig. 26. Reaction of PEG with fumaric acid in the presence of DMAP/DCC [8]. 


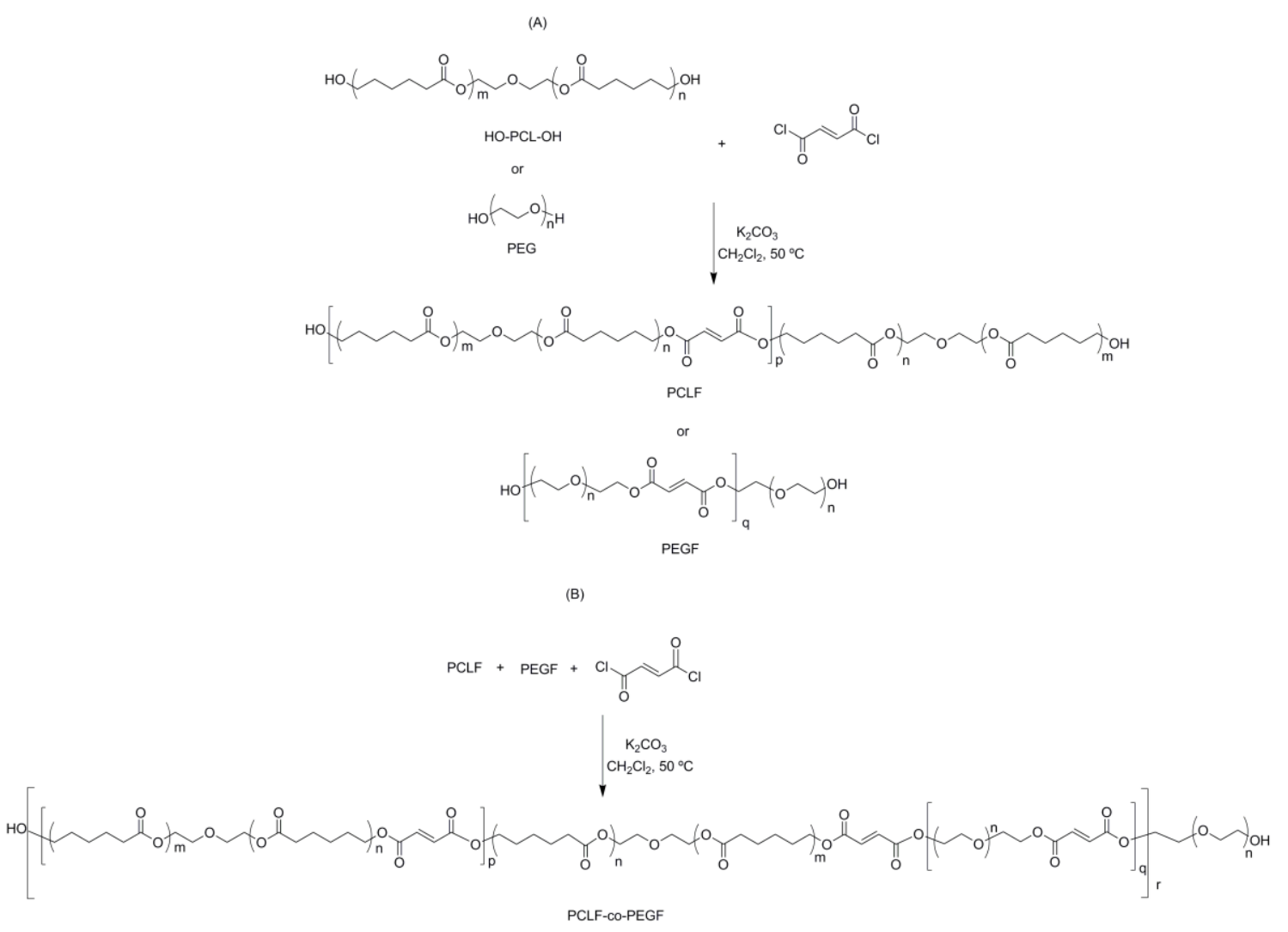

Fig. 27. Synthesis of: (A) PCLF, PEGF, and (B) PEGF-co-PCLF [104]. 


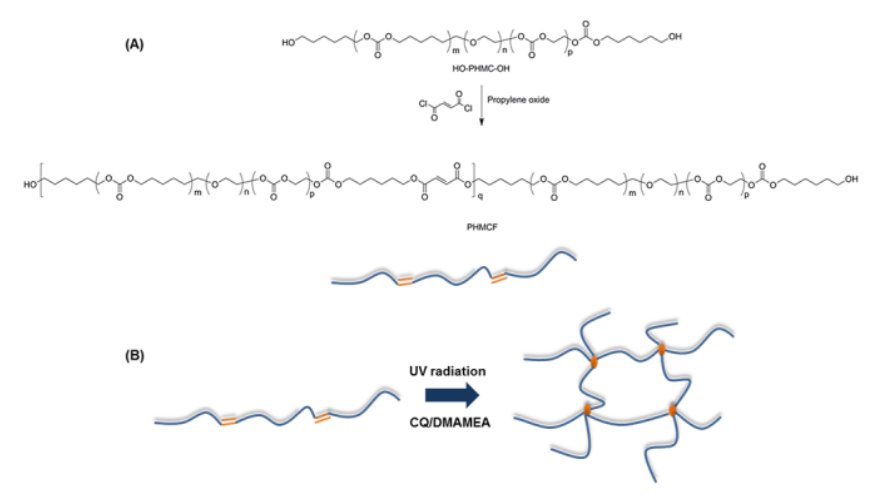

Fig. 28. Synthesis of: (A) PHMCF macromers, and (B) respective networks [107]. 
(A)

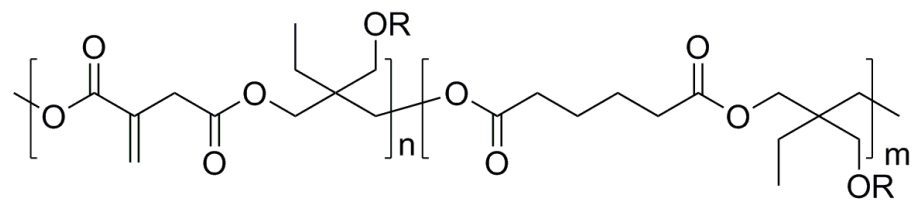

Poly(trimethylolpropane itaconate-co-trimethylolpropane adipate)

R: H, polymer

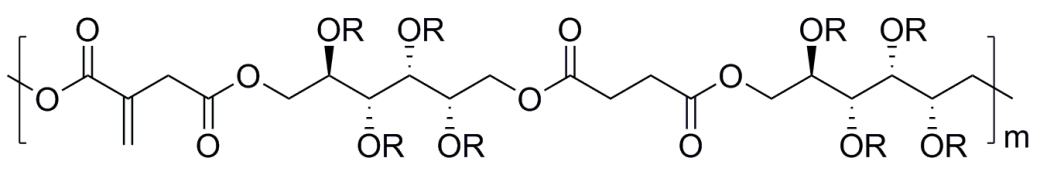

Poly(sorbitol itaconate-co-sorbitol succinate)

(B)<smiles>[R]C(C)(OC(=O)CCCCC(=O)OC(C)(C)[R]([H])([H])C)OC(=O)CC(=C)C(=O)OC</smiles>

Poly(diol itaconate-co-diol succinate)

Fig. 29. Branched polyesters obtained by thermal polyesterification (A) and the photocurable polymer achieved by enzymatic polymerization (B) using CALB as catalyst. 
(A)<smiles>O=C(O)C1C2C=CC(C2)C1C(=O)O</smiles>

Diacid I<smiles>O=C1OC(=O)C2C3C=CC(C3)C12</smiles>

Anhydride I<smiles>CC1=CCC(C(=O)O)C(C(=O)O)C1</smiles>

Diacid II

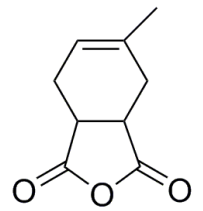

Anhydride II<smiles>CC1=C(C)CC(C(=O)O)C(C(=O)O)C1</smiles>

Diacid III<smiles>CC1=C(C)CC2C(=O)OC(=O)C2C1</smiles>

Anhydride III<smiles>CCN(CC)CC1=CCC(C(=O)O)C(C(=O)O)C1</smiles>

Diacid IV<smiles>CCN(CC)CC1=CCC2C(=O)OC(=O)C2C1</smiles>

Anhydride IV

(B)

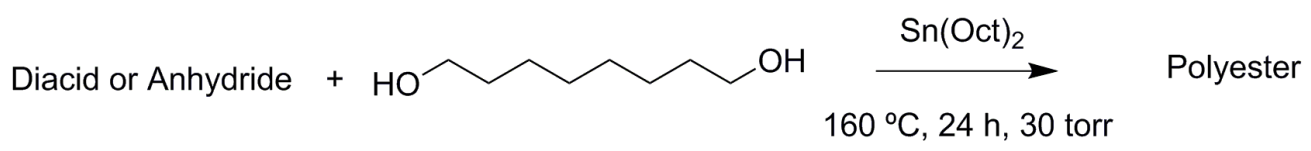

(C)

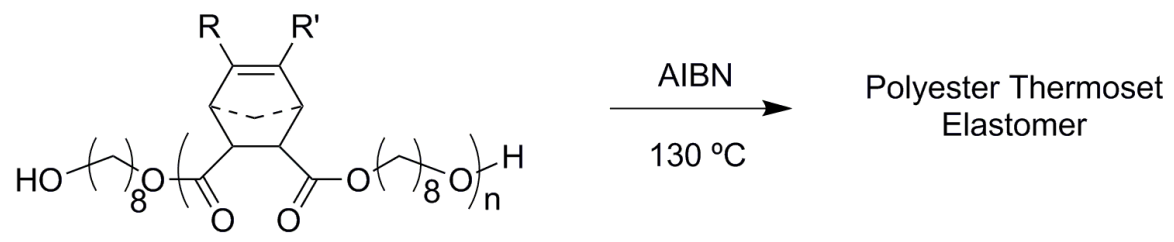

R, R': H; Me

Fig. 30. (A) Unsaturated dicarboxylic monomers synthesized for the preparation of new unsaturated aliphatic polyesters, (B) overall strategy for the synthesis of polyesters, and (C) synthesis strategy for polyester thermoset elastomer [109]. 


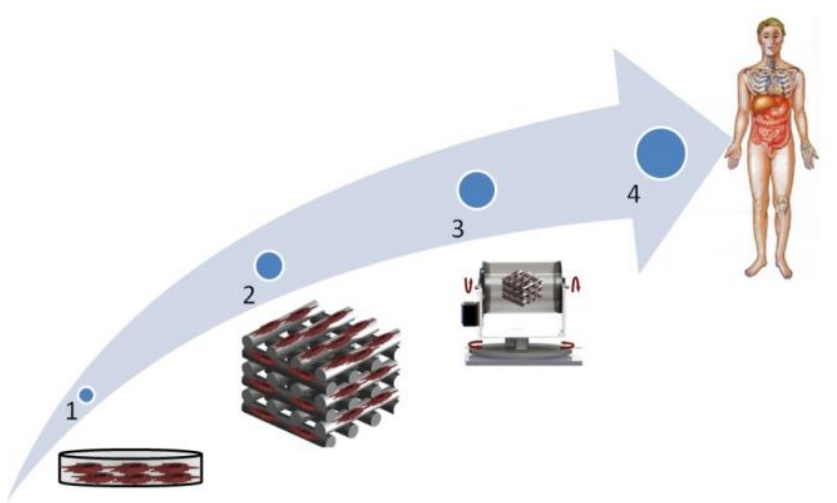

Fig. 31. Illustration of the four main steps in scaffold-based TE strategy. 1) Cell harvesting and in vitro expansion; 2) cell seeding in porous scaffolds; 3 ) in vitro dynamic cell culture using bioreactors; 4) scaffold+cell construct implantation. 


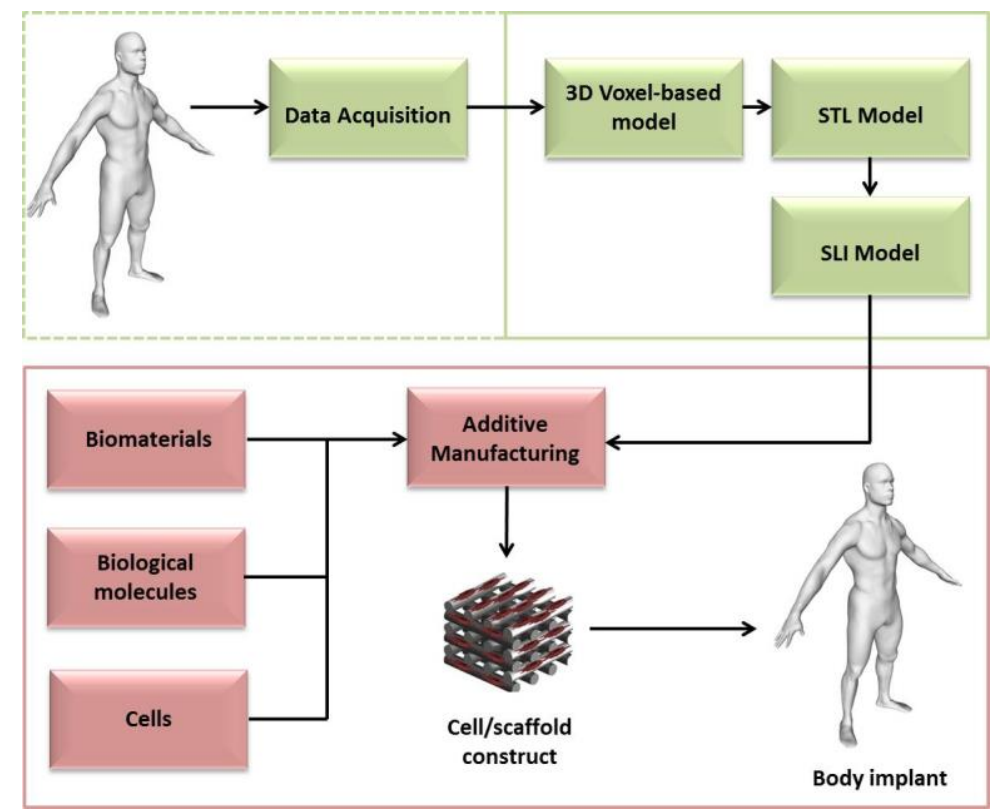

Fig. 32. Schematic representation of the main steps required to produce TE scaffolds using AM techniques. [136], Copyright 2004. Adapted with permission from WIT Press; and [141]. 
(A)
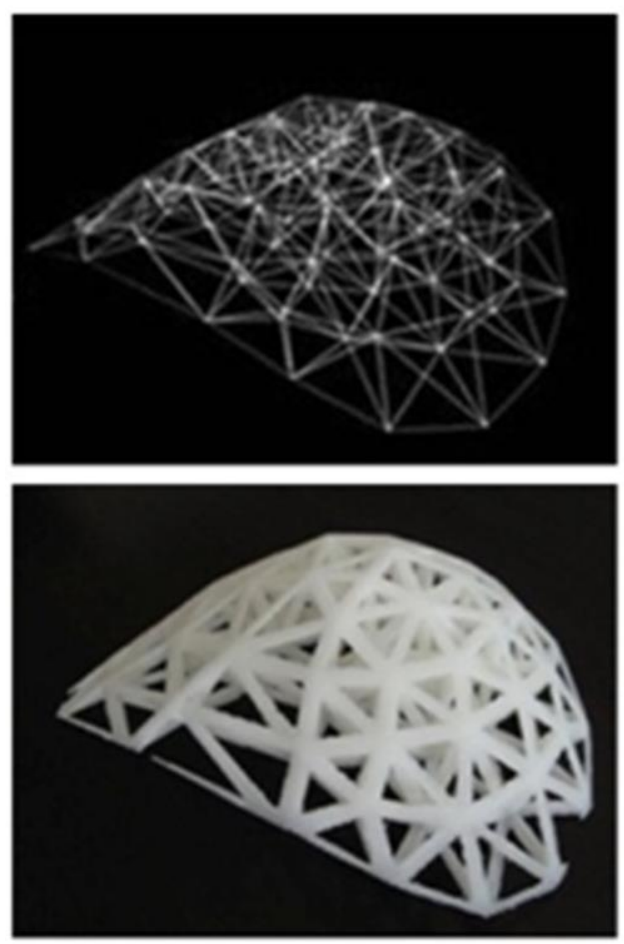

(D)
(B)
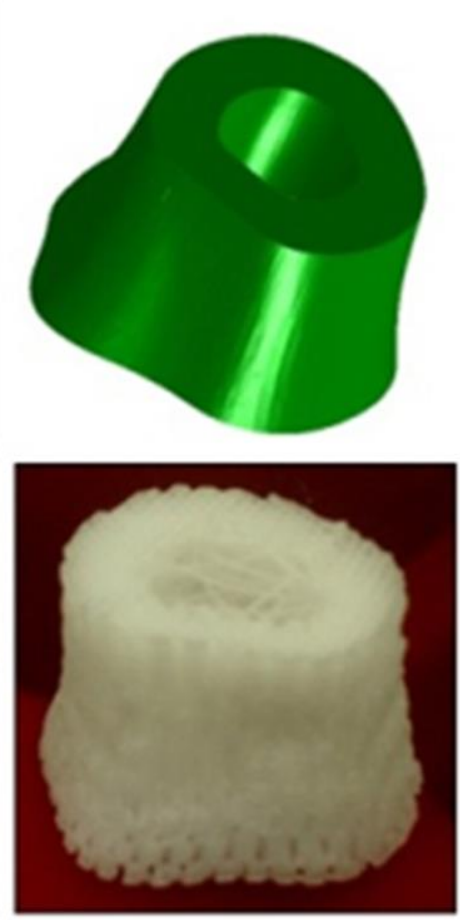

(E)
(C)
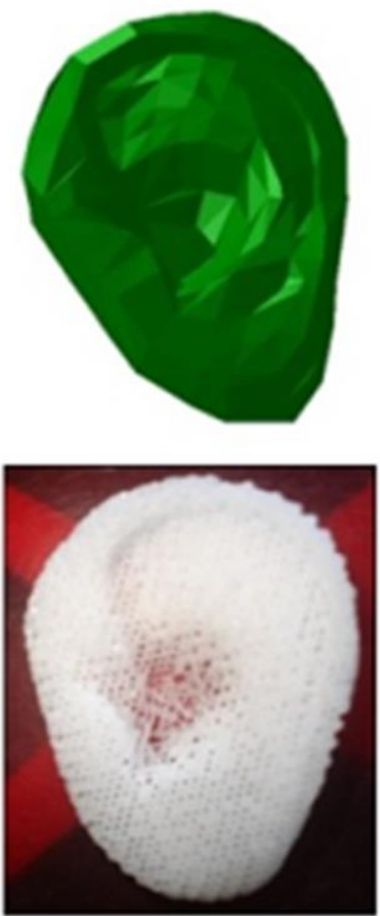

(F)

Fig. 33. 3D CAD and physical models produced via melt extrusion. (A) 3D CAD model of breast implant; (B) 3D CAD model of humerus bone; (C) 3D CAD model of human ear; (D) 3D physical model of breast implant; (E) 3D physical model of humerus bone; (F) 3D physical model of human ear. Part (d), [142]. Copyright 2012. Reproduced with permission from Elsevier Ltd. 
(A)

(B)
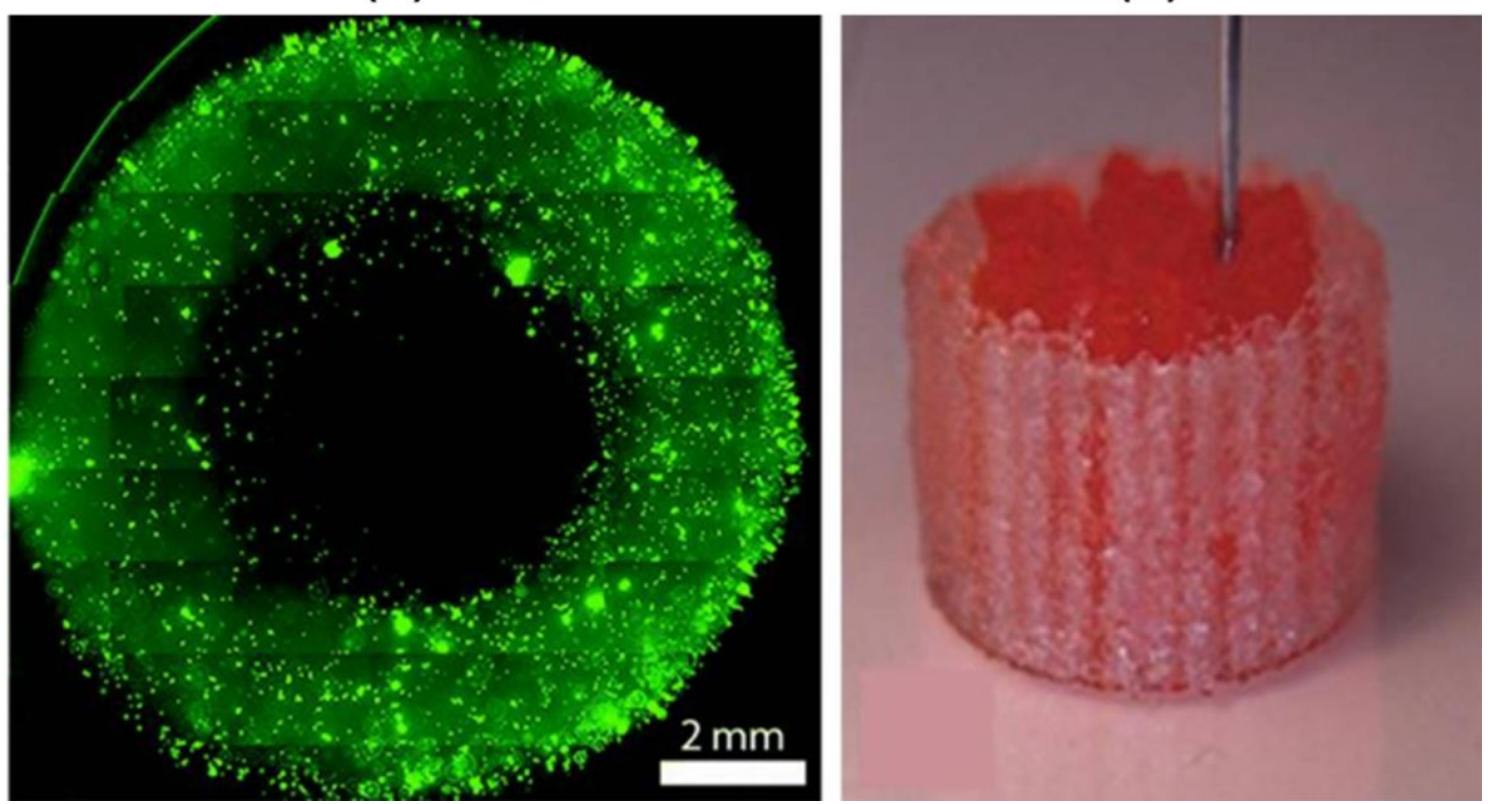

Fig. 34. Constructs with embedded cells. (A) PEG-co-PDP copolymer hydrogels with HUVECs encapsulated cells prepared via stereolithography (SLA). (B) gelatin/alginate/fibrinogen containing adipose-derived stem cells (in pink) and hepatocytes in gelatin/alginate/chitosan (white). [143] ; and Part (A), [144], Copyright 2015. Reproduced with permission from the Royal Chemistry Society. 


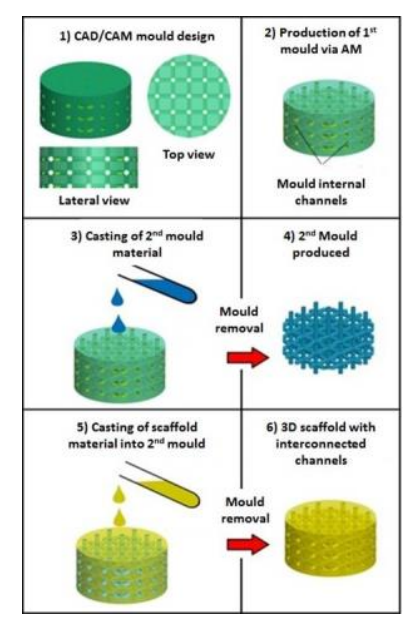

Fig. 35. Methodology for indirect fabrication of TE scaffolds. [145], Copyright 2008. Adapted with permission from Taylor \& Francis. 

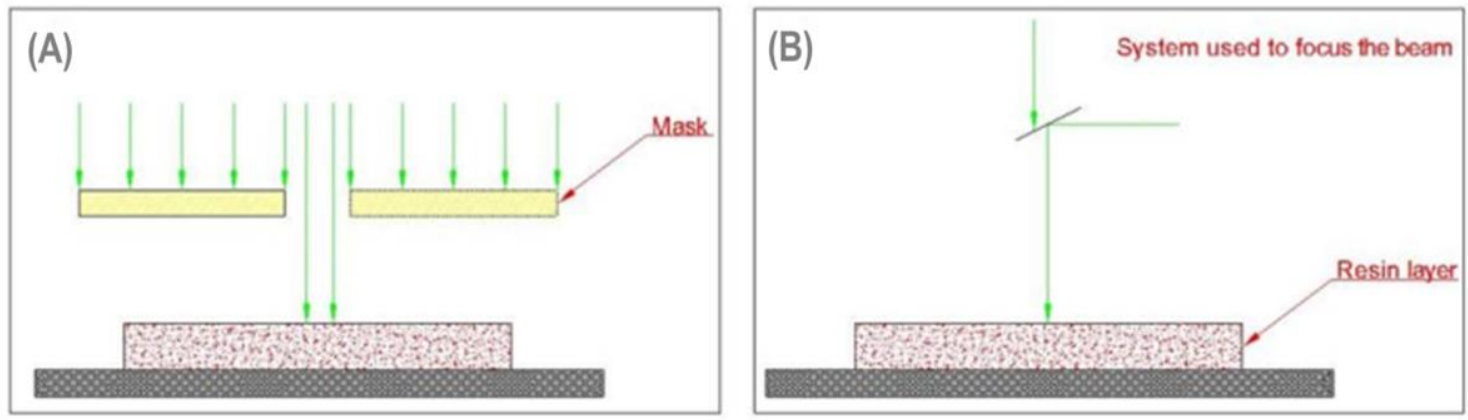

Fig. 36. Conventional stereolithography: Mask-based method (A); Direct or laser writing method (B). [148], Copyright 2011. Adapted with permission from Springer 


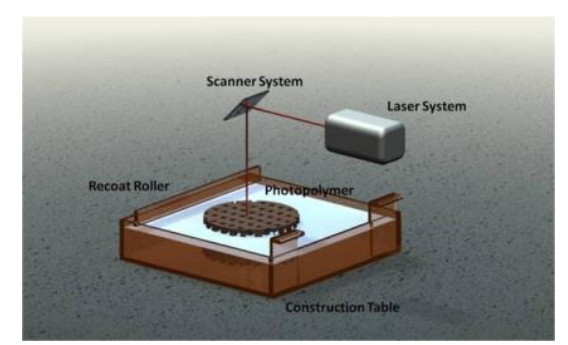

Fig. 37. Schematic representation of SLA system. [142], Copyright 2012. Reproduced with permission from Elsevier Ltd. 


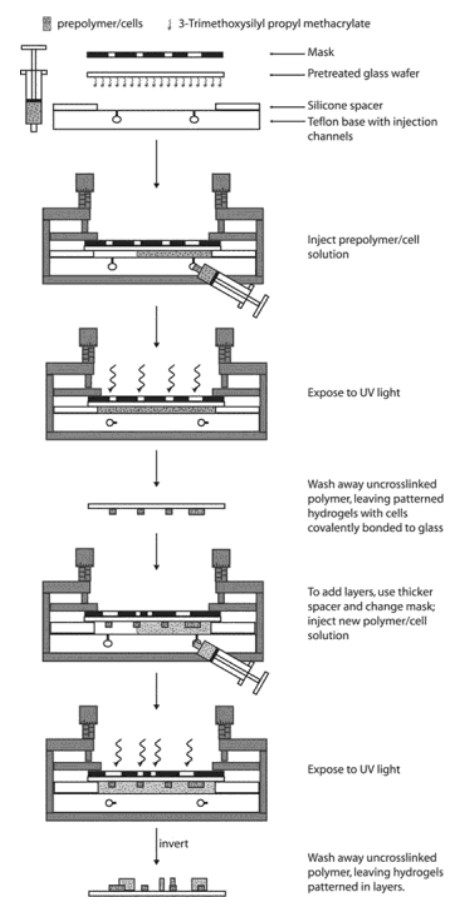

Fig. 38. Schematic illustration of the SLA process to produce micrometric resolution constructs containing cells. [154], Copyright 2002. Reproduced with permission from Springer 


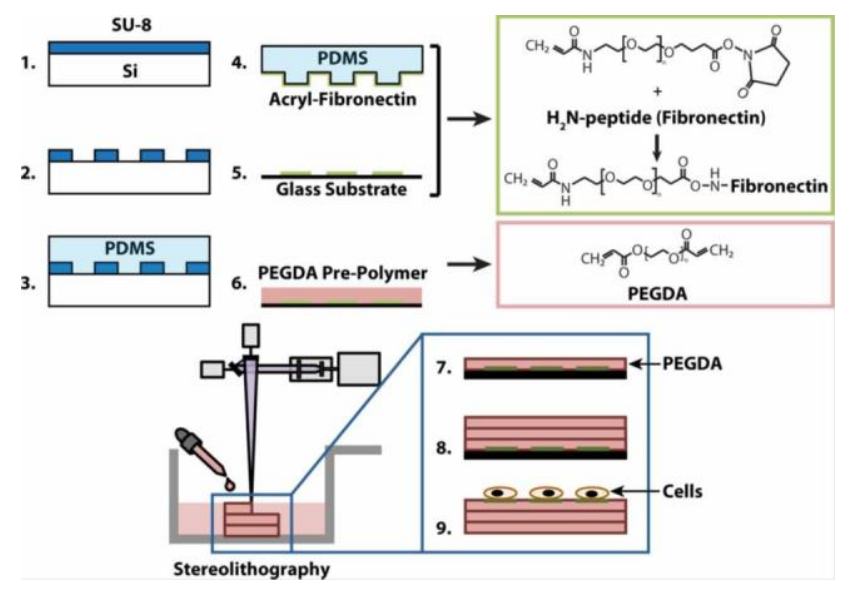

Fig. 39. Schematic illustration of the fabrication method used to create patterns of acryl-fibronectin on PEGDA hydrogels produced by SLA [. [155], Copyright 2012. Reproduced with permission from Taylor \& Francis. 


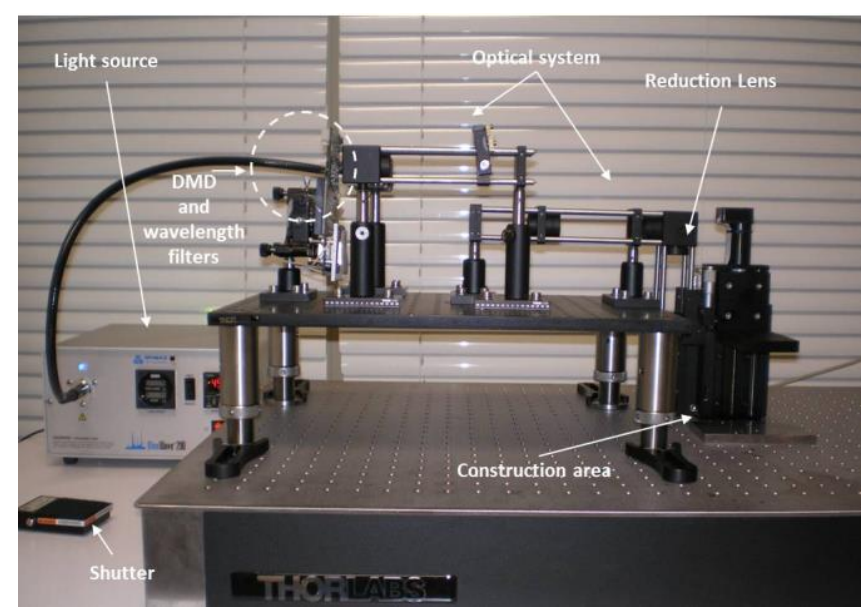

Fig. 40. Integral micro-SLA system developed by CDRSP researchers. 


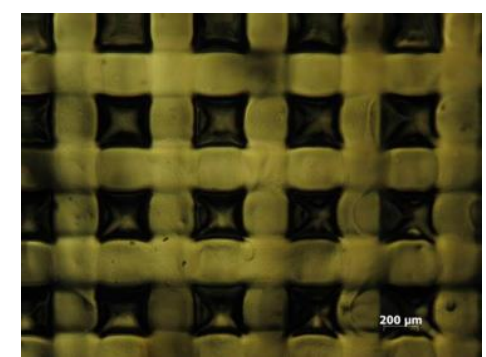

Fig. 41. PHEMA 3D scaffold produced via SLA. 


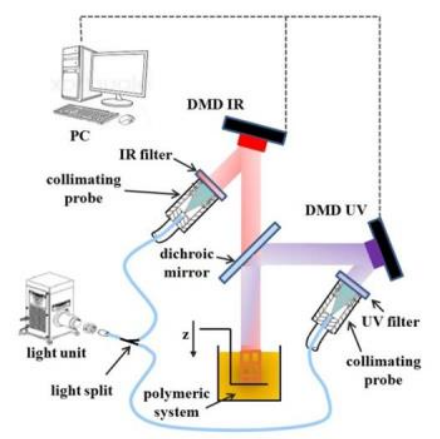

Fig. 42. Irradiation process in stereo-thermal-lithography. [148], Copyright 2011. Adapted with permission from Springe 


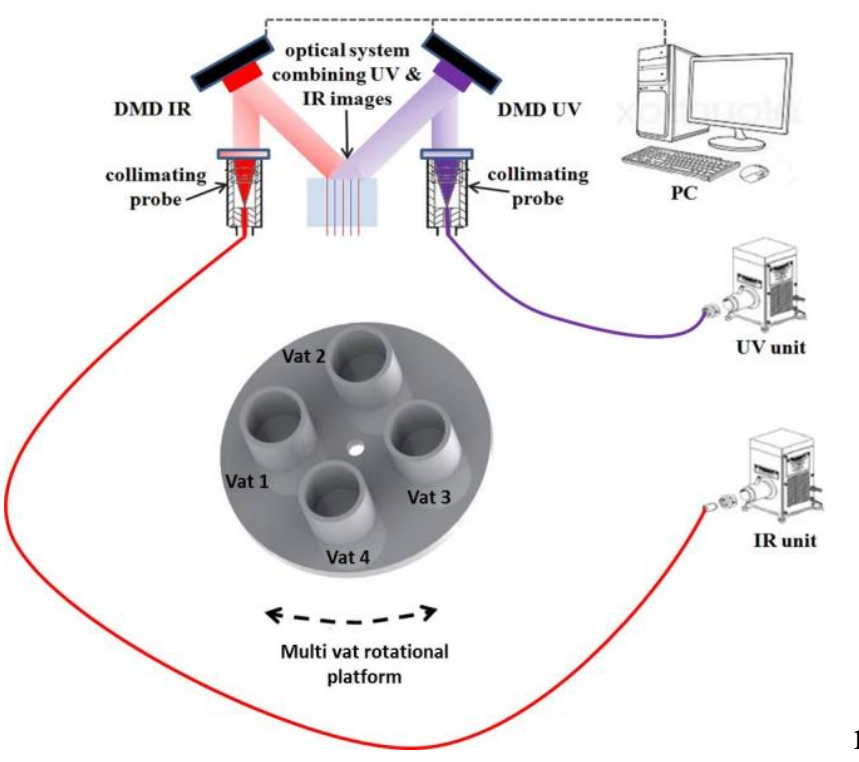

Fig. 43. Schematic representation of the stereo-thermal-lithography process with rotating multi-vat system which allows the production of multi-material constructs. Adapted with permission [142], Copyright 2012, from Elsevier Ltd; and [148], Copyright 2011, Springer 
<smiles>CC(COC(=O)CCC(C)(C)C)OC(=O)/C=C/C(=O)OCCOCCOC(C)(C)C</smiles>

UP4<smiles>CC(COC(=O)CCCCC(C)(C)C)OC(=O)/C=C/C(=O)OCCOCCOC(C)(C)C(C)C</smiles>

UP5

Fig. 44. Structures of the biobased UPs developed by Gonçalves and co-workers [18] that were used in the development of scaffolds by micro-STLA. 

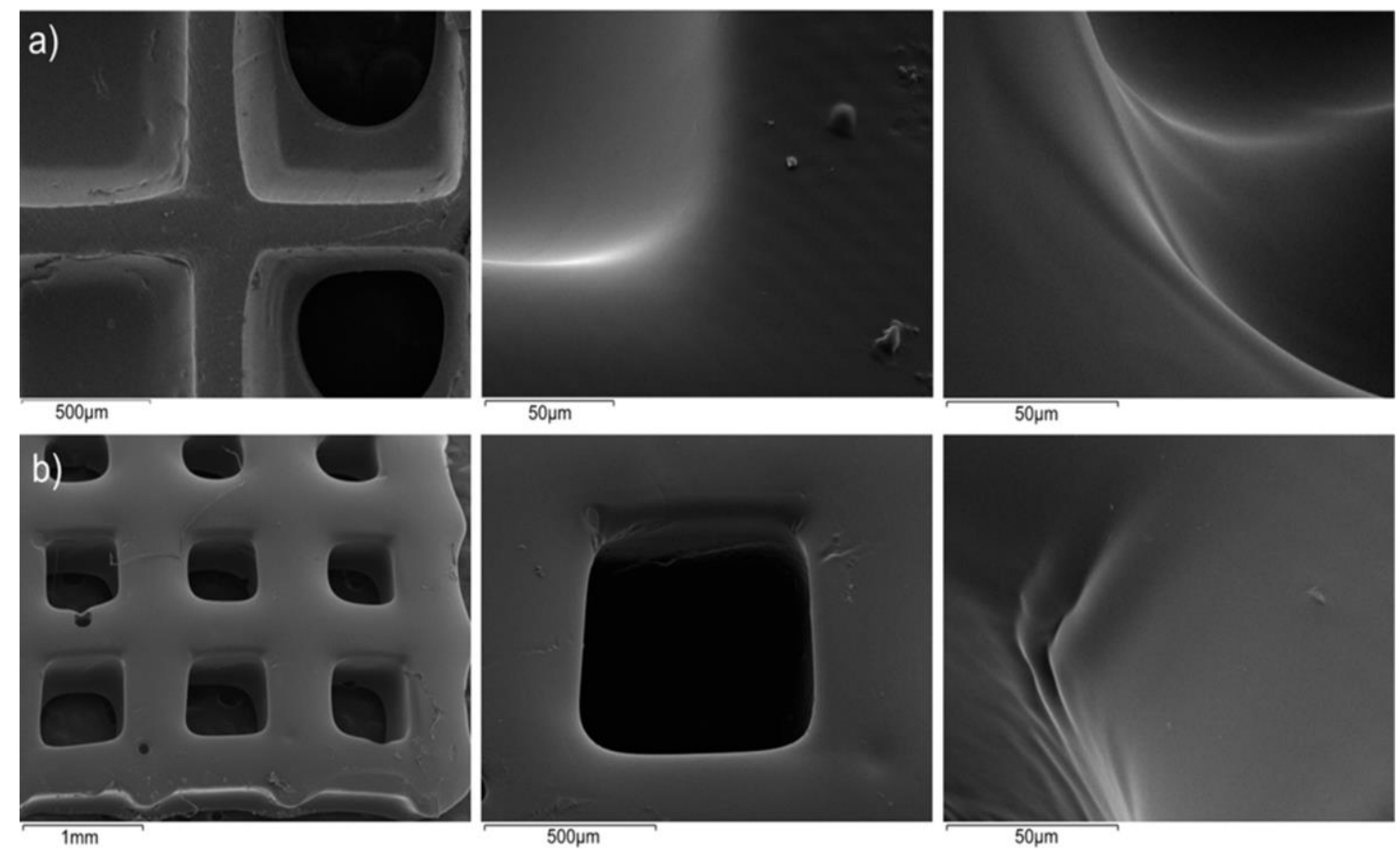

Fig. 45. SEM pictures of the scaffolds obtained by micro-SLA a) scaffolds based on UP5/Styrene, with different curing times and b) scaffold based on UP4/HEMA formulation (for UP4 and UP5 structures' see Figure 44). [18], Copyright 2014. Reproduced with permission from IOP 


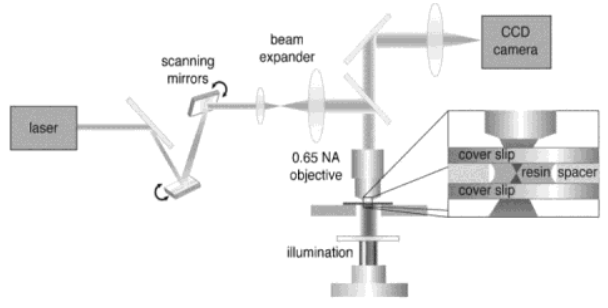

Fig. 46. A typical setup for multi-photon polymerization. [171], Copyright 2014. Reproduced with permission from John Wiley \& Sons Inc. 


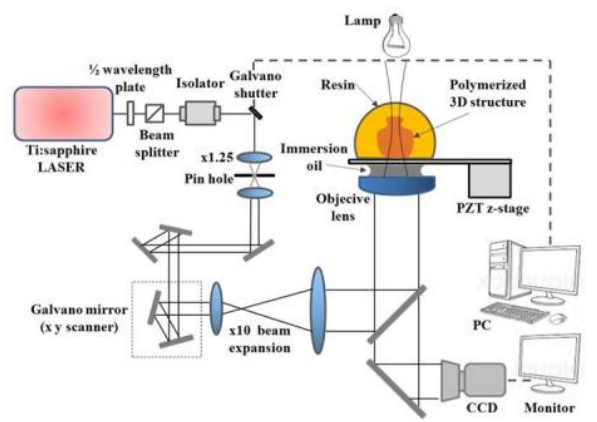

Fig. 47. Typical set-up for nano-stereolithography process. Adapted with permission from. [148], Copyright 2011, Springer; and [167], Copyright 2006, John Wiley \& Sons Inc. 